Distributions of 15 Elements on 58 Absorbers from Simulated Hanford Double-Shell

Slurry Feed (DSSF)

S. Fredric Marsh*

Zita V. Svitra

Scott M. Bowen 


\section{DISCLAIMER}

This report was prepared as an account of work sponsored by an agency of the United States Government. Neither the United States Government nor any agency thereof, nor any of their employees, make any warranty, express or implied, or assumes any legal liability or responsibility for the accuracy, completeness, or usefulness of any information, apparatus, product, or process disclosed, or represents that its use would not infringe privately owned rights. Reference herein to any specific commercial product, process, or service by trade name, trademark, manufacturer, or otherwise does not necessarily constitute or imply its endorsement, recommendation, or favoring by the United States Government or any agency thereof. The views and opinions of authors expressed herein do not necessarily state or reflect those of the United States Government or any agency thereof. 


\section{DISCLAIMER}

Portions of this document may be illegible in electronic image products. Images are produced from the best available original document. 


\section{CONTENTS}

TRADEMARKS

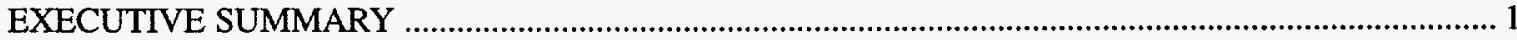

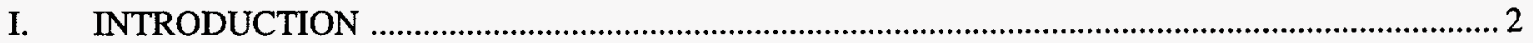

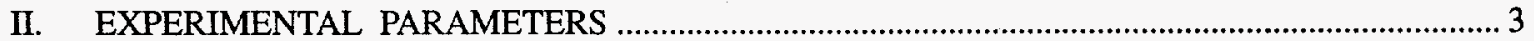

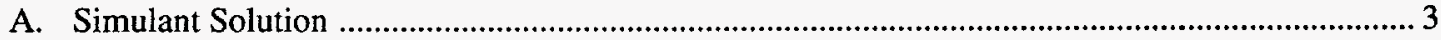

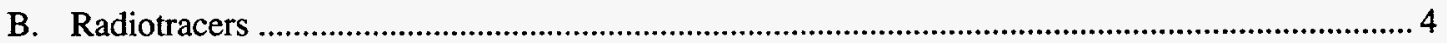

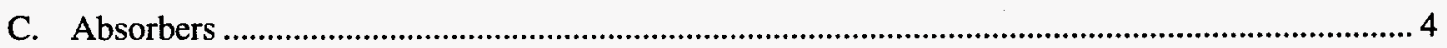

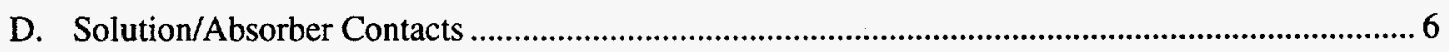

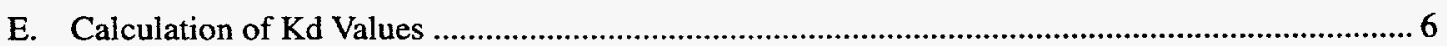

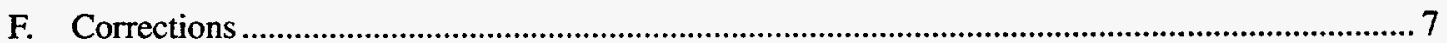

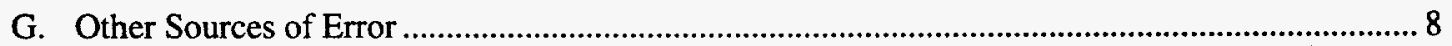

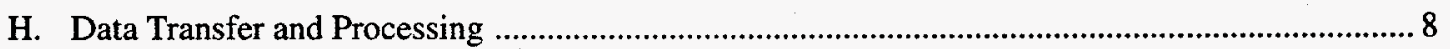

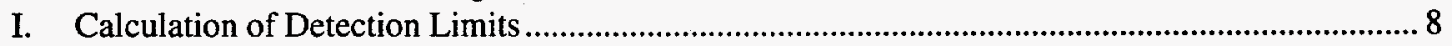

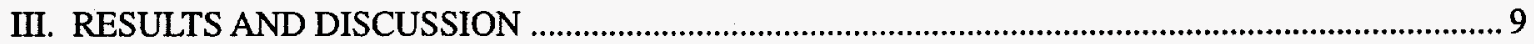

A. Individual Elements .............................................................................................................. 9

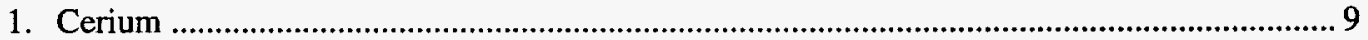

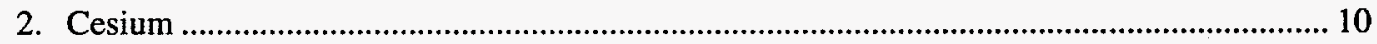

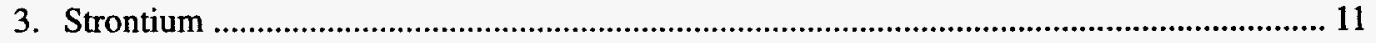

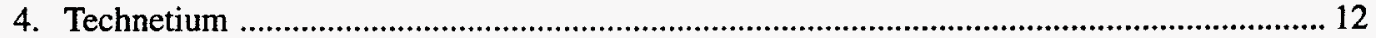

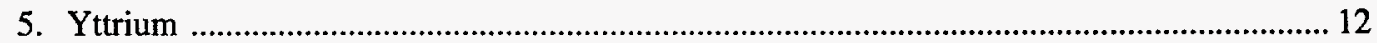

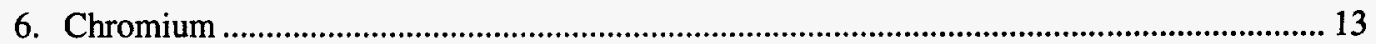

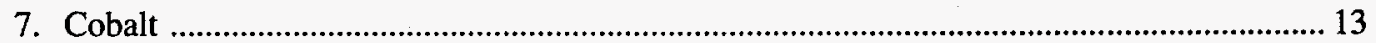

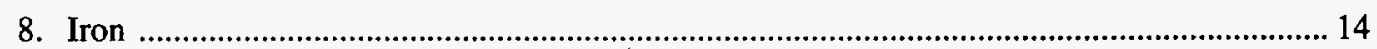

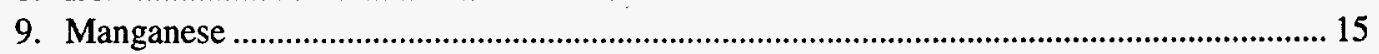

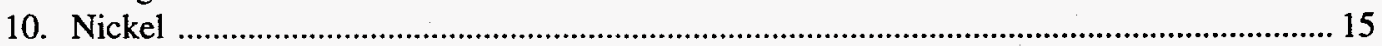

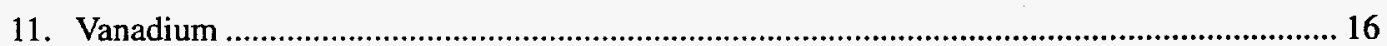

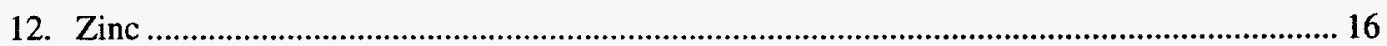

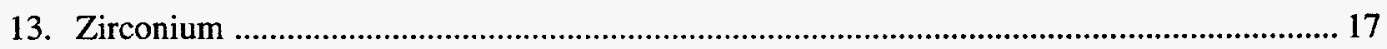

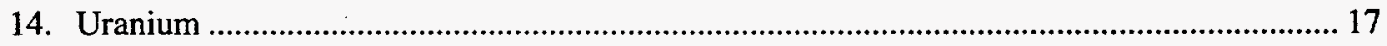

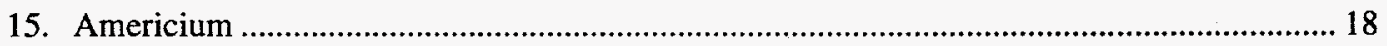

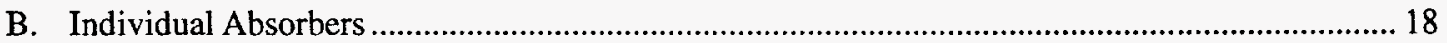

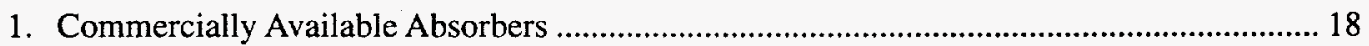

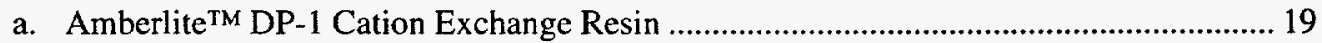

b. Amberlite ${ }^{\text {TM }}$ IRC-76 Cation Exchange Resin. ................................................................. 19

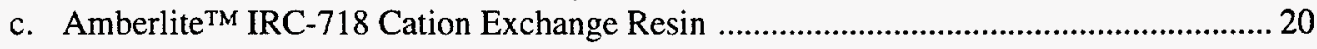

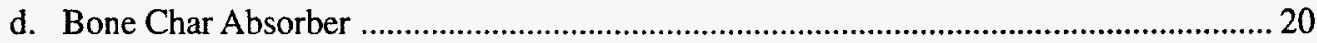




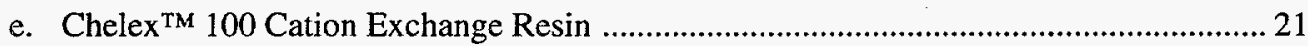

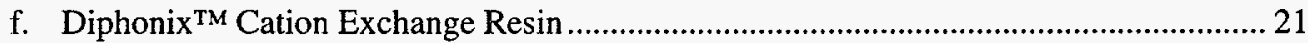

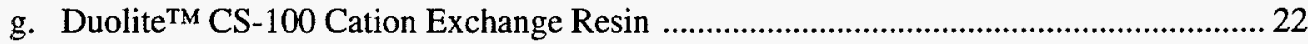

h. Duolite ${ }^{\mathrm{TM}} \mathrm{C}-467$ Cation Exchange Resin.......................................................................... 22

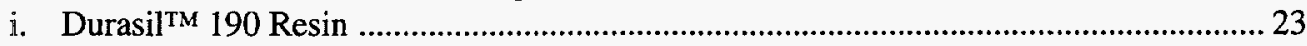

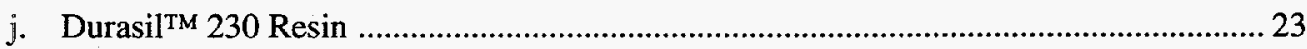

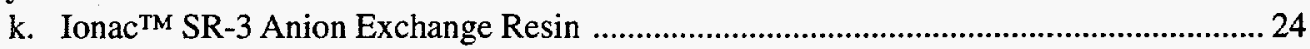

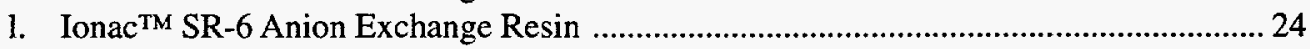

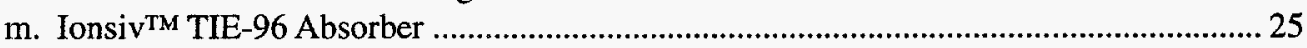

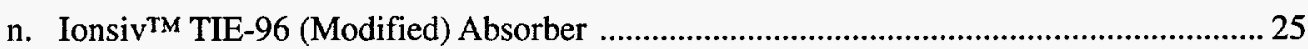

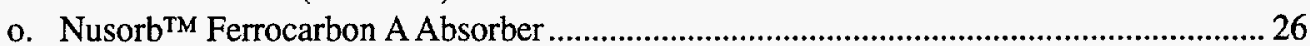

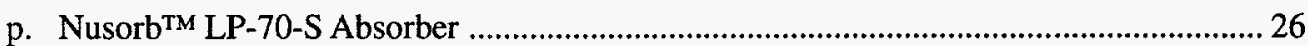

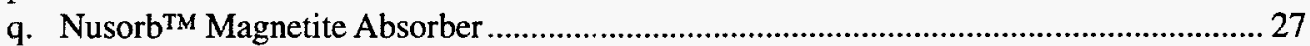

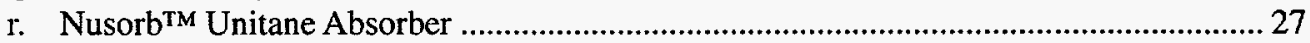

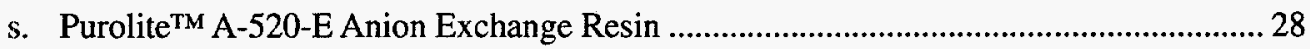

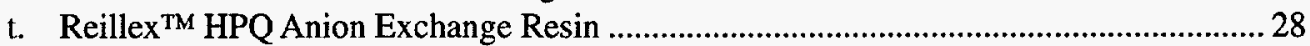

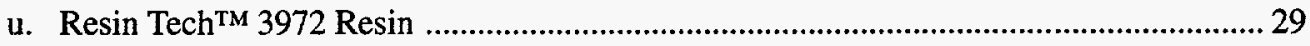

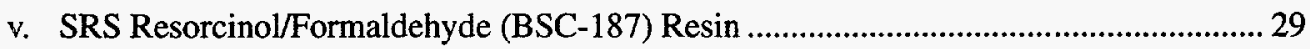

w. Tannin Absorber .............................................................................................................. 30

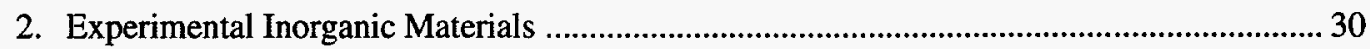

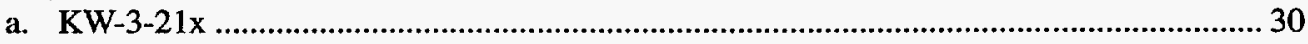

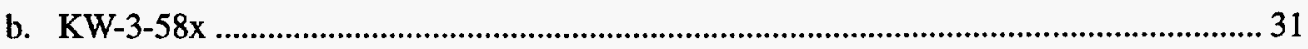

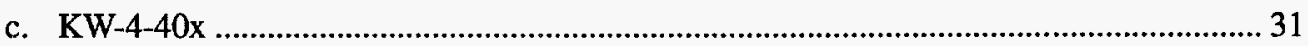

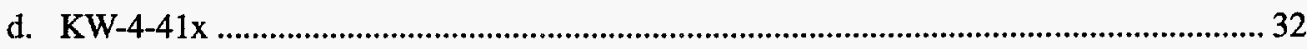

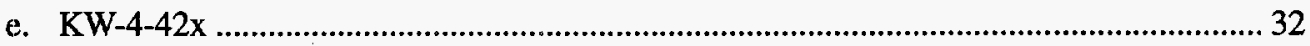

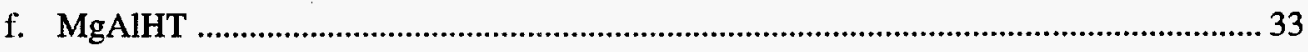

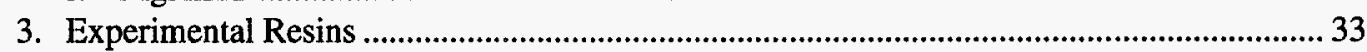

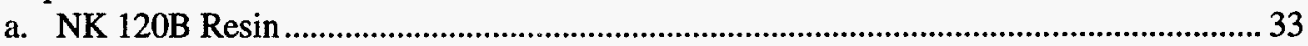

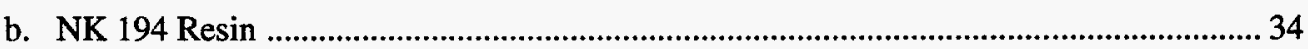

c. Sybron $(\mathrm{Et})_{3} \mathrm{~N}$ Anion Exchange Resin ............................................................................. 34

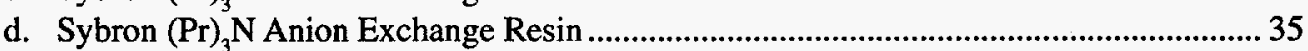

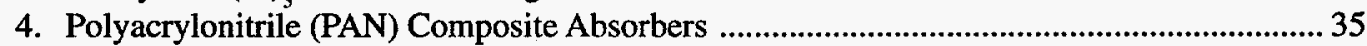

a. AMP-PAN Ammonium Molybdophosphate Composite …............................................. 35

b. $\mathrm{Ba}(\mathrm{Ca}) \mathrm{SO}_{4}-\mathrm{PAN}$ Barium/Calcium Sulfate Composite ..........................................................36

c. CSbA-PAN Crystalline Polyantimonic Acid Composite ....................................................... 36

d. M315-PAN Synthetic Mordenite Composite …………....................................................... 37

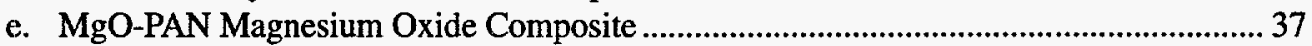

f. MnO-PAN Manganese Dioxide Composite …………...................................................... 38

g. NaTiO-PAN Sodium Titanate Composite ............................................................................... 38

h. NiFC-PAN Nickel Hexacyanoferrate Composite ………...................................................39

i. NM-PAN Nickel Hexacyanoferrate/Manganese Dioxide Composite .............................. 39

j. SnSbA-PAN Stannic Antimonate Composite ……........................................................ 40

k. TiO-PAN Titanium Dioxide Composite ...................................................................... 40

1. TiP-PAN Titanium Phosphate Composite ……............................................................ 41

m. TiSbA-PAN Titanium Antimonate Composite ............................................................ 41

n. ZrO-PAN Zirconium Oxide Composite ...................................................................... 42

o. ZrOP-PAN Zirconium Oxide/Zirconium Phosphate Composite ....................................... 42

p. ZrP-PAN Zirconium Phosphate Composite .................................................................43

5. Phenolsulfonic-Formaldehyde (PSF) Composite Absorbers ...................................................43

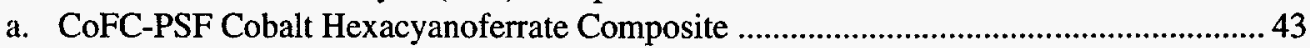

b. TiFC-PSF Titanium Hexacyanoferrate Composite ............................................................ 44 


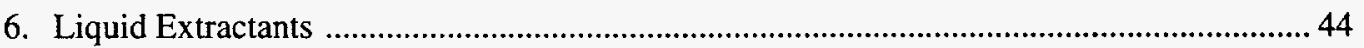

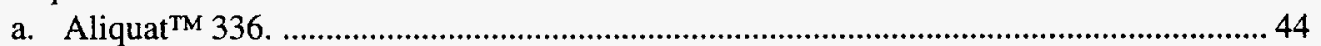

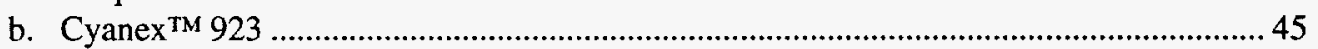

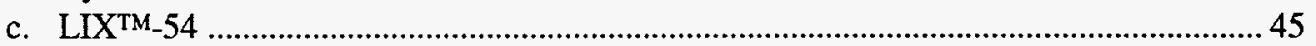

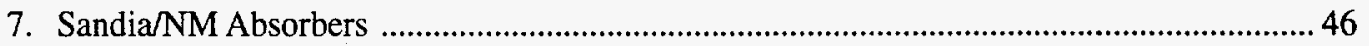

a. SNL/CST 120 Crystalline Silico-Titanate ……..................................................................46

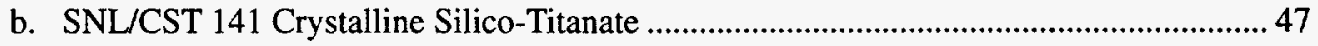

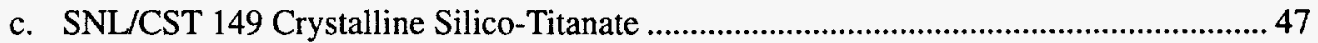

d. SNL/HTO Amorphous Hydrous Titanium Dioxide ..........................................................48

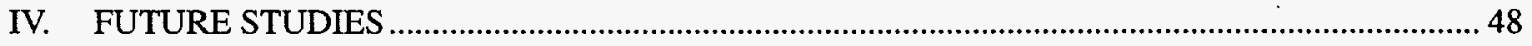

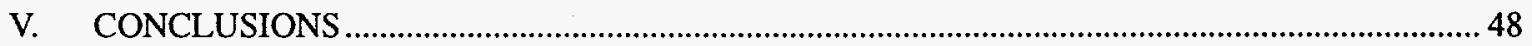

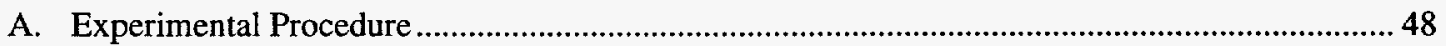

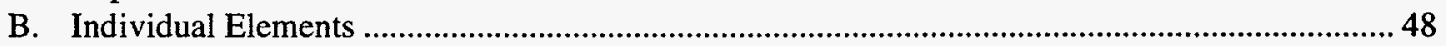

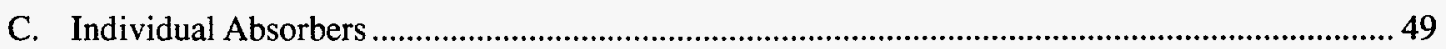

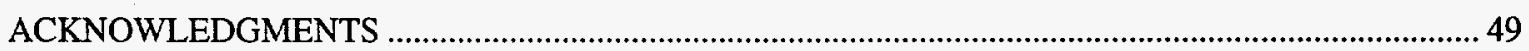

REFERENCES

TABLES

Table 1. Number of Absorbers Capable of Sorbing Each of 15 Elements from

Simulated Hanford DSSF Solution ........................................................................................... 2

Table 2. Composition of Simulated Hanford DSSF Solution Used in This Study .................................... 3

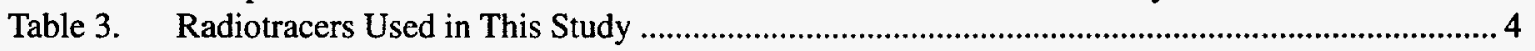

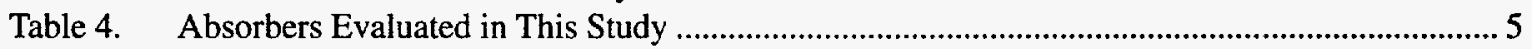

\section{Individual Elements}

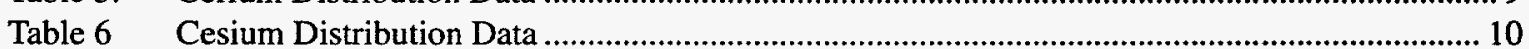

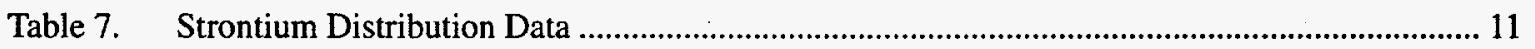

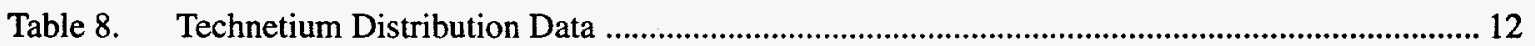

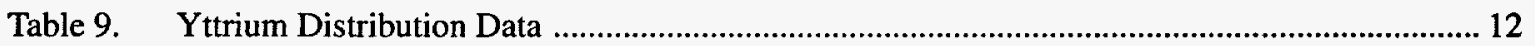

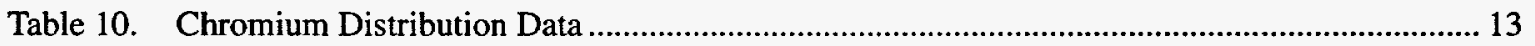

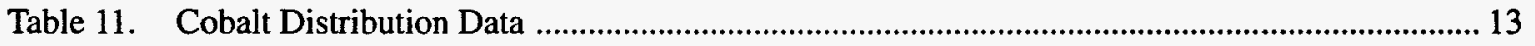

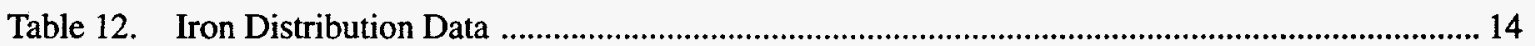

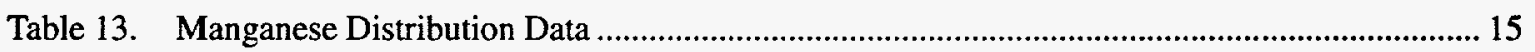

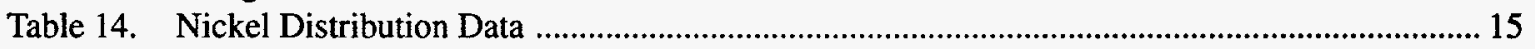

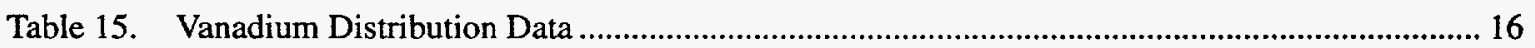

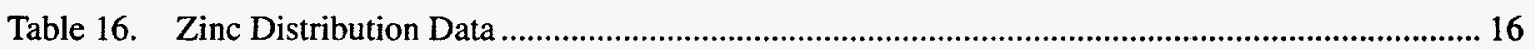

Table 17. Zirconium Distribution Data ……............................................................................ 17

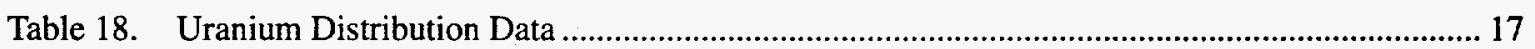

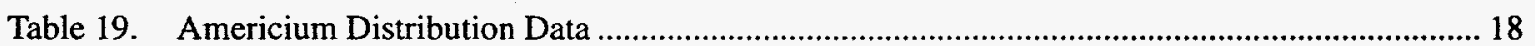

Commercially Available Absorbers

\section{Individual Absorbers}

Table 20. Amberlite ${ }^{\mathrm{TM}}$ DP-1 Cation Exchange Resin: Distribution of 15 Elements from

Simulated Hanford DSSF Solution

Table 21. Amberlite ${ }^{\mathrm{TM}}$ IRC-76 Cation Exchange Resin: Distribution of 15 Elements from

Simulated Hanford DSSF Solution 
Table 22. Amberlite ${ }^{\text {TM }}$ IRC-718 Cation Exchange Resin: Distribution of 15 Elements from Simulated Hanford DSSF Solution .................................................................................2 20

Table 23. Bone Char Absorber: Distribution of 15 Elements from Simulated Hanford DSSF Solution

Table 24. Chelex 100 Cation Exchange Resin: Distribution of 15 Elements from Simulated Hanford DSSF Solution

Table 25. Diphonix ${ }^{\mathrm{TM}}$ Cation Exchange Resin: Distribution of 15 Elements from Simulated Hanford DSSF Solution

Table 26. Duolite ${ }^{\mathrm{TM}}$ CS-100 Cation Exchange Resin: Distribution of 15 Elements from Simulated Hanford DSSF Solution

Table 27. Duolite ${ }^{\text {TM }}$ C-467 Cation Exchange Resin: Distribution of 15 Elements from Simulated Hanford DSSF Solution

Table 28. Durasil ${ }^{\mathrm{TM}} 190$ Resin: Distribution of 15 Elements from Simulated Hanford DSSF Solution

Table 29. Durasil ${ }^{\mathrm{TM}} 230$ Resin: Distribution of 15 Elements from Simulated Hanford DSSF Solution

Table 30. Ionac ${ }^{\text {TM }}$ SR-3 Anion Exchange Resin: Distribution of 15 Elements from Simulated Hanford DSSF Solution

Table 31. Ionac ${ }^{T M}$ SR-6 Anion Exchange Resin: Distribution of 15 Elements from Simulated Hanford DSSF Solution .

Table 32. IonsivTM TIE-96 Absorber: Distribution of 15 Elements from Simulated Hanford DSSF Solution 25

Table 33. Ionsiv ${ }^{\mathrm{TM}}$ TIE-96 (Modified) Absorber: Distribution of 15 Elements from Simulated Hanford DSSF Solution

Table 34. Nusorb ${ }^{\mathrm{TM}}$ Ferrocarbon A Absorber: Distribution of 15 Elements from Simulated Hanford DSSF Solution

Table 35. Nusorb ${ }^{\text {TM }}$ LP-70-S Absorber: Distribution of 15 Elements from Simulated Hanford DSSF Solution 26

Table 36. Nusorb ${ }^{\text {TM }}$ Magnetite Absorber: Distribution of 15 Elements from

Simulated Hanford DSSF Solution .

Table 37. Nusorb ${ }^{\mathrm{TM}}$ Unitane Absorber: Distribution of 15 Elements from

Simulated Hanford DSSF Solution

Table 38. Purolite ${ }^{\mathrm{TM}}$ A-520-E Anion Exchange Resin: Distribution of 15 Elements from

Simulated Hanford DSSF Solution

Table 39. Reillex ${ }^{\mathrm{TM}}$ HPQ Anion Exchange Resin: Distribution of 15 Elements from Simulated Hanford DSSF Solution ....

Table 40. Resin Tech ${ }^{\mathrm{TM}} 3972$ Resin: Distribution of 15 Elements from

Simulated Hanford DSSF Solution

Table 41. SRS Resorcinol/Formaldehyde (BSC-187) Resin: Distribution of 15 Elements from Simulated Hanford DSSF Solution

Table 42. Tannin Absorber: Distribution of 15 Elements from Simulated Hanford DSSF Solution

\section{Experimental Inorganic Materials}

Table 43. KW-3-21x: Distribution of 15 Elements from Simulated Hanford DSSF Solution 30

Table 44. KW-3-58x: Distribution of 15 Elements from Simulated Hanford DSSF Solution

Table 45.

KW-4-40x: Distribution of 15 Elements from Simulated Hanford DSSF Solution

Table 46.

KW-4-41x: Distribution of 15 Elements from Simulated Hanford DSSF Solution 


\section{Experimental Resins}

Table 49. NK 120B Resin: Distribution of 15 Elements from Simulated Hanford DSSF Solution .......... 33

Table 50. NK 194 Resin: Distribution of 15 Elements from Simulated Hanford DSSF Solution .............. 34

Table 51. Sybron (Et) ${ }_{3} \mathrm{~N}$ Anion Exchange Resin: Distribution of 15 Elements from

Simulated Hanford DSSF Solution

Table 52. Sybron ( $\mathrm{Pr})_{3} \mathrm{~N}$ Anion Exchange Resin: Distribution of 15 Elements from

Simulated Hanford DSSF Solution

Composite Absorbers

Table 53. AMP-PAN Composite: Distribution of 15 Elements from

Simulated Hanford DSSF Solution

Table 54. $\mathrm{Ba}(\mathrm{Ca}) \mathrm{SO}_{4}$-PAN Composite: Distribution of 15 Elements from

Simulated Hanford DSSF Solution

Table 55. CSbA-PAN Composite: Distribution of 15 Elements from

Simulated Hanford DSSF Solution

Table 56. M315-PAN Composite: Distribution of 15 Elements from Simulated Hanford DSSF Solution

Table 57. MgO-PAN Composite: Distribution of 15 Elements from Simulated Hanford DSSF Solution

Table 58. MnO-PAN Composite: Distribution of 15 Elements from Simulated Hanford DSSF Solution

Table 59. NaTiO-PAN Composite: Distribution of 15 Elements from

Simulated Hanford DSSF Solution

Table 60. NiFC-PAN Composite: Distribution of 15 Elements from

Simulated Hanford DSSF Solution

Table 61. NM-PAN Composite: Distribution of 15 Elements from Simulated

Hanford DSSF Solution

Table 62. SnSbA-PAN Composite: Distribution of 15 Elements from Simulated Hanford DSSF Solution

Table 63. TiO-PAN Composite: Distribution of 15 Elements from Simulated Hanford DSSF Solution

Table 64. TiP-PAN Composite: Distribution of 15 Elements from Simulated

Hanford DSSF Solution

Table 65. TiSbA-PAN Composite: Distribution of 15 Elements from

Simulated Hanford DSSF Solution

Table 66. ZrO-PAN Composite: Distribution of 15 Elements from

Simulated Hanford DSSF Solution

Table 67. ZrOP-PAN Composite: Distribution of 15 Elements from

Simulated Hanford DSSF Solution

Table 68. ZrP-PAN Composite: Distribution of 15 Elements from

Simulated Hanford DSSF Solution

Table 69. CoFC-PSF Composite: Distribution of 15 Elements from

Simulated Hanford DSSF Solution

Table 70. TiFC-PSF Composite: Distribution of 15 Elements from

Simulated Hanford DSSF Solution

\section{Liquid Extractants}

Table 71. Aliquat ${ }^{\mathrm{TM}}$ 336: Distribution of 15 Elements from

Simulated Hanford DSSF Solution

Table 72. Cyanex TM 923: Distribution of 15 Elements from Simulated Hanford DSSF Solution ...............45

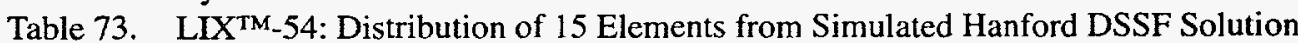




\section{Sandia/NM Absorbers}

Table 74. SNL/CST 120: Distribution of 15 Elements from Simulated Hanford DSSF Solution .............. 46

Table 75. SNL/CST 141: Distribution of 15 Elements from Simulated Hanford DSSF Solution .............. 47

Table 76. SNL/CST 149: Distribution of 15 Elements from Simulated Hanford DSSF Solution .............. 47

Table 77. SNL/HTO: Distribution of 15 Elements from Simulated Hanford DSSF Solution 48

\section{FIGURES}

Fig. 1. Hypodermic syringe, with porous Kynar ${ }^{\mathrm{TM}}$ filter in tip, as used for solution/absorber contacts. An uninstalled Kynar ${ }^{\mathrm{TM}}$ filter is shown below the syringe.

Fig. 2. Tube rotator used to mix the solution/absorber combinations. .7

\section{TRADEMARKS}

Aliquat is a registered trademark of the Henkel Corporation, Tucson, AZ, Tel. 602-622-8891.

Amberlite is a registered trademark of Rohm \& Haas, Philadelphia, PA, Tel. 215-592-3000.

Ambersorb is a registered trademark of Rohm \& Haas, Philadelphia, PA, Tel. 215-592-3000.

Chelex is a registered trademark of the Dow Chemical Company, Midland, MI, Tel. 800-441-4369.

Cyanex is a registered trademark of the American Cyanamid Company, Wayne, NJ, Tel. 800-438-5615.

Diphonix is a registered trademark of EIChroM Industries, Inc., Darien, IL, Tel. 800-424-9300.

Duolite is a registered trademark of Rohm \& Haas, Philadelphia, PA, Tel. 215-592-3000.

Durasil is a registered trademark of the Duratek Corporation, Columbia, MD, Tel. 410-312-5100.

EXCEL is a registered trademark of Microsoft Corporation, Redmond, WA, Tel. 800-426-9400.

Ionac is a registered trademark of Sybron Chemicals, Inc., Birmingham, NJ, Tel. 609-893-1100.

Ionsiv is a registered trademark of the UOP Corporation, Des Plaines, IL, Tel. 609-727-9400.

Kynar is a registered trademark of the Pennwalt Corporation, Philadelphia, PA, Tel. 215-587-7516.

LIX is a registered trademark of the Henkel Corporation, Tucson, AZ, Tel. 602-622-8891.

Nusorb is a registered trademark of Nucon International, Inc., Columbus, $\mathrm{OH}, \mathrm{Tel} .614-846-5710$.

Purolite is a registered trademark of the Purolite Company, Bala Cynwyd, PA, Tel. 215-668-9090.

Reillex is a registered trademark of Reilly Industries, Inc., Indianapolis, IN, Tel. 317-638-7531.

Resin Tech is a registered trademark of Resin Tech, Inc., Cherry Hill, NJ, Tel. 609-354-1152. 


\title{
DISTRIBUTIONS OF 15 ELEMENTS ON 58 ABSORBERS FROM SIMULATED HANFORD DOUBLE-SHELL SLURRY FEED (DSSF)
}

\author{
by
}

\author{
S. Fredric Marsh, Zita V. Svitra, and Scott M. Bowen
}

\begin{abstract}
As part of the Hanford Tank Waste Remediation System program at Los Alamos, we evaluated 58 commercially available or experimental absorber materials for their ability to remove hazardous components from high-level waste. These absorbers included cation and anion exchange resins, inorganic exchangers, composite absorbers, pillared layered materials, and a series of liquid extractants sorbed on porous supportbeads. We tested these absorbers with a solution that simulates Hanford double-shell slurry feed (DSSF) (pH 14.0). To this simulant solution we added the appropriate radionuclides and used gamma spectrometry to measure fission products $(\mathrm{Ce}, \mathrm{Cs}, \mathrm{Sr}$, $\mathrm{Tc}$, and $\mathrm{Y}$ ), actinides ( $\mathrm{U}$ and $\mathrm{Am}$ ), and matrix elements $(\mathrm{Cr}, \mathrm{Co}, \mathrm{Fe}, \mathrm{Mn}, \mathrm{Ni}, \mathrm{V}, \mathrm{Zn}$, and $\mathrm{Zr}$ ). For each of 870 element/absorber combinations, we measured distribution coefficients for dynamic contact periods of $30 \mathrm{~min}, 2 \mathrm{~h}$, and $6 \mathrm{~h}$ to obtain information about sorption kinetics. On the basis of these 2610 measured distribution coefficients, we determined that many of the tested absorbers may be suitable for processing DSSF solutions.
\end{abstract}

\section{EXECUTIVE SUMMARY}

Successful remediation of the large quantities of hazardous waste stored in underground tanks at the Hanford Reservation near Richland, Washington, requires the identification of reliable partitioning agents and the development of suitable technologies. To address this need, we measured the sorption of 15 elements onto 58 different absorbers from a simulant that represents Hanford double-shell slurry feed (DSSF) solution.

After each completed segment of our absorber screening studies, we review the performance of the tested absorbers, eliminate those that perform poorly, and replace them with new absorbers. Thus, although this study using DSSF simulant solution may resemble our previous study, it includes 24 absorbers not tested in our Hanford Tank 102-SY study. ${ }^{1}$ We also add or eliminate specific radiotracers depending on their availability and solubility in the simulant solutions being studied.

The results from this absorber screening study and our previous study of three simulant solutions for Hanford Tank 102-SY ${ }^{1}$ indicate that many existing partitioning agents may be suitable for remediating highlevel waste (HLW) tanks. The identification of reliable partitioning agents could allow the processing of HLW in Hanford tanks to begin and be completed sooner, and at a lower cost, than would otherwise be possible. The findings of our studies could have a major beneficial impact on decommissioning and environmental remediation efforts at Hanford and elsewhere within the U.S. Department of Energy (DOE) complex.

Our screening studies, intended to identify the most promising absorbers and extractants, include mainly absorbers that either are already commercially available or could be produced in commercial quantities at acceptable cost and within a reasonable time. Distribution coefficients for each element/absorber combination were measured for dynamic contact periods of $30 \mathrm{~min}$, $2 \mathrm{~h}$, and $6 \mathrm{~h}$ to provide information about the sorption kinetics of each system.

In many cases, the observed behavior of the element/ absorber combination in the simulant solution was significantly different from the expected behavior, based on published measurements from solutions of more simple 
chemical composition. We attribute such differences to the effects of other cations that compete for absorber sites, as well as the competition from anions that form soluble complexes with metal ions that would otherwise be sorbed. Such matrix-dependent differences in absorber performance demonstrate the value of using realistic simulant solutions for such measurements.

We also found numerous inexpensive commercial materials that outperform specialty products costing much more.

Table 1 summarizes the number of absorbers identified as effective in each of six distribution coefficient (Kd) ranges.

From simulated DSSF solution, all elements except vanadium show good to excellent sorption on at least one absorber. Strontium, iron, and manganese are sorbed with $\mathrm{Kd}$ values greater than 1000 by many absorbers.

Absorbers that perform well in our screening studies will be evaluated with increasingly realistic simulants that contain degraded organic constituents known to form competing complexes with multivalent cations. We then plan to evaluate the best identified absorbers with actual radioactive waste solutions as soon as such waste can be obtained. We also suggest an accelerated effort to identify or develop partitioning agents to achieve separations for which we have identified no satisfactory absorbers.

\section{INTRODUCTION}

The Hanford Reservation near Richland, Washington, incorporates 177 underground tanks that store more than 65 million gallons of radioactive waste containing some 165 million curies. These high-level wastes (HLWs) are a byproduct of the production of nuclear materials for national defense needs during the past halfcentury. Because Hanford operating contractors used numerous chemical processes during this period, many different reagents and waste streams were generated and combined in underground tanks. The resulting wastes consist of complex and sometimes unstable mixtures of sludges, saltcakes, slurries, and supernates. Adding significantly to the stored-waste problem is the fact that 67 of these underground waste storage tanks are known, or are presumed, to have leaked.

The U.S. Department of Energy (DOE) is committed to the remediation of hazardous wastes stored at Hanford and has directed Los Alamos National Laboratory (LANL) and Sandia National Laboratories/New Mexico (SNL) to support the Hanford Tank Waste Remediation System (TWRS) mission, which is to store, treat, and dispose of all tank waste in a safe, cost-effective, and environmentally sound manner. An essential prerequisite for achieving this goal is the identification of suitable partitioning agents and technologies.

Table 1. Number of Absorbers Capable of Sorbing Each of 15 Elements from Simulated Hanford DSSF Solution

\begin{tabular}{lrrrrrr}
\hline & \multicolumn{7}{c}{ Kd Values } \\
\cline { 2 - 7 } Element & $\mathbf{1 0 0 0}$ & $\mathbf{3 0 0 - 1 0 0 0}$ & $\mathbf{1 0 0 - 3 0 0}$ & $\mathbf{2 0 - 1 0 0}$ & $\mathbf{1 0 - 2 0}$ & $\mathbf{5 - 1 0}$ \\
\hline $\mathrm{Ce}$ & 2 & 5 & 4 & $\mathbf{1 0}$ & $\mathbf{5}$ & $\mathbf{1 0}$ \\
$\mathrm{Cs}$ & 0 & 2 & 1 & $\mathbf{4}$ & 5 & $\mathbf{8}$ \\
$\mathrm{Sr}$ & 26 & 7 & 6 & 7 & 4 & 2 \\
$\mathrm{Tc}$ & 0 & 7 & 2 & 1 & 1 & $\mathbf{1 0}$ \\
$\mathbf{Y}$ & 1 & 11 & 7 & 23 & 5 & 3 \\
$\mathrm{Cr}$ & 1 & 1 & 0 & 0 & 0 & 8 \\
$\mathrm{Co}$ & 0 & 1 & 0 & 6 & 1 & 3 \\
$\mathrm{Fe}$ & 10 & 7 & 7 & 10 & 2 & 5 \\
$\mathrm{Mn}$ & 6 & 8 & $\mathbf{1 1}$ & 9 & 3 & 6 \\
$\mathrm{Ni}$ & 1 & 2 & 2 & 9 & 9 & 10 \\
$\mathrm{~V}$ & 0 & 0 & 0 & 1 & 1 & 1 \\
$\mathrm{Zn}$ & 1 & 6 & 3 & 8 & 7 & 2 \\
$\mathrm{Zr}$ & 3 & 5 & 9 & 8 & 11 & 2 \\
$\mathrm{U}$ & 2 & 2 & 0 & 9 & 6 & 3 \\
$\mathrm{Am}$ & 0 & 5 & 4 & 13 & 10 & 16 \\
\hline \hline
\end{tabular}


Ion exchange is a partitioning technology that has been extensively used in the nuclear industry. Anion exchange has been used for many decades to recover plutonium $^{2}$ and neptunium ${ }^{3}$ from a wide variety of impure nuclear materials. Cation exchange resins also have been used in the nuclear industry, ${ }^{4}$ although they generally are considered to be less selective than anion exchange resins.

Although most of the absorbers we tested in this study and in our previous study with three simulant solutions for Hanford Tank 102-SY' are cation exchangers, we also included anion exchange resins, inorganic exchangers, composite resins, pillared layered materials, and a series of liquid ion exchangers (sorbed on porous carbon beads). Our intent was to obtain more comprehensive data as well as to supply convenient reference points for other studies. We also included some experimental absorbers to provide guidance for future research activities.

Some of the absorbers included in our study have been reported by others to offer high selectivity for specific ions; however, few of these absorbers have been evaluated with media approaching the complexity of the HLW solutions stored at Hanford. Nor have any other investigators, to our knowledge, measured the distribution of as many elements (15) onto so many different absorber materials (58) from a realistic Hanford doubleshell slurry feed (DSSF) simulant solution under identical test conditions. Moreover, because we measured the sorption of so many different elements, our study provides selectivity information that specifies which unwanted elements are most likely to interfere by competing for absorber sites.

After each completed segment of our absorber screening studies, we review the performance of the tested absorbers, eliminate those that perform poorly, and replace them with new absorbers. Thus, although this study using DSSF simulant solution may resemble our previous study, it includes 24 absorbers not tested in our Hanford Tank 102-SY study. ${ }^{1}$ We also add or eliminate specific radiotracers depending on their availability and solubility in the simulant solutions being studied.

Our objective was to evaluate numerous potentially useful absorber materials, including some not previously studied, for their ability to recover selected elements from a realistic DSSF simulant solution. Because no simulant can accurately represent the contents of any HLW storage tank, the most promising absorbers eventually must be tested with actual waste. However, because actual waste samples are expensive and difficult to obtain, we continue to advocate preliminary screening of candidate absorbers with simulants before testing with actual tank waste solutions.
Although we include comments and observations about our experimental data, we intentionally refrain from recommending specific absorbers. Our purpose is to identify options from which the designated engineers can develop reliable process flow sheets. Which partitioning options they select will, of course, depend on the specific objectives of their flow sheet.

\section{EXPERIMENTAL PARAMETERS}

\section{A. Simulant Solution}

The simulated DSSF solution was prepared by Garrett Brown of Battelle Pacific Northwest Laboratory (PNL). The composition of this solution, as supplied by PNL, is given in Table 2.

We initially passed the DSSF simulant through a $0.45-\mu \mathrm{m}$ filter to remove any suspended solids and then refiltered it after adding the radiotracers to remove any portion not in solution. Finally, we filtered each portion of precontacted and postcontacted simulant solution again through a $0.45-\mu \mathrm{m}$ filter before gamma-spectrometric assay.

Table 2. Composition of Simulated Hanford DSSF Solution Used in This Study

\begin{tabular}{ll}
\hline & Concentration (M) \\
\hline Cations & \\
$\mathrm{Na}$ & 7.0 \\
$\mathrm{~K}$ & 0.945 \\
$\mathrm{Cs}$ & $7.0 \times 10^{-5}$ \\
$\mathrm{Al}$ & 0.721 \\
$\mathrm{Anions}$ & \\
$\mathrm{Cl}$ & 0.102 \\
$\mathrm{NO}_{3}$ & 3.52 \\
$\mathrm{NO}_{2}$ & 1.51 \\
$\mathrm{PO}_{4}$ & 0.014 \\
$\mathrm{SO}_{4}$ & 0.008 \\
$\mathrm{CO}_{3}$ & 0.147 \\
$\mathrm{OH}^{-}$(total) & 4.63 \\
$\mathrm{OH}^{-}$(free) & 1.75 \\
\hline Theoretical $\mathrm{pH}=14.56$ \\
Measured $\mathrm{pH}=14.0$ \\
\hline \hline
\end{tabular}




\section{B. Radiotracers}

Having selected gamma spectrometry as the technique for measuring the distribution of the selected elements, we obtained suitable radiotracers to be added to the simulant solutions. The selected tracers and the gamma energies measured are listed in Table 3.

The two actinides were isolated and purified in the Los Alamos Plutonium Facility. We purchased ${ }^{51} \mathrm{Cr}$, ${ }^{141} \mathrm{Ce}$, and ${ }^{60} \mathrm{Co}$ from DuPont New England Nuclear Products, Boston, Massachusetts. The Medical Isotopes Program of the Brookhaven National Laboratory Medical Department supplied ${ }^{56} \mathrm{Ni}$ and ${ }^{48} \mathrm{~V}$. The ${ }^{137} \mathrm{Cs},{ }^{85} \mathrm{Sr}$, ${ }^{95 \mathrm{~m}} \mathrm{Tc}$, ${ }^{59} \mathrm{Fe},{ }^{54} \mathrm{Mn},{ }^{88} \mathrm{Y},{ }^{65} \mathrm{Zn}$, and ${ }^{88} \mathrm{Zr}$ were obtained from the Medical Radioisotopes and Reactor Applications Group at Los Alamos.

To minimize interference among gamma rays with similar energies, we divided the 15 radiotracers into two easily resolved groups. One group consisted of ${ }^{241} \mathrm{Am}$, ${ }^{141} \mathrm{Ce},{ }^{51} \mathrm{Cr},{ }^{137} \mathrm{Cs},{ }^{85} \mathrm{Sr}$, and ${ }^{95 m} \mathrm{Tc}$. The other group contained ${ }^{60} \mathrm{Co},{ }^{59} \mathrm{Fe},{ }^{54} \mathrm{Mn},{ }^{56} \mathrm{Ni},{ }^{237} \mathrm{U},{ }^{48} \mathrm{~V},{ }^{88} \mathrm{Y},{ }^{65} \mathrm{Zn}$, and ${ }^{88} \mathrm{Zr}$. We divided the simulant solution into two equal portions and added six tracers to one portion and nine tracers to a separate portion. Both portions were tested with all 58 absorbers.

\section{Absorbers}

The absorbers evaluated in this study are listed in Table 4. Details about the supplier or preparation of the absorbers are provided in Section III.B. These absorbers, which encompassed a wide range of particle sizes and porosities, were air-dried and used without further treatment except where otherwise noted.

Although the suppliers of the polyacrylonitrile (PAN) composites, tannin, and Diphonix ${ }^{\mathrm{TM}}$ prefer that their absorbers not be dried, we intentionally air-dried all absorbers before testing to put them all on a directly comparable basis. We also sought to avoid diluting the simulant solution by adding as-received wet resins, which in the worst case would have diluted the simulant by $23 \%$. Because the DSSF simulant was essentially saturated with various salts, large dilutions could significantly change the chemical properties of the solution, which could substantially affect the performance of many absorbers.

The concern expressed by a few colleagues about the adverse effects of air-drying absorbers appears to be overstated. Specifically, our study using air-dried absorbers yielded a distribution coefficient $(\mathrm{Kd})$ value of 7000 for one element with Diphonix ${ }^{\mathrm{TM}}$

Table 3. Radiotracers Used in This Study

\begin{tabular}{cccc}
\hline Radiotracer & $\begin{array}{c}\text { Gamma } \\
\text { Energy (MeV) }\end{array}$ & $\begin{array}{c}\text { Gamma } \\
\text { Branching (\%) }\end{array}$ & $\begin{array}{c}\text { Estimated } \\
\text { Concentration }\end{array}$ \\
\hline${ }^{241} \mathrm{Am}$ & 0.0595 & 35.9 & $30 \mu \mathrm{g} / \mathrm{L}$ \\
${ }^{141} \mathrm{Ce}$ & 0.145 & 48 & $50 \mathrm{pg} / \mathrm{L}$ \\
${ }^{56} \mathrm{Ni}$ & 0.158 & 100 & $60 \mathrm{pg} / \mathrm{L}$ \\
${ }^{95 \mathrm{~m}} \mathrm{Tc}$ & 0.204 & 100 & $2 \mathrm{pg} / \mathrm{L}$ \\
${ }^{237} \mathrm{U}$ & 0.208 & 23.3 & $20 \mathrm{mg} / \mathrm{L}$ \\
${ }^{51} \mathrm{Cr}$ & 0.320 & 10 & $0.3 \mu \mathrm{g} / \mathrm{L}$ \\
${ }^{88} \mathrm{Zr}$ & 0.394 & 97 & $50 \mu \mathrm{g} / \mathrm{L}$ \\
${ }^{85} \mathrm{Sr}$ & 0.514 & 100 & $3 \mu \mathrm{g} / \mathrm{L}$ \\
${ }^{137} \mathrm{Cs}$ & 0.662 & 85 & $6 \mu \mathrm{g} / \mathrm{L}$ \\
${ }^{54} \mathrm{Mn}$ & 0.835 & 100 & $3 \mu \mathrm{g} / \mathrm{L}$ \\
${ }^{88} \mathrm{Y}$ & 0.898 & 92 & $50 \mu \mathrm{g} / \mathrm{L}$ \\
${ }^{48} \mathrm{~V}$ & 0.983 & 100 & $80 \mathrm{pg} / \mathrm{L}$ \\
${ }^{59} \mathrm{Fe}$ & 1.099 & 56 & $20 \mu \mathrm{g} / \mathrm{L}$ \\
${ }^{65} \mathrm{Zn}$ & 1.115 & 51 & $6 \mu \mathrm{g} / \mathrm{L}$ \\
${ }^{60} \mathrm{Co}$ & 1.173 & 100 & $2 \mu \mathrm{g} / \mathrm{L}$
\end{tabular}

${ }^{\mathrm{a}} \mathrm{Gamma}$ branching information is provided to indicate the assay sensitivity.

"The elemental concentrations given for the radiotracers are based on the best information available from suppliers; however, these values do not account for low levels of these elements that could have been unintentionally added as impurities in the reagents used to prepare the simulant. 
Table 4. Absorbers Evaluated in This Study

\begin{tabular}{|c|c|}
\hline Absorber Type/Source & Trademark $^{a}$ or Other Identification \\
\hline $\begin{array}{l}\text { Commercial } \\
\text { Absorbers }\end{array}$ & 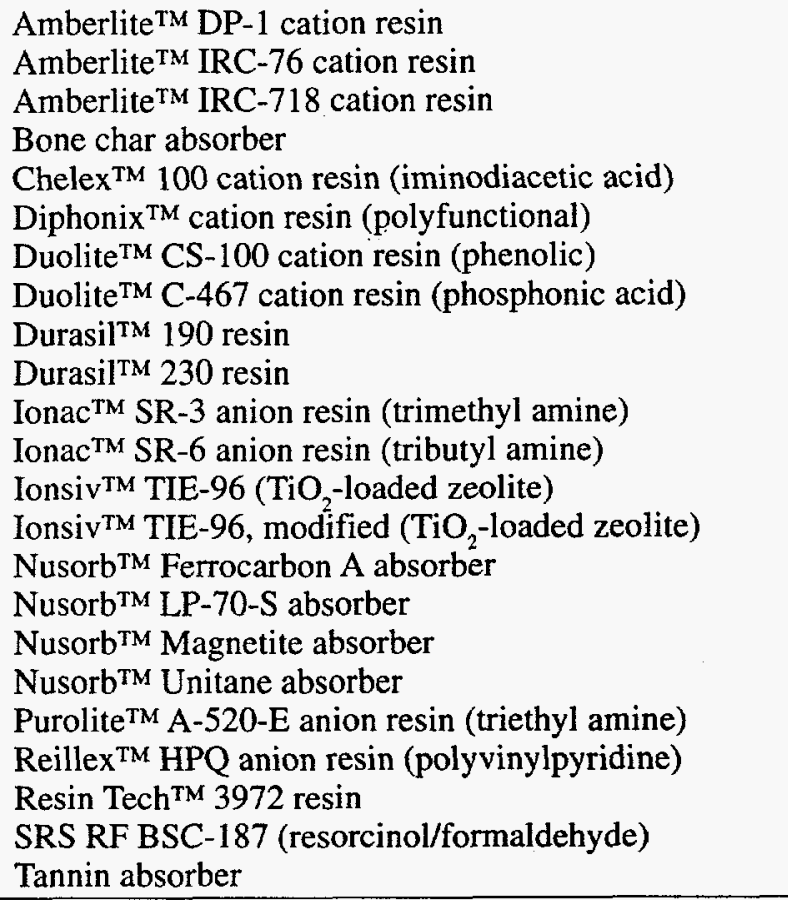 \\
\hline $\begin{array}{l}\text { Experimental } \\
\text { Absorbers }\end{array}$ & $\begin{array}{l}\text { KW-3-21x (pillared layered material) } \\
\text { KW-3-58x (pillared layered material) } \\
\text { KW-4-40x (pillared layered material) } \\
\text { KW-4-41x (pillared layered material) } \\
\text { KW-4-42x (pillared layered material) } \\
\text { MgAlHT (hydrotalcite) } \\
\text { NK } 120 B \text { (hydroxamic acid functionality) } \\
\text { NK } 194 \text { (amidoxime functionality) } \\
\text { Sybron (Et) } \mathrm{N} \text { anion resin } \\
\text { Sybron (Pr) }{ }_{3} \mathrm{~N} \text { anion resin }\end{array}$ \\
\hline $\begin{array}{l}\text { Composite Absorbers } \\
\text { F. Sebesta, Czech Republic } \\
\text { (polyacrylonitrile matrix) }\end{array}$ & $\begin{array}{l}\text { AMP-PAN ammonium molybdophosphate } \\
\mathrm{Ba} \text { (Ca)SO } \text {-PAN barium/calcium sulfate }_{\text {CSBA-PAN crystalline polyantimonic acid }} \\
\text { M315-PAN synthetic mordenite } \\
\text { MgO-PAN magnesium oxide } \\
\text { MnO-PAN manganese dioxide } \\
\text { NaTiO-PAN sodium titanate } \\
\text { NiFC-PAN nickel hexacyanoferrate } \\
\text { NM-PAN nickel hexacyanoferrate/manganese dioxide } \\
\text { SnSbA-PAN stannic antimonate } \\
\text { TiO-PAN titanium dioxide } \\
\text { TiP-PAN titanium phosphate } \\
\text { TiSbA-PAN titanium antimonate } \\
\text { ZrO-PAN zirconium oxide } \\
\text { ZrOP-PAN zirconium oxide/zirconium phosphate } \\
\text { ZrP-PAN zirconium phosphate }\end{array}$ \\
\hline $\begin{array}{l}\text { J. Narbutt, Poland } \\
\text { (phenolsulfonic- } \\
\text { formaldehyde matrix) }\end{array}$ & $\begin{array}{l}\text { CoFC-PSF cobalt hexacyanoferrate } \\
\text { TiFC-PSF titanium hexacyanoferrate }\end{array}$ \\
\hline
\end{tabular}


Table 4. Absorbers Evaluated in This Study (Cont.)

\begin{tabular}{ll} 
Absorber Type/Source & Trademark $^{\mathbf{a}}$ or Other Identification \\
\hline LANL-Prepared & Aliquat $^{\mathrm{TM}} 336$ (methyltricaprylammonium chloride) \\
Extractant Beads & Cyanex $^{\mathrm{TM}}$ 923 (trialkylphosphine oxide) \\
& LIX $^{\mathrm{TM}}$-54 (a beta diketone) \\
\hline Sandia/NM & SNL/CST 120 crystalline silico-titanate \\
Absorbers & SNL/CST 141 crystalline silico-titanate \\
& SNL/CST 149 crystalline silico-titanate \\
& SNL/HTO amorphous hydrous titanium dioxide
\end{tabular}

${ }^{a}$ Trademark owners are identified on page $x$.

(Section III.B.1.f), three triple-digit $\mathrm{Kd}$ values and two four-digit Kd values with tannin (Section III.B.1.w), and four-digit or higher Kd values with 13 of 16 PAN absorbers (Sections III.B.4.c and III.B.4.e through III.B.4.p). Moreover, these high $\mathrm{Kd}$ values may qualify the cited absorbers for future column tests, in which none of the tested absorbers will require drying.

\section{Solution/Absorber Contacts}

In most cases, a 250-mg portion of each air-dried absorber was contacted with a measured 6-mL volume of simulant solution in a specially modified $20-\mathrm{mL}$ disposable hypodermic syringe. We modified these syringes by inserting cylindrical plugs cut from 1/4-in.-thick porous Kynar $^{\mathrm{TM}}$, obtained from Porex Technologies, Fairburn, Georgia, into the tapered tips as filters, which permitted only liquid to pass through (Fig. 1).

Each group of experiments usually consisted of six syringes, each containing a different absorber. A measured volume of the simulant solution was transferred by pipet into a plastic beaker and then drawn into a syringe through the Kynar ${ }^{\mathrm{TM}}$ filter. We then sealed the tip of each syringe and placed the syringes on a 48-rpm tube rotator (Fig. 2) for dynamic contact periods of $30 \mathrm{~min}, 2 \mathrm{~h}$, and $6 \mathrm{~h}$. At the end of each contact period, approximately $25 \%$ of the total solution volume was expelled from the syringe through an attached $0.45 \mu \mathrm{m}$ filter (center left in Fig. 1) into a tared counting vial. We then weighed the dispensed solution and used that figure in the calculation of $\mathrm{Kd}$ values.

The described filter-tip syringes were unsuitable for the crystalline silico-titanate (CST) absorbers from Sandia/NM and for the pillared layered materials because these small particles often plugged the filters. For these finely divided materials, we pipetted $6 \mathrm{~mL}$ of solution directly into a $30-\mathrm{mL}$ centrifuge tube that contained $250 \mathrm{mg}$ of absorber and mixed each absorber/ solution on the rotator for the prescribed time. At the end of each contact period, the tubes were centrifuged at high speed for $10 \mathrm{~min}$. We then transferred approximately $1.5 \mathrm{~mL}$ of the centrifuged solution into a $2.5-\mathrm{mL}$ hypodermic syringe with a $0.45-\mu \mathrm{m}$ filter (center left in Fig. 1) attached to the Luer-lock tip. The centrifuged solution was expelled through this filter into a tared counting vial, from which we determined the solution weight.

\section{E. Calculation of Kd Values}

Distribution coefficients (Kds) normally are calculated in terms of the dry absorber weight $;^{5}$ optionally, Kds can be calculated in terms of the wet absorber volume. Because most of the absorbers we tested were received in dry form, we tested all absorbers on a comparable, dry basis to conform to a consistent $\mathrm{Kd}$ convention. We recognize that air-drying moist absorbers to constant weight at room temperature causes some polymers to temporarily shrink as they lose physically sorbed water; however, such polymers swell again when they recontact aqueous solution. Therefore, the only adverse effect of air-drying might be a temporary decrease in polymer porosity that could result in slower kinetics until the polymer regains its lost water. To protect the airdried absorbers from any lasting damage, we never applied heat during the drying cylces.

Each portion of postcontact solution was assayed by gamma spectrometry using the characteristic gamma energies of the added radionuclides. The fraction of each element sorbed was determined indirectly from the difference in the measured gamma activity of the selected radionuclide before and after contact with each specified absorber. 


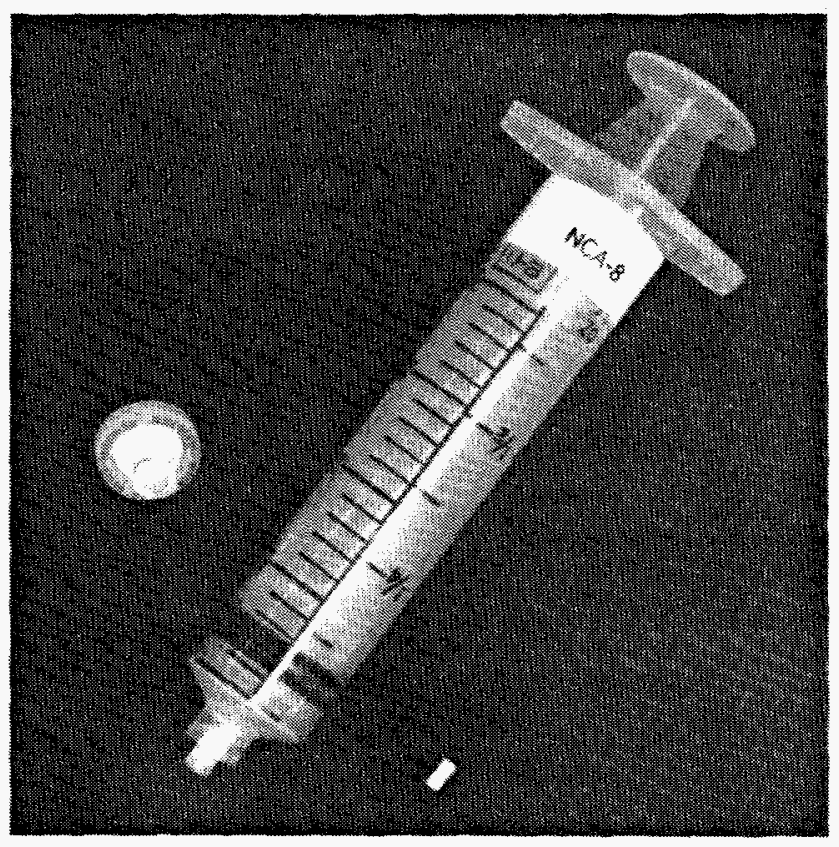

Fig. 1. Hypodermic syringe, with porous Kynar TM filter in tip, as used for solution/absorber contacts. An uninstalled Kynar ${ }^{\mathrm{TM}}$ filter is shown below the syringe.

The Kd value for each element was calculated as follows:

$$
\mathrm{Kd}=\frac{\mathrm{Pr}-\mathrm{Po}}{\mathrm{Po}} \frac{\mathrm{S}}{\mathrm{A}},
$$

where $\operatorname{Pr}=$ measured precontact activity,

$\mathrm{Po}=$ measured postcontact activity,

$\mathrm{S}=$ milliliters of solution contacted, and

$A=$ grams of dry absorber contacted.

Uncertainties are larger when Kd values are very low (when the numerator in the first fraction represents a small difference between two large numbers), as well as when Kd values are very high (when the denominator in the first fraction becomes very small). However, the objective of this screening study was to identify absorbers that sorb specific elements poorly or very well.

Although we report most $\mathrm{Kd}$ values below 5000 as calculated, this obviously should not be taken to indicate that all four figures are significant. The uncertainty associated with our highest and lowest $\mathrm{Kd}$ values appears to be within a factor of 2 or 3 . We estimate the uncertainty associated with our best $\mathrm{Kd}$ values to range from $10 \%$ to $20 \%$. To avoid implying more precision than is justified, we report Kd values above 5000 as the next

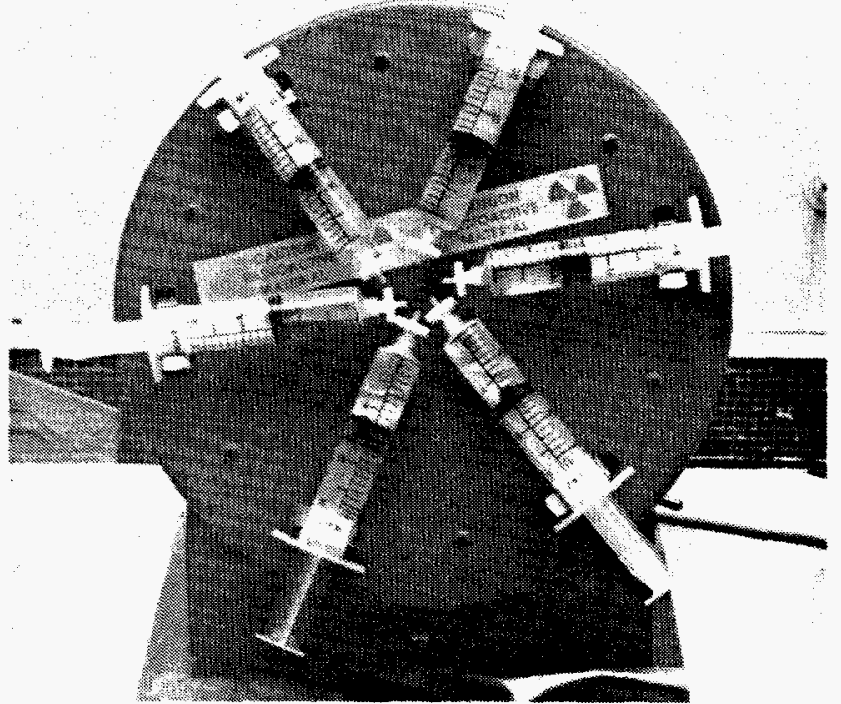

Fig. 2. Tube rotator used to mix the solution/ absorber combinations.

lower thousand $(K)$ value. In some cases where we feel the uncertainty is unusually high, even though the $\mathrm{Kd}$ value is less than 5000 , we report the $\mathrm{Kd}$ as the next lower hundred value.

The need for highly precise $\mathrm{Kd}$ values decreases as the $\mathrm{Kd}$ values increase. For example, the difference between a Kd value of 5000 ( $99.98 \%$ sorbed) and a Kd value of 10,000 ( $99.99 \%$ sorbed) is only $0.01 \%$. We therefore elected to evaluate a larger number of candidate absorbers, rather than spend a comparable effort trying to increase the number of significant figures in our measured $\mathrm{Kd}$ values. If it is necessary to determine $\mathrm{Kd}$ values with higher accuracy, such data can be obtained in follow-up studies, which would be limited to the most promising absorbers identified in our screening studies.

\section{F. Corrections}

Because the solution weights of the postcontact assay portions usually differed slightly from that of the precontact standard solution, each postcontact solution was normalized to the same weight basis as the standard.

We also made appropriate corrections to account for the fact that the liquid/solid ratio and the remaining activity of every radionuclide decreased as successive assay portions were removed. 
To determine the quantities of sorbed radionuclides, we compared the activity of each radionuclide in the postcontact solution with the activity of that same radionuclide in the precontact standard. Because most absorbers were initially added in air-dried form, the aqueous solvent was often preferentially sorbed, which decreased the aqueous volume and simultaneously increased the concentration of the solutes. Consequently, the activity of certain radionuclides was at times slightly higher in the postcontact solution than in the precontact solution. Whenever the postcontact/precontact solution activity ratio of a radionuclide exceeded unity, we assigned a value of 1.000 to the ratio having the highest value and normalized all other radionuclides in that same portion of solution accordingly.

We also made time-dependent corrections for the decay of ${ }^{237} \mathrm{U}$ (6.8-day half-life), ${ }^{56} \mathrm{Ni}$ (6.1-day half-life), and ${ }^{48} \mathrm{~V}$ (16-day half-life) during the gamma assay period. All calculations and corrections were performed in an EXCEL ${ }^{\mathrm{TM}}$ spreadsheet.

\section{G. Other Sources of Error}

Each combination of element/absorber/contact time was measured only once. The absence of duplicates is offset by the fact that we measured individual $\mathrm{Kd}$ values for three consecutive contact periods. Any abrupt change in the expected smooth trend of these three data points indicates an unreliable point.

Poor precision is also indicated by excessive variation within a set of three data points where no trend is evident. For very low or very high $\mathrm{Kd}$ values, the variation is expected to be large for reasons already discussed.

The difficulties in accurately correcting for the complex background under the low-energy (59.5-keV) gamma peak of ${ }^{241} \mathrm{Am}$ resulted in Kd values with unusually large uncertainties for this element.

\section{H. Data Transfer and Processing}

To save time and also minimize the human errors that can be introduced in transcribing large quantities of data, we automated the data transfer and calculation process. We used Gamanal ${ }^{6}$ to determine the area of each gamma peak from the raw data in the multichannel analyzer memory. Gamanal provides a complete qualitative and quantitative analysis of mixtures of radionuclides by computer interpretation of high-resolution gamma spectra. Gamanal determines background, fits and resolves complex peak groupings, determines the energies and absolute intensities of the gamma rays, and calculates the quantities of the source radionuclides. All interferences are resolved by a least-squares solution of the matrix of equations for the gamma intensities.

The Gamanal output was electronically imported into an EXCEL ${ }^{\mathrm{TM}}$ spreadsheet in which the described calculations and corrections were applied. Finally, all calculated $\mathrm{Kd}$ values were combined into one master spreadsheet and converted to a database to provide tabulated comparisons of the measured $\mathrm{Kd}$ values according to element and absorber. Because small $\mathrm{Kd}$ values always have large associated uncertainties, we rounded all $\mathrm{Kd}$ values to not more than one place beyond the decimal point.

\section{Calculation of Detection Limits}

When peaks in a gamma spectrum were too small to be detected by the Gamanal program, we used a simple method $^{7}$ to calculate the appropriate detection limits. First, for each radionuclide of interest, the same detector was used to determine the peak position and full width at half maximum (FWHM) from a spectrum with a strong gamma signal. The FWHM then was doubled to include the entire gamma-peak region (and always rounded up to the next integer) to define the position and width of the region of interest to be applied to the background spectra. The number of background counts in this region was summed, and the square root of the sum multiplied by a confidence-limit scale factor. A scale-factor value of 2.772 was used to ensure that $95 \%$ of the signal peaks of this magnitude would be statistically detected on the observed background.

The scale factor was determined as follows. Counting statistics dictate that the square root of the number of counts in a region is an estimate of the standard deviation uncertainty of those counts. The detection of a peak requires that the background in the region of interest be subtracted; the single standard deviation of their difference is the square root of the sum of the squares of the single-standard-deviation values for each of the two spectra. Thus, the standard deviation is the square root of the sums of the counts in the two corresponding regions of interest.

Because the hypothetical sample spectrum contains no detectable peak signal, the number of counts in the sample region of interest is equal to the number of counts in the background. Therefore, an estimate of the singlestandard-deviation uncertainty (the confidence limits of 
detection) is the square root of twice the number of background counts, or 1.414 times the square root of the number of background counts. Scaling to exactly two standard deviations ( $95.44 \%$ confidence) would yield a scale factor of 2.828. Standard math tables permit the scale factor to be calculated to any desired confidence limit.

Using these calculated minimum peak area values that could be detected with a $95 \%$ confidence level to calculate the corresponding minimum $\mathrm{Kd}$ values, we report $\mathrm{Kd}$ values in terms of greater than $(>)$ the computed minimum $\mathrm{Kd}$ values.

\section{RESULTS AND DISCUSSION}

\section{A. Individual Elements}

Tables 5 through 19 list the most promising absorbers for each element, ranked in order of $\mathrm{Kd}$ value, for sorption from simulated DSSF solution. Partitioning agents that sorb the specified element poorly are generally omitted from these tables, although absorbers designated as baseline technologies for TWRS are always included, even when they perform poorly. A complete listing for all elements for each absorber is presented in Section III.B, Individual Absorbers.

1. Cerium. Many absorbers offer at least triple-digit $\mathrm{Kd}$ values for sorbing cerium from DSSF simulant.

Table 5. Cerium Distribution Data

\begin{tabular}{|c|c|c|c|}
\hline \multirow[b]{2}{*}{ Absorber } & \multicolumn{3}{|c|}{ Kd Value for Specified Time } \\
\hline & $30 \mathrm{~min}$ & $2 \mathbf{h}$ & $6 \mathrm{~h}$ \\
\hline ZrP-PAN & $>1500$ & $>1500$ & $>1500$ \\
\hline MgAlHT & 378 & 664 & 673 \\
\hline SNL/HTO & 282 & 416 & 542 \\
\hline Bone char & 160 & $>1500$ & $>1600$ \\
\hline TiSbA-PAN & 65 & 212 & 376 \\
\hline Nusorb $^{\mathrm{TM}}$ Ferrocarbon A & 15 & 124 & 920 \\
\hline TiP-PAN & 10 & 34 & 65 \\
\hline NM-PAN & 8.5 & 18 & 29 \\
\hline NiFC-PAN & 7.6 & 9.3 & 19 \\
\hline SNL/CST 141 & 6.5 & 9.6 & 17 \\
\hline Durasil $^{\mathrm{TM}} 230$ & 6.1 & 21 & 45 \\
\hline MnO-PAN & 4.1 & 26 & 193 \\
\hline Ionsiv ${ }^{\mathrm{TM}}$ TIE-96 (mod.) & 1.8 & 14 & 41 \\
\hline NusorbTM LP-70-S $^{\text {TM }}$ & 1.6 & 17 & 124 \\
\hline Nusorb ${ }^{\mathrm{TM}}$ Unitane & 1.3 & 18 & 112 \\
\hline TiO-PAN & 0.6 & 34 & $>100$ \\
\hline
\end{tabular}


2. Cesium. The CSTs, CoFC-PSF composite, and resorcinol/formaldehyde (RF) resin all offer tripledigit Kd values for sorbing cesium from DSSF simulant.

\begin{tabular}{|c|c|c|c|}
\hline \multirow[b]{2}{*}{ Absorber } & \multicolumn{3}{|c|}{ Kd Value for Specified Time } \\
\hline & $30 \mathrm{~min}$ & $2 \mathrm{~h}$ & $6 \mathrm{~h}$ \\
\hline SNL/CST 141 & 530 & 649 & 736 \\
\hline SNL/CST 149 & 436 & 570 & 612 \\
\hline CoFC-PSF & 55 & 213 & 354 \\
\hline Duolite $^{\mathrm{TM}} \mathrm{CS}-100$ & 46 & 49 & 50 \\
\hline SRS RF BSC- 187 & 46 & 140 & 236 \\
\hline M315-PAN & 29 & 30 & 29 \\
\hline SNL/CST 120 & 20 & 26 & 27 \\
\hline NiFC-PAN & 16 & 2.6 & 2.4 \\
\hline TiFC-PSF & 14 & 20 & 23 \\
\hline Ionsiv ${ }^{\mathrm{TM}}$ TIE-96 & 9.1 & 11 & 12 \\
\hline Ionsiv TM TIE-96 (mod.) & 8.2 & 11 & 12 \\
\hline
\end{tabular}


3. Strontium. The number of effective absorbers for removing strontium from alkaline solution is especially large. More than 20 absorbers offer four-digit Kd values for sorbing strontium from DSSF simulant.

Table 7. Strontium Estribution Data

\begin{tabular}{|c|c|c|c|}
\hline \multirow[b]{2}{*}{ Absorber } & \multicolumn{3}{|c|}{ Kd Value for Specified Time } \\
\hline & $30 \mathrm{~min}$ & $2 \mathrm{~h}$ & $6 \mathrm{~h}$ \\
\hline KW-4-40x & $>26 \mathrm{~K}$ & $>25 \mathrm{~K}$ & $>26 \mathrm{~K}$ \\
\hline SNL/HTO & $23 \mathrm{~K}$ & $10 \mathrm{~K}$ & $>24 \mathrm{~K}$ \\
\hline SNL/CST 120 & $13 \mathrm{~K}$ & $>32 \mathrm{~K}$ & $>32 \mathrm{~K}$ \\
\hline $\mathrm{KW}-4-41 \mathrm{x}$ & $11 \mathrm{~K}$ & $>26 \mathrm{~K}$ & $>25 \mathrm{~K}$ \\
\hline MnO-PAN & $8 \mathrm{~K}$ & $>27 \mathrm{~K}$ & $>27 \mathrm{~K}$ \\
\hline TiO-PAN & $6 \mathrm{~K}$ & $24 \mathrm{~K}$ & $>29 \mathrm{~K}$ \\
\hline ZrP-PAN & $6 \mathrm{~K}$ & $>26 \mathrm{~K}$ & $>27 \mathrm{~K}$ \\
\hline CSbA-PAN & $5 \mathrm{~K}$ & $18 \mathrm{~K}$ & $19 \mathrm{~K}$ \\
\hline NM-PAN & $>5 \mathrm{~K}$ & $27 \mathrm{~K}$ & $>28 \mathrm{~K}$ \\
\hline TiP-PAN & 2708 & $6 \mathrm{~K}$ & $9 \mathrm{~K}$ \\
\hline NaTiO-PAN & 2415 & $9 \mathrm{~K}$ & $25 \mathrm{~K}$ \\
\hline SNL/CST 149 & 2047 & 3808 & 4692 \\
\hline Diphonix $^{\mathrm{TM}}$ & 1930 & 4921 & $7 \mathrm{~K}$ \\
\hline NiFC-PAN & 1750 & $5 \mathrm{~K}$ & $12 \mathrm{~K}$ \\
\hline SNL/CST 141 & 1319 & 1839 & 2343 \\
\hline SnSbA-PAN & 1105 & 4911 & $9 \mathrm{~K}$ \\
\hline TiSbA-PAN & 935 & 1671 & 3644 \\
\hline MgO-PAN & 751 & 1214 & 1690 \\
\hline Bone char & 713 & 2378 & 4836 \\
\hline Duolite $^{\mathrm{TM}} \mathrm{C}-467$ & 324 & 604 & 777 \\
\hline MgAlHT & 301 & 513 & 710 \\
\hline Amberlite ${ }^{\mathrm{TM}} \mathrm{IRC}-718$ & 244 & 632 & 969 \\
\hline Ionsiv TM TIE-96 & 235 & 484 & 657 \\
\hline Ionsiv'TM TIE-96 (mod.) & 222 & 578 & 1053 \\
\hline Nusorb $^{\mathrm{TM}}$ Ferrocarbon $\mathrm{A}$ & 215 & 723 & 1753 \\
\hline NK $120 B$ & 211 & 251 & 273 \\
\hline Tannin & 203 & 476 & 761 \\
\hline TiFC-PSF & 147 & 1076 & 1716 \\
\hline Chelex TM 100 & 135 & 345 & 358 \\
\hline Duolite $^{\mathrm{TM}}$ CS-100 & 70 & 106 & 126 \\
\hline ZrO-PAN & 43 & 398 & 2077 \\
\hline SRS RF BSC-187 & 42 & 88 & 124 \\
\hline CoFC-PSF & 34 & 140 & 1222 \\
\hline LIX $^{\text {TM }}-54$ & 32 & 108 & 185 \\
\hline Amberlite ${ }^{\mathrm{TM}}$ DP-1 & 25 & 32 & 34 \\
\hline Nusorb $^{\mathrm{TM}}$ Unitane & 19 & 117 & 504 \\
\hline AMP-PAN & 18 & 26 & 33 \\
\hline ZrOP-PAN & 15 & 113 & 1031 \\
\hline
\end{tabular}


4. Technetium. Many anion exchange resins and several extractants whose structures mimic anion exchange functional groups provide triple-digit Kd values for sorbing technetium from DSSF simulant.

\begin{tabular}{|c|c|c|c|}
\hline \multicolumn{4}{|c|}{ Table 8. Technetium Distribution Data } \\
\hline \multirow[b]{2}{*}{ Absorber } & \multicolumn{3}{|c|}{ Kd Value for Specified Time } \\
\hline & $30 \mathrm{~min}$ & $2 \mathrm{~h}$ & $6 h$ \\
\hline$\overline{\text { Reillex }^{\mathrm{TM}} \mathrm{HPQ}}$ & 254 & 293 & 332 \\
\hline Purolite $^{\mathrm{TM}} \mathrm{A}-520-\mathrm{E}$ & 189 & 392 & 527 \\
\hline Aliquat TM 336 & 177 & 464 & 524 \\
\hline Sybron $(E t)_{2} N$ & 167 & 401 & 471 \\
\hline Cyanex TM 923 & 121 & 244 & 230 \\
\hline Ionac TM SR-3 & 115 & 279 & 312 \\
\hline Sybron (Pr) N & 96 & 257 & 390 \\
\hline Ionac TM SR-6 & 45 & 105 & 188 \\
\hline Nusorb ${ }^{T M}$ LP-70-S & 15 & 24 & 26 \\
\hline
\end{tabular}

5. Yttrium. More than 15 absorbers offer at least triple-digit $\mathrm{Kd}$ values for yttrium.

Table 9. Yttrium Distribution Data

\begin{tabular}{|c|c|c|c|}
\hline \multirow[b]{2}{*}{ Absorber } & \multicolumn{3}{|c|}{ Kd Value for Specified Time } \\
\hline & $30 \mathrm{~min}$ & $2 \mathrm{~h}$ & $6 \mathrm{~h}$ \\
\hline ZrP-PAN & 456 & 644 & 1340 \\
\hline SNL/HTO & 245 & 288 & 465 \\
\hline NiFC-PAN & 174 & 379 & 940 \\
\hline NM-PAN & 128 & 316 & 635 \\
\hline MgAlHT & 121 & 258 & 332 \\
\hline TiO-PAN & 108 & 429 & 622 \\
\hline Bone char & 97 & 529 & 723 \\
\hline MgO-PAN & 83 & 164 & 394 \\
\hline Ionsiv TM TIE-96 (mod.) & 82 & 221 & 410 \\
\hline Ionsiv"M TIE-96 & 72 & 133 & 241 \\
\hline MnO-PAN & 60 & 336 & 665 \\
\hline NaTiO-PAN & 52 & 135 & 389 \\
\hline Duolite $^{\mathrm{TM}}$ CS-100 & 52 & 123 & 187 \\
\hline TiSbA-PSF & 51 & 167 & 413 \\
\hline Diphonix $^{\mathrm{TM}}$ & 44 & 66 & 71 \\
\hline SNL/CST 120 & 32 & 67 & 93 \\
\hline $\mathrm{Ba}(\mathrm{Ca}) \mathrm{SO}_{4}-\mathrm{PAN}$ & 28 & 74 & 197 \\
\hline Amberlite $^{T M}$ DP-1 & 21 & 42 & 76 \\
\hline TiP-PAN & 19 & 37 & 66 \\
\hline 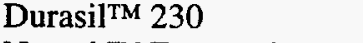 & 16 & 44 & 165 \\
\hline Nusorb $^{\mathrm{TM}}$ Ferrocarbon A & 11 & 30 & 146 \\
\hline
\end{tabular}


6. Chromium. Only tannin and the RF resin offer high Kd values for sorbing chromium from DSSF simulant; moreover, the sorption kinetics are very slow in both cases.

\begin{tabular}{|c|c|c|c|}
\hline \multicolumn{4}{|c|}{ Table 10. Chromium Distribution Data } \\
\hline \multirow[b]{2}{*}{ Absorber } & \multicolumn{3}{|c|}{ Kd Value for Specified Time } \\
\hline & $30 \mathrm{~min}$ & $2 \mathbf{h}$ & $6 \mathrm{~h}$ \\
\hline $\mathrm{Ba}(\mathrm{Ca}) \mathrm{SO}_{4}-\mathrm{PAN}$ & 7.7 & 11 & 14 \\
\hline Tannin & 6.7 & 59 & 2213 \\
\hline Resin Tech" ${ }^{\mathrm{TM}} 3972$ & 5.3 & 6.5 & 6.4 \\
\hline SRS RF BSC- 187 & 2.9 & 43 & 413 \\
\hline
\end{tabular}

7. Cobalt. Only Nusorb ${ }^{\mathrm{TM}}$ LP-70-S sorbs cobalt with a triple-digit Kd value, although many other absorbers offer high double-digit $\mathrm{Kd}$ values.

Table 11. Cobalt Distribution Data

\begin{tabular}{|c|c|c|c|}
\hline \multirow[b]{2}{*}{ Absorber } & \multicolumn{3}{|c|}{ Kd Value for Specified Time } \\
\hline & 30 min & $2 \mathrm{~h}$ & $6 \mathrm{~h}$ \\
\hline Nusorb $^{\text {TM }}$ LP-70-S & 44 & 262 & 443 \\
\hline NiFC-PAN & 29 & 65 & 89 \\
\hline Duolite $^{\text {TM }}$ CS-100 & 25 & 51 & 85 \\
\hline NM-PAN & 20 & 39 & 45 \\
\hline Bone char & 14 & 28 & 40 \\
\hline Tannin & 13 & 29 & 49 \\
\hline SRS RF BSC- 187 & 5.9 & 19 & 41 \\
\hline Nusorb $^{\mathrm{TM}}$ Ferrocarbon A & 2.3 & 6.1 & 19 \\
\hline TiFC-PSF & 0.8 & 5.5 & 14 \\
\hline
\end{tabular}


8. Iron. The high $\mathrm{Kd}$ values for sorbing iron on many absorbers from DSSF solution may preclude their use for sorbing other elements of interest.

\begin{tabular}{lrrr}
\hline \multicolumn{4}{c}{ Kable 12. Iron Distribution Data } \\
\cline { 2 - 4 } Absorber & $\mathbf{3 0}$ min & \multicolumn{1}{c}{$\mathbf{2 ~ h}$} & $\mathbf{6 h}$ \\
\hline ZrP-PAN & $>1400$ & $>1800$ & $>1900$ \\
MnO-PAN & $>1300$ & $>1400$ & $>1400$ \\
TiO-PAN & 1174 & $>4900$ & $>5200$ \\
NiFC-PAN & 586 & 2621 & $>4400$ \\
SNL/HTO & 526 & 267 & 253 \\
NM-PAN & 524 & 1353 & 1592 \\
Tannin & 452 & 721 & $>1600$ \\
DuoliteT CS-100 & 277 & 590 & 1011 \\
MgO-PAN & 174 & 304 & 403 \\
NATiO-PAN & 120 & 602 & 1373 \\
TiSbA-PAN & 97 & 308 & 519 \\
SRS RF BSC-187 & 72 & 209 & 330 \\
TiP-PAN & 70 & 99 & 131 \\
IonsivTM TIE-96 & 69 & 215 & 478 \\
MgAlHT & 61 & 77 & 96 \\
IonsivTM TIE-96 (mod.) & 47 & 234 & 720 \\
SnSbA-PAN & 24 & 45 & 71 \\
NusorbTM Ferrocarbon A & 18 & 46 & 230 \\
TiFC-PAN & 13 & 115 & 230 \\
ZrO-PAN & 13 & 63 & 291 \\
CoFC-PSF & 5.2 & 31 & 145 \\
ZrOP-PAN & 4.2 & 21 & 134 \\
\hline \hline
\end{tabular}


9. Manganese. Many absorbers offer high Kd values for sorbing manganese from DSSF simulant, which may preclude the use of these absorbers for removing other elements of interest.

\begin{tabular}{|c|c|c|c|}
\hline \multicolumn{4}{|c|}{ Table 13. Manganese Distribution Data } \\
\hline \multirow[b]{2}{*}{ Absorber } & \multicolumn{3}{|c|}{ Kd Value for Specified Time } \\
\hline & $30 \mathrm{~min}$ & $2 \mathbf{h}$ & $6 \mathrm{~h}$ \\
\hline ZrP-PAN & 1072 & $>5600$ & $>5900$ \\
\hline MnO-PAN & 483 & $>4200$ & $>4600$ \\
\hline TiO-PAN & 318 & 658 & 1483 \\
\hline SNL/HTO & 313 & 353 & 501 \\
\hline Duolite ${ }^{\mathrm{TM}}$ CS-100 & 204 & 377 & 687 \\
\hline Tannin & 123 & 217 & 362 \\
\hline TiP-PAN & 67 & 129 & 217 \\
\hline NiFC-PAN & 58 & 235 & 232 \\
\hline NaTiO-PAN & 58 & 218 & 622 \\
\hline NM-PAN & 46 & 296 & 1364 \\
\hline TiSbA-PAN & 52 & 160 & 372 \\
\hline Ionsiv ${ }^{\mathrm{TM}}$ TIE-96 & 42 & 115 & 268 \\
\hline Ionsiv'TM TIE-96 (mod.) & 31 & 151 & 506 \\
\hline MgAlHT & 20 & 40 & 90 \\
\hline SRS RF BSC-187 & 20 & 56 & 111 \\
\hline TiFC-PSF & 12 & 108 & 283 \\
\hline ZrO-PAN & 12 & 46 & 143 \\
\hline Nusorb $^{\mathrm{TM}}$ Ferrocarbon A & 11 & 31 & 189 \\
\hline 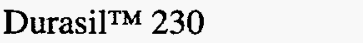 & 11 & 51 & 418 \\
\hline CoFC-PSF & 7.8 & 39 & 217 \\
\hline SNL/CST 120 & 7.2 & 36 & 240 \\
\hline ZrOP-PAN & 4.8 & 24 & 131 \\
\hline
\end{tabular}

10. Nickel. Five absorbers offer at least triple-digit Kd values for sorbing nickel from DSSF simulant.

Table 14. Nickel Distribution Data

\begin{tabular}{|c|c|c|c|}
\hline \multirow[b]{2}{*}{ Absorber } & \multicolumn{3}{|c|}{ Kd Value for Specified Time } \\
\hline & $30 \mathrm{~min}$ & $2 \mathrm{~h}$ & $6 \mathrm{~h}$ \\
\hline NiFC-PAN & 357 & 1290 & $>1800$ \\
\hline NM-PAN & 150 & 612 & 660 \\
\hline Bone char & 92 & 184 & 109 \\
\hline Duolite ${ }^{\mathrm{TM}}$ CS-100 & 68 & 140 & 219 \\
\hline Nusorb $^{\text {TM }}$ LP-70-S & 63 & 472 & 481 \\
\hline LIX $^{\text {TM-54 }}$ & 12 & 27 & 64 \\
\hline SRS RF BSC-187 & 6.8 & 21 & 50 \\
\hline Amberlite ${ }^{\mathrm{TM}} \mathrm{IRC}-718$ & 6.6 & 15 & 28 \\
\hline Tannin & 6.6 & 12 & 10 \\
\hline ZrP-PAN & 6.5 & 9.5 & 12 \\
\hline Nusorb $^{\mathrm{TM}}$ Ferrocarbon A & 3.6 & 11 & 33 \\
\hline Chelex TM 100 & 3.3 & 8.3 & 20 \\
\hline TiFC-PSF & 3.0 & 18 & 33 \\
\hline MgO-PAN & 2.3 & 9.2 & 34 \\
\hline
\end{tabular}


11. Vanadium. Only Zr-PAN offers even double-digit Kd values for sorbing vanadium from DSSF simulant.

\begin{tabular}{lcrr}
\hline \hline \multicolumn{4}{c}{ Table 15. Vanadium Distribution Data } \\
\hline & \multicolumn{4}{c}{ Kd Value for Specified Time } \\
\cline { 2 - 4 } Absorber & $\mathbf{3 0 ~} \mathbf{~}$ in & $\mathbf{2 ~ h}$ & $\mathbf{6 ~ h}$ \\
\hline ZrP-PAN & 2.3 & 39 & 44 \\
ZrO-PAN & 1.4 & 2.2 & 5.0 \\
ZrOP-PAN & 0.8 & 2.3 & 3.4 \\
\hline \hline
\end{tabular}

12. Zinc. Seven absorbers offer at least triple-digit Kd values for sorbing zinc from DSSF simulant.

\begin{tabular}{lcrr}
\hline \multicolumn{5}{c}{ Table 16. Zinc Distribution Data } \\
\hline & \multicolumn{3}{c}{ Kd Value for Specified Time } \\
\cline { 2 - 4 } Absorber & $\mathbf{3 0}$ min & $\mathbf{2 ~ h}$ & $\mathbf{6 ~ h}$ \\
\hline NiFC-PAN & 309 & 819 & $\mathbf{1 1 1 6}$ \\
MgO-PAN & 251 & 429 & 502 \\
TiO-PAN & 217 & 317 & 365 \\
NM-PAN & 163 & 364 & 483 \\
SNL/HTO & 107 & 170 & 207 \\
TiP-PAN & 72 & 228 & 334 \\
MnO-PAN & 68 & 132 & 241 \\
ZrP-PAN & 18 & 64 & 92 \\
MgAlHT & 13 & 19 & 27 \\
Bone char & 10 & 15 & 18 \\
IonsivTM TIE-96 & 9.5 & 9.7 & 15 \\
Tannin & 8.5 & 13 & 16 \\
Diphonix & 8.5 & 9.8 & 11 \\
ZrO-PAN & 5.5 & 15 & 30 \\
NaTiO-PAN & 5.5 & 11 & 23 \\
IonsivTM TIE-96 & 5.5 & 7.7 & 13 \\
SnSbA-PAN & 4.7 & 8.5 & 16 \\
TiSbA-PAN & 4.0 & 8.2 & 20 \\
ZrOP-PAN & 2.0 & 8.8 & 22 \\
CoFC-PSF & 1.0 & 5.2 & 14 \\
\hline \hline
\end{tabular}


13. Zirconium. More than ten absorbers offer at least triple-digit $\mathrm{Kd}$ values for sorbing zirconium from DSSF simulant.

\begin{tabular}{|c|c|c|c|}
\hline \multicolumn{4}{|c|}{ Table 17. Zirconium Distribution Data } \\
\hline \multirow[b]{2}{*}{ Absorber } & \multicolumn{3}{|c|}{ Kd Value for Specified Time } \\
\hline & $30 \mathrm{~min}$ & $2 \mathrm{~h}$ & $6 \mathrm{~h}$ \\
\hline TiO-PAN & 2242 & 4780 & 4841 \\
\hline ZrP-PAN & 2032 & $>3400$ & $>3600$ \\
\hline SNL/HTO & 1444 & 1625 & 2735 \\
\hline NK 120B & 199 & 169 & 176 \\
\hline TiP-PAN & 108 & 260 & 461 \\
\hline Tannin & 87 & 168 & 260 \\
\hline TiSbA-PAN & 79 & 453 & 892 \\
\hline MnO-PAN & 59 & 112 & 171 \\
\hline IonsivTM TIE-96 & 55 & 191 & 414 \\
\hline Duolite ${ }^{\mathrm{TM}}$ CS-100 & 48 & 92 & 142 \\
\hline Ionsiv ${ }^{\mathrm{TM}}$ TIE-96 (mod.) & 38 & 189 & 527 \\
\hline Bone char & 36 & 72 & 95 \\
\hline SNL/CST 120 & 36 & 31 & 57 \\
\hline NK 194 & 32 & 45 & 47 \\
\hline Diphonix $^{\mathrm{TM}}$ & 28 & 52 & 78 \\
\hline$K W-4-40 x$ & 18 & 54 & 115 \\
\hline SNL/CST 149 & 16 & 25 & 28 \\
\hline MgO-PAN & 15 & 25 & 41 \\
\hline SRS RF BSC-187 & 13 & 37 & 68 \\
\hline ZrO-PAN & 10 & 44 & 170 \\
\hline TiFC-PSF & 9.1 & 74 & 195 \\
\hline Durasil $^{\mathrm{TM}} 230$ & 7.9 & 16 & 35 \\
\hline ZrOP-PAN & 3.5 & 17 & 102 \\
\hline
\end{tabular}

14. Uranium. Four absorbers, three of which contain titanium, offer at least triple-digit Kd values for sorbing uranium from DSSF simulant.

\begin{tabular}{|c|c|c|c|}
\hline \multicolumn{4}{|c|}{ Table 18. Uranium Distribution Data } \\
\hline \multirow[b]{2}{*}{ Absorber } & \multicolumn{3}{|c|}{ Kd Value for Specified Time } \\
\hline & $30 \mathrm{~min}$ & $2 \mathrm{~h}$ & $6 \mathrm{~h}$ \\
\hline 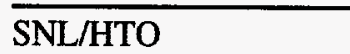 & 622 & 1419 & $>2300$ \\
\hline TIO-PAN & 574 & 1707 & 2671 \\
\hline TiP-PAN & 101 & 369 & 872 \\
\hline ZrP-PAN & 51 & 296 & 340 \\
\hline SNL/CST 120 & 26 & 25 & 28 \\
\hline Tannin & 20 & 37 & 57 \\
\hline Ionsiv $^{\text {TM }}$ TIE-96 & 14 & 28 & 71 \\
\hline NaTiO-PAN & 12 & 32 & 69 \\
\hline Ionsiv ${ }^{\mathrm{TM}}$ TIE-96 (mod.) & 8.7 & 20 & 53 \\
\hline$D^{\text {Diphonix }}{ }^{\mathrm{TM}}$ & $\begin{array}{l}0.1 \\
7.4\end{array}$ & 6.2 & 4.9 \\
\hline ZrO-PAN & 6.3 & 23 & 89 \\
\hline TiSbA-PAN & 5.2 & 15 & 69 \\
\hline SRS RF BSC-187 & 3.8 & 11 & 23 \\
\hline TiFC-PSF & 2.7 & 19 & 40 \\
\hline ZrOP-PAN & 1.8 & 10 & 40 \\
\hline
\end{tabular}


15. Americium. Many absorbers offer at least triple-digit Kd values for sorbing americium from DSSF simulant.

\begin{tabular}{|c|c|c|c|}
\hline \multicolumn{4}{|c|}{ Table 19. Americium Distribution Data } \\
\hline \multirow[b]{2}{*}{ Absorber } & \multicolumn{3}{|c|}{ Kd Value for Specified Time } \\
\hline & $30 \mathrm{~min}$ & $\mathbf{2 h}$ & $6 \mathrm{~h}$ \\
\hline ZrP-PAN & $>580$ & $>590$ & $>590$ \\
\hline Bone char & 215 & $>590$ & $>590$ \\
\hline MgAlHT & 76 & 163 & 215 \\
\hline SNL/HTO & 66 & 104 & 172 \\
\hline$K W-4-40 x$ & 60 & 70 & 75 \\
\hline NiFC-PAN & 53 & 93 & 170 \\
\hline KW-4-41x & 46 & 59 & 60 \\
\hline NM-PAN & 38 & 83 & 132 \\
\hline TiSbA-PAN & 28 & 52 & 95 \\
\hline MnO-PAN & 22 & 83 & 473 \\
\hline Nusorb $^{\text {TM }}$ Ferrocarbon A & 22 & 109 & 602 \\
\hline TIO-PAN & 17 & 135 & 647 \\
\hline Duolite ${ }^{\mathrm{TM}}$ CS-100 & 12 & 22 & 63 \\
\hline MgO-PAN & 11 & 13 & 38 \\
\hline TiP-PAN & 10 & 19 & 31 \\
\hline Durasil ${ }^{\mathrm{TM}} 230$ & 9.5 & 28 & 78 \\
\hline Nusorb $^{\mathrm{TM}}$ LP-70-S & 9.3 & 29 & 41 \\
\hline IonsivTM TIE-96 (mod.) & 9.0 & 27 & 66 \\
\hline Diphonix ${ }^{\mathrm{TM}}$ & 6.2 & 12 & 22 \\
\hline NaTiO-PAN & 5.9 & 7.9 & 19 \\
\hline CoFC-PSF & 3.5 & 6.2 & 28 \\
\hline
\end{tabular}

\section{B. Individual Absorbers}

Tables 20 through 77 present Kd values for sorption of all 15 elements onto each of the 58 absorbers from simulated DSSF solution. The measured Kd values for three different times - $30 \mathrm{~min}, 2 \mathrm{~h}$, and $6 \mathrm{~h}$ - provide some limited information about the sorption kinetics. Moreover, because we measured the sorption of 15 different elements, these tables provide information about which unwanted elements are most likely to interfere with the targeted element by competing for absorber sites. Therefore, Tables 20 through 77 may be used to predict the selectivity of each individual absorber for any of these elements.

Although long-term stability is an essential attribute of any absorber that would be seriously considered for waste processing, we made no attempt to evaluate the stability of these absorbers in the simulated DSSF solution. All candidate absorbers were included in our tests unless we observed noticeable degradation in the test solution. Although we eliminated those absorbers whose chemical degradation was apparent, we recommend that the remaining absorbers that show promise for HLW tank processing should be evaluated for long-term chemical stability and for radiation resistance if these properties are not already known.

1. Commercially Available Absorbers. The 23 commercially available absorbers listed in Table 4 were included in our study. 
a. Amberlite TM DP-I Cation Exchange Resin. Amberlite TM DP-1, manufactured by Rohm \& Haas, Philadelphia, Pennsylvania, is a weak-acid cation exchanger consisting of a crosslinked methacrylic polymer with carboxylic acid functionality. This resin was air-dried before use.

Table 20 shows that Amberlite ${ }^{\text {TM }}$ DP- 1 sorbs yttrium and strontium from DSSF simulant at useful levels.

Table 20. Amberlite ${ }^{\mathrm{TM}}$ DP-1 Cation Exchange

Resin: Distribution of 15 Elements from

Simulated Hanford DSSF Solution

\begin{tabular}{lrrr}
\hline & \multicolumn{3}{c}{ Kd Value for Specified Time } \\
\cline { 2 - 4 } Element & $\mathbf{3 0} \mathbf{~ m i n}$ & $\mathbf{2} \mathbf{~ h}$ & $\mathbf{6 ~ h}$ \\
\hline $\mathrm{Ce}$ & $<0.1$ & $<0.1$ & 0.4 \\
$\mathrm{Cs}$ & 6.6 & 4.8 & 3.4 \\
$\mathrm{Sr}$ & 25 & 32 & 34 \\
$\mathrm{Tc}$ & 6.2 & 4.6 & 3.2 \\
$\mathrm{Y}$ & 21 & 42 & 76 \\
$\mathrm{Cr}$ & 6.0 & 4.4 & 3.2 \\
$\mathrm{Co}$ & 0.4 & 0.6 & 0.7 \\
$\mathrm{Fe}$ & 3.1 & 4.3 & 5.4 \\
$\mathrm{Mn}$ & 1.7 & 1.9 & 2.1 \\
$\mathrm{Ni}$ & 0.8 & 1.6 & 2.3 \\
$\mathrm{~V}$ & 0.3 & $<0.1$ & $<0.1$ \\
$\mathrm{Zn}$ & 0.8 & 1.0 & 1.1 \\
$\mathrm{Zr}$ & 2.9 & 4.3 & 6.5 \\
$\mathrm{U}$ & $<0.1$ & $<0.1$ & 0.3 \\
$\mathrm{Am}$ & 5.2 & 5.7 & 7.3 \\
\hline
\end{tabular}

b. Amberlite ${ }^{\mathrm{TM}}$ IRC-76 Cation Exchange Resin. Amberlite $^{\text {TM }}$ IRC-76, manufactured by Rohm \& Haas, Philadelphia, Pennsylvania, is a weak-acid cation exchanger consisting of a crosslinked acrylic acid polymer with carboxylic acid functionality. This resin was air-dried before use.

Only strontium and manganese are sorbed with even double-digit $\mathrm{Kd}$ values.

Table 21. Amberlite TM IRC-76 Cation

Exchange Resin: Distribution of 15 Elements

from Simulated Hanford DSSF Solution

\begin{tabular}{lrrr}
\hline & \multicolumn{3}{c}{ Kd Value for Specified Time } \\
\cline { 2 - 4 } Element & $\mathbf{3 0} \mathbf{~ m i n}$ & $\mathbf{2} \mathbf{h}$ & $\mathbf{6 ~ h}$ \\
\hline $\mathrm{Ce}$ & $<0.1$ & $<0.1$ & $<0.1$ \\
$\mathrm{Cs}$ & 1.9 & 3.7 & 4.2 \\
$\mathrm{Sr}$ & 17 & 37 & 58 \\
$\mathrm{Tc}$ & 2.0 & 3.7 & 4.2 \\
$\mathrm{Y}$ & 1.1 & 2.4 & 4.1 \\
$\mathrm{Cr}$ & 1.6 & 3.2 & 3.8 \\
$\mathrm{Co}$ & 0.3 & 0.6 & 0.9 \\
$\mathrm{Fe}$ & 2.9 & 3.7 & 3.7 \\
$\mathrm{Mn}$ & 4.1 & 9.2 & 14 \\
$\mathrm{Ni}$ & 1.0 & 1.6 & 1.6 \\
$\mathrm{~V}$ & $<0.1$ & $<0.1$ & $<0.1$ \\
$\mathrm{Zn}$ & 0.5 & 0.8 & 0.8 \\
$\mathrm{Zr}$ & 0.8 & 1.9 & 2.6 \\
$\mathrm{U}$ & 0.2 & 0.5 & 0.7 \\
$\mathrm{Am}$ & 1.0 & 1.8 & 2.4 \\
\hline
\end{tabular}


c. Amberlite ${ }^{\mathrm{TM}}$ IRC-718 Cation Exchange Resin. Amberlite ${ }^{\mathrm{TM}}$ IRC-718, manufactured by Rohm \& Haas, Philadelphia, Pennsylvania, is a weak-acid cation exchanger consisting of a styrene/divinylbenzene copolymer with iminodiacetic acid functionality. This resin was air-dried before use.

Amberlite TM IRC-718 sorbs strontium well and yttrium, nickel, and americium at useful, but much lower, $\mathrm{Kd}$ values.

\begin{tabular}{|c|c|c|c|}
\hline \multicolumn{4}{|c|}{$\begin{array}{l}\text { Table 22. Amberlite }{ }^{\mathrm{TM}} \text { IRC-718 Cation } \\
\text { Exchange Resin: Distribution of } 15 \text { Elements } \\
\text { from Simulated Hanford DSSF Solution }\end{array}$} \\
\hline \multirow[b]{2}{*}{ Element } & \multicolumn{3}{|c|}{ Kd Value for Specified Time } \\
\hline & $30 \mathrm{~min}$ & $2 \mathrm{~h}$ & $6 \mathrm{~h}$ \\
\hline $\mathrm{Ce}$ & $<0.1$ & $<0.1$ & 3.6 \\
\hline Cs & 2.2 & 2.0 & 2.0 \\
\hline $\mathrm{Sr}$ & 244 & 632 & 969 \\
\hline Tc & 5.8 & 5.6 & 5.7 \\
\hline $\mathrm{Y}$ & 9.9 & 22 & 34 \\
\hline $\mathrm{Cr}$ & 1.9 & 1.7 & 2.0 \\
\hline Co & 0.6 & 1.0 & 1.1 \\
\hline $\mathrm{Fe}$ & 2.1 & 2.4 & 2.8 \\
\hline $\mathrm{Mn}$ & 2.1 & 3.0 & 3.4 \\
\hline $\mathrm{Ni}$ & 6.6 & 15 & 28 \\
\hline V & $<0.1$ & $<0.1$ & $<0.1$ \\
\hline $\mathrm{Zn}$ & 1.0 & 1.3 & 1.4 \\
\hline $\mathrm{Zr}$ & 0.7 & 1.4 & 1.8 \\
\hline U & 0.4 & 0.3 & 0.7 \\
\hline Am & 1.4 & 4.8 & 12 \\
\hline
\end{tabular}

d. Bone Char Absorber. Bone char, produced by calcining cattle bones in the absence of air, was obtained from Stauffer Chemical Company, Westport, Connecticut. Bone char, which is predominantly calcium phosphate, was used as received.

Bone char sorbs strontium, cerium, americium, yttrium, and nickel well from DSSF simulant.

Table 23. Bone Char Absorber: Distribution of 15 Elements from Simulated Hanford DSSF

Solution

\begin{tabular}{lcrr}
\hline & \multicolumn{3}{c}{ Kd Value for Specified Time } \\
\cline { 2 - 4 } Element & $\mathbf{3 0 ~} \mathbf{~ m i n}$ & $\mathbf{2} \mathbf{~ h}$ & $\mathbf{6 ~ h}$ \\
\hline $\mathrm{Ce}$ & 160 & $>1500$ & $>1600$ \\
$\mathrm{Cs}$ & $<0.1$ & $<0.1$ & $<0.1$ \\
$\mathrm{Sr}$ & 713 & 2378 & 4836 \\
$\mathrm{Tc}$ & 0.7 & 1.0 & 1.2 \\
$\mathrm{Y}$ & 97 & 529 & 723 \\
$\mathrm{Cr}$ & 0.1 & 0.3 & 0.7 \\
$\mathrm{Co}$ & 14 & 28 & 40 \\
$\mathrm{Fe}$ & 13 & 18 & 24 \\
$\mathrm{Mn}$ & 22 & 38 & 60 \\
$\mathrm{Ni}$ & 92 & 184 & 109 \\
$\mathrm{~V}$ & $<0.1$ & $<0.1$ & $<0.1$ \\
$\mathrm{Zn}$ & 10 & 15 & 18 \\
$\mathrm{Zr}$ & 36 & 72 & 95 \\
$\mathrm{U}$ & 3.7 & 5.9 & 6.0 \\
$\mathrm{Am}$ & 215 & $>590$ & $>590$ \\
\hline \hline
\end{tabular}


e. Chelex ${ }^{\mathrm{TM}} 100$ Cation Exchange Resin. Chelex ${ }^{\mathrm{TM}}$ 100, manufactured by the Dow Chemical Company, Midland, Michigan, is a weak-acid cation exchanger that consists of a styrene/divinylbenzene copolymer with iminodiacetic acid functionality. This resin was air-dried before use.

Chelex ${ }^{\mathrm{TM}} 100$ provides high selectivity for sorbing strontium from DSSF simulant, with nickel the only other element sorbed with even a double-digit $\mathrm{Kd}$ value.

\begin{tabular}{|c|c|c|c|}
\hline \multicolumn{4}{|c|}{$\begin{array}{l}\text { Table 24. Chelex TM } 100 \text { Cation Exchange } \\
\text { Resin: Distribution of } 15 \text { Elements from } \\
\text { Simulated Hanford DSSF Solution } \\
\end{array}$} \\
\hline \multirow[b]{2}{*}{ Element } & \multicolumn{3}{|c|}{ Kd Value for Specified Time } \\
\hline & $30 \mathrm{~min}$ & $2 \mathrm{~h}$ & $6 \mathrm{~h}$ \\
\hline $\mathrm{Ce}$ & $<0.1$ & $<0.1$ & $<0.1$ \\
\hline Cs & 4.2 & 6.3 & 4.7 \\
\hline $\mathrm{Sr}$ & 135 & 345 & 358 \\
\hline $\mathrm{Tc}$ & 5.6 & 7.9 & 6.2 \\
\hline Y & 1.1 & 0.4 & 1.2 \\
\hline $\mathrm{Cr}$ & 4.2 & 6.3 & 4.8 \\
\hline $\mathrm{Co}$ & 0.7 & 0.9 & 1.0 \\
\hline $\mathrm{Fe}$ & 0.6 & 0.8 & 1.1 \\
\hline $\mathrm{Mn}$ & 0.7 & 0.7 & 1.1 \\
\hline $\mathrm{Ni}$ & 3.3 & 8.3 & 20 \\
\hline V & 0.4 & $<0.1$ & $<0.1$ \\
\hline $\mathrm{Zn}$ & 0.3 & 0.4 & 0.5 \\
\hline $\mathrm{Zr}$ & 0.4 & 0.4 & 0.6 \\
\hline $\mathrm{U}$ & $<0.1$ & 0.4 & 0.4 \\
\hline $\mathrm{Am}$ & 0.2 & 2.1 & 1.9 \\
\hline
\end{tabular}

f. Diphonix ${ }^{\mathrm{TM}}$ Cation Exchange Resin. Diphonix ${ }^{\mathrm{TM}}$, a polyfunctional resin that contains diphosphonic acid, sulfonic acid, and carboxylic acid functional groups, was obtained from EIChroM Industries, Inc., Darien, Illinois. We air-dried this resin before testing for reasons detailed in Section II.C.

Diphonix ${ }^{\mathrm{TM}}$ resin sorbs strontium well and sorbs numerous other elements with double-digit $\mathrm{Kd}$ values from DSSF simulant.

Table 25. Diphonix ${ }^{\mathrm{TM}}$ Cation Exchange Resin: Distribution of 15 Elements from Simulated Hanford DSSF Solution

\begin{tabular}{lrrr} 
& \multicolumn{3}{c}{ Kd Value for Specified Time } \\
\cline { 2 - 4 } Element & 30 $\mathbf{~ m i n}$ & $\mathbf{2 ~ h}$ & $\mathbf{6 ~ h}$ \\
\hline $\mathrm{Ce}$ & $<0.1$ & 12 & 47 \\
$\mathrm{Cs}$ & 0.8 & 0.3 & 0.3 \\
$\mathrm{Sr}$ & 1930 & 4921 & $7 \mathrm{~K}$ \\
$\mathrm{Tc}$ & 2.6 & 2.5 & 2.5 \\
$\mathrm{Y}$ & 44 & 66 & 71 \\
$\mathrm{Cr}$ & 0.5 & 0.1 & 0.2 \\
$\mathrm{Co}$ & 1.2 & 0.8 & 1.0 \\
$\mathrm{Fe}$ & 18 & 25 & 29 \\
$\mathrm{Mn}$ & 5.6 & 4.0 & 4.4 \\
$\mathrm{Ni}$ & $<0.1$ & 1.5 & 4.6 \\
$\mathrm{~V}$ & 0.9 & 0.2 & 0.2 \\
$\mathrm{Zn}$ & 8.5 & 9.8 & 11 \\
$\mathrm{Zr}$ & 28 & 52 & 78 \\
$\mathrm{U}$ & 7.4 & 6.2 & 4.9 \\
$\mathrm{Am}$ & 6.2 & 12 & 22 \\
\hline \hline
\end{tabular}


g. Duolite ${ }^{\mathrm{TM}}$ CS-100 Cation Exchange Resin. Duolite $^{\mathrm{TM}}$ CS-100 is a phenol-formaldehyde condensate cation exchange resin manufactured by Rohm \& Haas, Philadelphia, Pennsylvania. (However, Rohm \& Haas has recently discontinued CS-100 as one of their standard products.) This resin was air-dried before use.

Duolite ${ }^{\mathrm{TM}}$ CS-100 resin, the current baseline technology for removing cesium from Hanford waste, sorbs cesium with only a moderate $\mathrm{Kd}$ value. However, six other elements, including high-concentration matrix elements iron, manganese, and nickel, are sorbed with at least triple-digit Kd values and could seriously interfere with cesium sorption.

Table 26. Duolite ${ }^{\mathrm{TM}}$ CS-100 Cation Exchange Resin: Distribution of 15 Elements from Simulated Hanford DSSF Solution

\begin{tabular}{lcrr}
\hline & \multicolumn{3}{c}{ Kd Value for Specified Time } \\
\cline { 2 - 4 } Element & $\mathbf{3 0} \mathbf{~ m i n}$ & $\mathbf{2} \mathbf{h}$ & $\mathbf{6 ~ h}$ \\
\hline $\mathrm{Ce}$ & 5.0 & 5.6 & 19 \\
$\mathrm{Cs}$ & 46 & 49 & 50 \\
$\mathrm{Sr}$ & 70 & 106 & 126 \\
$\mathrm{Tc}$ & $<0.1$ & $<0.1$ & 0.3 \\
$\mathrm{Y}$ & 52 & 123 & 187 \\
$\mathrm{Cr}$ & 0.7 & 1.7 & 4.7 \\
$\mathrm{Co}$ & 25 & 51 & 85 \\
$\mathrm{Fe}$ & 277 & 590 & 1011 \\
$\mathrm{Mn}$ & 204 & 377 & 687 \\
$\mathrm{Ni}$ & 68 & 140 & 219 \\
$\mathrm{~V}$ & $<0.1$ & $<0.1$ & $<0.1$ \\
$\mathrm{Zn}$ & 2.6 & 4.0 & 5.9 \\
$\mathrm{Zr}$ & 48 & 92 & 142 \\
$\mathrm{U}$ & 6.5 & 8.0 & 7.7 \\
$\mathrm{Am}$ & 12 & 22 & 63 \\
\hline \hline
\end{tabular}

h. Duolite ${ }^{\mathrm{TM}}$ C-467 Cation Exchange Resin. Duolite ${ }^{\mathrm{TM}}$ C-467, a chelating cation exchange resin composed of a polystyrene/divinylbenzene copolymer with aminophosphonic acid functionality, is manufactured by Rohm \& Haas, Philadelphia, Pennsylvania. This resin was air-dried before use.

Duolite ${ }^{\mathrm{TM}} \mathrm{C}-467$ provides high selectivity for strontium from DSSF simulant, with a Kd 30-fold higher than that for yttrium, the only other element with even a double-digit $\mathrm{Kd}$ value. The commercial availability of this resin at moderate cost makes it an attractive candidate for removing strontium from alkaline solution.

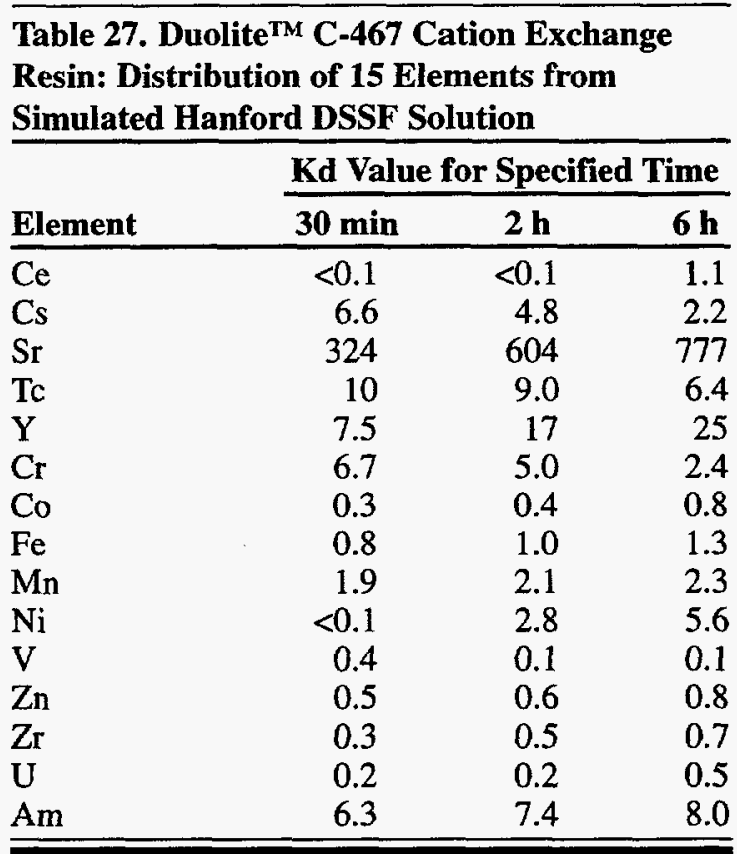


i. Durasil ${ }^{\mathrm{TM}} 190$ Resin. Durasil ${ }^{\mathrm{TM}} 190$, a vitreous glass absorber obtained from the Duratek Corporation, Beltsville, Maryland, was used as received.

Durasil ${ }^{\mathrm{TM}} 190$ sorbs none of the 15 elements from DSSF simulant at useful levels.

Table 28. Durasil ${ }^{\mathrm{rM}} 190$ Resin: Distribution of 15 Elements from Simulated Hanford DSSF Solution

\begin{tabular}{lccc}
\hline & \multicolumn{3}{c}{ Kd Value for Specified Time } \\
\cline { 2 - 4 } Element & $\mathbf{3 0} \mathbf{~ m i n}$ & $\mathbf{2} \mathbf{~ h}$ & $\mathbf{6 ~ h}$ \\
\hline $\mathrm{Ce}$ & $<0.1$ & $<0.1$ & 1.4 \\
$\mathrm{Cs}$ & 4.4 & 1.2 & 1.0 \\
$\mathrm{Sr}$ & 4.5 & 1.7 & 2.2 \\
$\mathrm{Tc}$ & 5.0 & 2.0 & 1.8 \\
$\mathrm{Y}$ & 1.5 & 1.6 & 5.2 \\
$\mathrm{Cr}$ & 4.3 & 1.3 & 1.1 \\
$\mathrm{Co}$ & 0.7 & 0.4 & 0.6 \\
$\mathrm{Fe}$ & 1.5 & 0.9 & 1.3 \\
$\mathrm{Mn}$ & 0.8 & 0.5 & 1.1 \\
$\mathrm{Ni}$ & $<0.1$ & 0.3 & 0.8 \\
$\mathrm{~V}$ & 0.7 & 0.2 & 0.2 \\
$\mathrm{Zn}$ & 0.8 & 0.5 & 0.6 \\
$\mathrm{Zr}$ & 0.4 & 0.4 & 0.9 \\
$\mathrm{U}$ & 0.9 & 0.5 & 0.6 \\
$\mathrm{Am}$ & 2.7 & 0.9 & 2.2 \\
\hline \hline
\end{tabular}

j. Durasil 230 Resin. Durasil 230 , an aluminosilicate absorber obtained from the Duratek Corporation, Beltsville, Maryland, was used as received.

Durasil TM 230 sorbs manganese and yttrium with triple-digit $\mathrm{Kd}$ values and sorbs six other elements with double-digit $\mathrm{Kd}$ values.

\begin{tabular}{|c|c|c|c|}
\hline \multirow[b]{2}{*}{ Element } & \multicolumn{3}{|c|}{ Kd Value for Specified Time } \\
\hline & $30 \mathrm{~min}$ & $2 \mathrm{~h}$ & $6 h$ \\
\hline$\overline{\mathrm{Ce}}$ & 6.1 & 21 & 45 \\
\hline Cs & 10 & 13 & 13 \\
\hline $\mathrm{Sr}$ & 17 & 38 & 69 \\
\hline $\mathrm{Tc}$ & 0.2 & 0.3 & 0.1 \\
\hline$Y$ & 16 & 44 & 165 \\
\hline $\mathrm{Cr}$ & $<0.1$ & $<0.1$ & $<0.1$ \\
\hline $\mathrm{Co}$ & 0.7 & 1.1 & 1.2 \\
\hline $\mathrm{Fe}$ & 5.6 & 13 & 43 \\
\hline Mn & 11 & 51 & 418 \\
\hline $\mathrm{Ni}$ & 2.8 & 5.5 & 7.5 \\
\hline V & $<0.1$ & $<0.1$ & $<0.1$ \\
\hline $\mathrm{Zn}$ & 2.1 & 3.2 & 3.8 \\
\hline $\mathrm{Zr}$ & 7.9 & 16 & 35 \\
\hline $\mathrm{U}$ & 0.7 & 1.1 & 1.2 \\
\hline $\mathrm{Am}$ & 9.5 & 28 & 78 \\
\hline
\end{tabular}


k. Ionac ${ }^{\mathrm{TM}}$ SR-3 Anion Exchange Resin. Ionac ${ }^{\mathrm{TM}}$ SR-3, a macroporous strong-base anion exchange resin with trimethyl amine as the functional group, was obtained from Sybron Chemicals, Inc., Birmingham, New Jersey. This resin was air-dried before use.

Ionac ${ }^{\mathrm{TM}} \mathrm{SR}-3$ sorbs technetium strongly and quite selectively from DSSF simulant.

\begin{tabular}{|c|c|c|c|}
\hline $\begin{array}{l}\text { Table } 30 \\
\text { Distribu } \\
\text { Hanford }\end{array}$ & $\begin{array}{l}\text { SR-3 Ar } \\
\text { Elemen } \\
\text { lution }\end{array}$ & $\begin{array}{l}\text { xcha } \\
\text { m Sin }\end{array}$ & $\begin{array}{l}\text { Resin: } \\
\text { ed }\end{array}$ \\
\hline & Kd Valu & Spec & Time \\
\hline Element & $30 \mathrm{~min}$ & $2 \mathrm{~h}$ & $6 \mathrm{~h}$ \\
\hline $\mathrm{Ce}$ & $<0.1$ & $<0.1$ & $<0.1$ \\
\hline Cs & 3.4 & 4.4 & 2.9 \\
\hline $\mathrm{Sr}$ & 3.5 & 4.6 & 3.1 \\
\hline Tc & 115 & 279 & 312 \\
\hline Y & 0.3 & 1.2 & 2.2 \\
\hline $\mathrm{Cr}$ & 3.4 & 4.5 & 3.2 \\
\hline Co & 0.6 & 0.9 & 1.0 \\
\hline $\mathrm{Fe}$ & 0.6 & 0.9 & 1.3 \\
\hline $\mathrm{Mn}$ & 0.8 & 1.2 & 1.4 \\
\hline $\mathrm{Ni}$ & 0.9 & 0.9 & 1.7 \\
\hline V & $<0.1$ & $<0.1$ & $<0.1$ \\
\hline $\mathrm{Zn}$ & 0.5 & 0.7 & 0.9 \\
\hline $\mathrm{Zr}$ & 0.4 & 0.8 & 1.0 \\
\hline $\mathbf{U}$ & 0.6 & 0.7 & 0.8 \\
\hline Am & 3.0 & 3.6 & 3.0 \\
\hline
\end{tabular}

l. Ionac ${ }^{\mathrm{TM}}$ SR-6 Anion Exchange Resin. Ionac ${ }^{\mathrm{TM}}$ SR-6, a macroporous strong-base anion exchange resin with tributyl amine as the functional group, was obtained from Sybron Chemicals, Inc., Birmingham, New Jersey. Ionac ${ }^{\mathrm{TM}}$ SR-6 resin has been reported ${ }^{8}$ to offer greatly increased selectivity for sorbing nitrate ion from groundwater. This resin was air-dried before use.

Ionac ${ }^{\text {TM }}$ SR-6 sorbs technetium selectively from DSSF simulant, although not as strongly as does Ionac ${ }^{\mathrm{TM}}$ SR-3.

Table 31. Ionac ${ }^{\mathrm{TM}}$ SR-6 Anion Exchange Resin: Distribution of 15 Elements from Simulated Hanford DSSF Solution

\begin{tabular}{lrrr}
\hline & \multicolumn{3}{c}{ Kd Value for Specified Time } \\
\cline { 2 - 4 } Element & $\mathbf{3 0} \mathbf{~} \mathbf{m i n}$ & $\mathbf{2} \mathbf{~ h}$ & $\mathbf{6 ~ h}$ \\
\hline $\mathrm{Ce}$ & 3.6 & 2.2 & 3.5 \\
$\mathrm{Cs}$ & $<0.1$ & $<0.1$ & $<0.1$ \\
$\mathrm{Sr}$ & 0.5 & 0.5 & 0.5 \\
$\mathrm{Tc}$ & 45 & 105 & 188 \\
$\mathrm{Y}$ & 0.2 & 1.5 & 2.7 \\
$\mathrm{Cr}$ & $<0.1$ & 0.2 & 0.3 \\
$\mathrm{Co}$ & 0.4 & 0.6 & 0.8 \\
$\mathrm{Fe}$ & 0.9 & 1.5 & 1.8 \\
$\mathrm{Mn}$ & 0.5 & 0.7 & 1.2 \\
$\mathrm{Ni}$ & 0.4 & 0.8 & 1.1 \\
$\mathrm{~V}$ & $<0.1$ & $<0.1$ & $<0.1$ \\
$\mathrm{Zn}$ & 0.3 & 0.5 & 0.7 \\
$\mathrm{Zr}$ & 0.4 & 0.8 & 1.0 \\
$\mathrm{U}$ & $<0.1$ & 0.5 & 0.7 \\
$\mathrm{Am}$ & 3.3 & 4.0 & 5.4 \\
\hline \hline
\end{tabular}


m. Ionsiv ${ }^{\mathrm{TM}}$ TIE-96 Absorber. Ionsiv ${ }^{\mathrm{TM}}$ TIE-96 is a titanium-loaded zeolite manufactured by UOP Molecular Sieves Division, Moorestown, New Jersey. This absorber was used as received.

Ionsiv $^{\mathrm{TM}}$ TIE-96 sorbs strontium, iron, zirconium, and manganese well from DSSF simulant. Several other elements are sorbed at lower, but useful, levels.

Table 32. Ionsiv ${ }^{\mathrm{TM}}$ TIE-96 Absorber: Distribution of 15 Elements from Simulated Hanford DSSF Solution

\begin{tabular}{lrrr}
\hline & \multicolumn{3}{c}{ Kd Value for Specified Time } \\
\cline { 2 - 4 } Element & $\mathbf{3 0} \mathbf{~ m i n}$ & $\mathbf{2} \mathbf{h}$ & $\mathbf{6} \mathbf{~ h}$ \\
\hline $\mathrm{Ce}$ & $<0.1$ & 13 & 28 \\
$\mathrm{Cs}$ & 9.1 & 11 & 12 \\
$\mathrm{Sr}$ & 235 & 484 & 657 \\
$\mathrm{Tc}$ & 1.4 & 0.4 & 0.4 \\
$\mathrm{Y}$ & 72 & 133 & 241 \\
$\mathrm{Cr}$ & 1.9 & 1.0 & 0.9 \\
$\mathrm{Co}$ & 4.8 & 1.8 & 2.0 \\
$\mathrm{Fe}$ & 69 & 215 & 478 \\
$\mathrm{Mn}$ & 42 & 115 & 268 \\
$\mathrm{Ni}$ & $<0.1$ & $<0.1$ & 1.0 \\
$\mathrm{~V}$ & 4.3 & 1.0 & 0.9 \\
$\mathrm{Zn}$ & 9.5 & 9.7 & 15 \\
$\mathrm{Zr}$ & 55 & 191 & 414 \\
$\mathrm{U}$ & 14 & 28 & 71 \\
$\mathrm{Am}$ & 4.3 & 16 & 39 \\
\hline \hline
\end{tabular}

n. Ionsiv ${ }^{\mathrm{TM}}$ TIE-96 (Modified) Absorber. Ionsiv ${ }^{\mathrm{TM}}$ TIE-96 (modified) is an improved version of the Ionsiv TM TIE-96 titanium-loaded zeolite manufactured by UOP Molecular Sieves Division, Moorestown, New Jersey. This absorber was used as received.

The modified form of Ionsiv ${ }^{\mathrm{TM}}$ TIE-96 provides a generally improved version of the sorption pattern of unmodified Ionsiv ${ }^{\text {TM }}$ TIE-96.

Table 33. Ionsiv TM TIE-96 (Modified) Absorber: Distribution of 15 Elements from Simulated Hanford DSSF Solution

\begin{tabular}{lcrr}
\hline & \multicolumn{3}{c}{ Kd Value for Specified Time } \\
\cline { 2 - 4 } Element & $\mathbf{3 0} \mathbf{~ m i n}$ & $\mathbf{2} \mathbf{h}$ & $\mathbf{6 ~ h}$ \\
\hline $\mathrm{Ce}$ & 1.8 & 14 & 41 \\
$\mathrm{Cs}$ & 8.2 & 11 & 12 \\
$\mathrm{Sr}$ & 222 & 578 & 1053 \\
$\mathrm{Tc}$ & $<0.1$ & $<0.1$ & $<0.1$ \\
$\mathrm{Y}$ & 82 & 221 & 410 \\
$\mathrm{Cr}$ & 0.1 & 0.4 & 0.2 \\
$\mathrm{Co}$ & 2.1 & 1.3 & 1.4 \\
$\mathrm{Fe}$ & 47 & 234 & 720 \\
$\mathrm{Mn}$ & 31 & 151 & 506 \\
$\mathrm{Ni}$ & $<0.1$ & 0.7 & 2.3 \\
$\mathrm{~V}$ & 1.5 & 0.4 & 0.4 \\
$\mathrm{Zn}$ & 5.5 & 7.7 & 13 \\
$\mathrm{Zr}$ & 38 & 189 & 527 \\
$\mathrm{U}$ & 8.7 & 20 & 53 \\
$\mathrm{Am}$ & 9.0 & 27 & 66 \\
\hline \hline
\end{tabular}


o. Nusorb ${ }^{\mathrm{TM}}$ Ferrocarbon A Absorber. Nusorb ${ }^{\mathrm{TM}}$ Ferrocarbon $A$ is a carbon/iron oxide composite manufactured by Nucon International, Inc., Columbus, Ohio. This material was used as received.

Nusorb $^{\mathrm{TM}}$ Ferrocarbon A sorbs strontium, cerium, americium, iron, manganese, and yttrium with at least triple-digit $\mathrm{Kd}$ values.

\begin{tabular}{lrrr}
\hline \hline \multicolumn{4}{l}{ Table 34. Nusorb } \\
Distribution of 15 Elements from Simulated \\
Hanford DSSF Solution \\
\multicolumn{4}{c}{ Kd Value for Specified Time } \\
\cline { 2 - 4 } Element & $\mathbf{3 0}$ min & $\mathbf{2 ~ h}$ & $\mathbf{6 ~ h}$ \\
\hline $\mathrm{Ce}$ & 15 & 124 & 920 \\
$\mathrm{Cs}$ & 1.2 & 2.1 & 2.0 \\
$\mathrm{Sr}$ & 215 & 723 & 1753 \\
$\mathrm{Tc}$ & 3.1 & 3.7 & 4.2 \\
$\mathrm{Y}$ & 11 & 30 & 146 \\
$\mathrm{Cr}$ & 7.3 & 6.9 & 2.9 \\
$\mathrm{Co}$ & 2.3 & 6.1 & 19 \\
$\mathrm{Fe}$ & 18 & 46 & 230 \\
$\mathrm{Mn}$ & 11 & 31 & 189 \\
$\mathrm{Ni}$ & 3.6 & 11 & 33 \\
$\mathrm{~V}$ & $<0.1$ & $<0.1$ & $<0.1$ \\
$\mathrm{Zn}$ & 1.5 & 3.0 & 5.3 \\
$\mathrm{Zr}$ & 2.7 & 6.1 & 16 \\
$\mathrm{U}$ & 0.7 & 1.0 & 1.0 \\
$\mathrm{Am}$ & 22 & 109 & 602 \\
\hline \hline
\end{tabular}

p. Nusorb ${ }^{\mathrm{TM}}$ LP-70-S Absorber. Nusorb ${ }^{\mathrm{TM}}$ LP-70-S, an activated carbon whose surface is activated to provide cation exchange functionality, is manufactured by Nucon International, Inc., Columbus, Ohio. This material was used as received.

Nusorb $^{\mathrm{TM}}$ LP-70-S strongly sorbs nickel and cobalt, both of which have radioisotopes of environmental concern. Several other elements also are sorbed at useful levels.

Table 35. Nusorb ${ }^{\mathrm{TM}}$ LP-70-S Absorber: Distribution of 15 Elements from Simulated Hanford DSSF Solution

\begin{tabular}{lcrr}
\hline & \multicolumn{3}{c}{ Kd Value for Specified Time } \\
\cline { 2 - 4 } Element & $\mathbf{3 0} \mathbf{~ m i n}$ & $\mathbf{2} \mathbf{~ h}$ & $\mathbf{6 ~ h}$ \\
\hline $\mathrm{Ce}$ & 1.6 & 17 & 124 \\
$\mathrm{Cs}$ & 1.8 & 1.8 & 1.6 \\
$\mathrm{Sr}$ & 4.9 & 9.0 & 15 \\
$\mathrm{Tc}$ & 15 & 24 & 26 \\
$\mathrm{Y}$ & 5.8 & 28 & 93 \\
$\mathrm{Cr}$ & $<0.1$ & $<0.1$ & $<0.1$ \\
$\mathrm{Co}$ & 44 & 262 & 443 \\
$\mathrm{Fe}$ & 2.0 & 3.4 & 5.6 \\
$\mathrm{Mn}$ & 7.2 & 16 & 45 \\
$\mathrm{Ni}$ & 63 & 472 & 481 \\
$\mathrm{~V}$ & $<0.1$ & $<0.1$ & $<0.1$ \\
$\mathrm{Zn}$ & 0.6 & 0.6 & 0.9 \\
$\mathrm{Zr}$ & 1.7 & 3.6 & 6.0 \\
$\mathrm{U}$ & 0.5 & 0.5 & 0.5 \\
$\mathrm{Am}$ & 9.3 & 29 & 41 \\
\hline \hline
\end{tabular}


q. Nusorb ${ }^{\mathrm{TM}}$ Magnetite Absorber. Nusorb ${ }^{\mathrm{TM}}$ Magnetite, a porous low-density single-phase $\mathrm{Fe}_{3} \mathrm{O}_{4}$, is manufactured by Nucon International, Inc., Columbus, Ohio. This material was used as received.

Even the elements best sorbed from DSSF simulant by Nusorb ${ }^{\mathrm{TM}}$ Magnetite sorb only at low to moderate levels.

Table 36. Nusorb ${ }^{\mathrm{TM}}$ Magnetite Absorber: Distribution of 15 Elements from Simulated Hanford DSSF Solution

\begin{tabular}{lrrr}
\hline & \multicolumn{3}{c}{ Kd Value for Specified Time } \\
\cline { 2 - 4 } Element & $\mathbf{3 0 ~} \mathbf{~}$ in & $\mathbf{2 ~ h}$ & $\mathbf{6 ~ h}$ \\
\hline $\mathrm{Ce}$ & 0.2 & $<0.1$ & 6.1 \\
$\mathrm{Cs}$ & $<0.1$ & $<0.1$ & $<0.1$ \\
$\mathrm{Sr}$ & 3.4 & 7.0 & 12 \\
$\mathrm{Tc}$ & 0.8 & 0.6 & 0.6 \\
$\mathrm{Y}$ & 2.8 & 6.8 & 12 \\
$\mathrm{Cr}$ & $<0.1$ & 0.3 & 0.3 \\
$\mathrm{Co}$ & 0.3 & 0.5 & 0.8 \\
$\mathrm{Fe}$ & 2.2 & 4.4 & 8.7 \\
$\mathrm{Mn}$ & 1.0 & 2.3 & 4.5 \\
$\mathrm{Ni}$ & 0.9 & 1.7 & 2.4 \\
$\mathrm{~V}$ & $<0.1$ & $<0.1$ & $<0.1$ \\
$\mathrm{Zn}$ & 0.4 & 0.6 & 0.8 \\
$\mathrm{Zr}$ & 1.0 & 1.5 & 1.8 \\
$\mathrm{U}$ & 0.7 & 0.7 & 1.0 \\
$\mathrm{Am}$ & 1.4 & 4.4 & 9.7 \\
\hline \hline
\end{tabular}

r. Nusorb ${ }^{\mathrm{TM}}$ Unitane Absorber. Nusorb ${ }^{\mathrm{TM}}$ Unitane, titanium oxide beads with pores in the 1- to $10-\mu \mathrm{m}$ range, is manufactured by Nucon International, Inc., Columbus, Ohio. This material was used as received.

Nusorb ${ }^{\mathrm{TM}}$ Unitane sorbs strontium and cerium with triple-digit Kd values, and several other elements are sorbed with useful, but lower, $\mathrm{Kd}$ values.

Table 37. Nusorb ${ }^{\mathrm{TM}}$ Unitane Absorber: Distribution of 15 Elements from Simulated Hanford DSSF Solution

\begin{tabular}{lcrr}
\hline & \multicolumn{3}{c}{ Kd Value for Specified Time } \\
\cline { 2 - 4 } Element & $\mathbf{3 0} \mathbf{~} \mathbf{\text { in }}$ & $\mathbf{2} \mathbf{~ h}$ & $\mathbf{6 ~ h}$ \\
\hline $\mathrm{Ce}$ & 1.3 & 18 & $\mathbf{1 1 2}$ \\
$\mathrm{Cs}$ & 0.2 & 0.2 & $<0.1$ \\
$\mathrm{Sr}$ & 19 & 117 & 504 \\
$\mathrm{Tc}$ & 0.5 & 0.8 & 0.9 \\
$\mathrm{Y}$ & 6.1 & 20 & 75 \\
$\mathrm{Cr}$ & 0.1 & 0.3 & 0.2 \\
$\mathrm{Co}$ & 0.6 & 2.0 & 5.4 \\
$\mathrm{Fe}$ & 5.1 & 13 & 35 \\
$\mathrm{Mn}$ & 4.4 & 13 & 40 \\
$\mathrm{Ni}$ & 1.9 & 4.9 & 13 \\
$\mathrm{~V}$ & $<0.1$ & $<0.1$ & $<0.1$ \\
$\mathrm{Zn}$ & 1.1 & 1.6 & 2.0 \\
$\mathrm{Zr}$ & 2.7 & 6.2 & 10 \\
$\mathrm{U}$ & 0.3 & 0.9 & 1.0 \\
$\mathrm{Am}$ & 3.3 & 17 & 55 \\
\hline \hline
\end{tabular}


s. Purolite ${ }^{\mathrm{TM}}$ A-520-E Anion Exchange Resin. Purolite $^{\mathrm{TM}}$ A-520-E, a macroporous strong-base anion exchange resin with triethyl amine as the functional group, was obtained from the Purolite Company, Bala Cynwyd, Pennsylvania. This resin was air-dried before use.

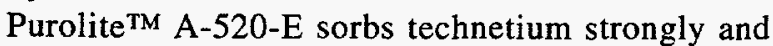
quite selectively from DSSF simulant.

\begin{tabular}{|c|c|c|c|}
\hline \multirow[b]{2}{*}{ Element } & \multicolumn{3}{|c|}{ Kd Value for Specified Time } \\
\hline & $30 \mathrm{~min}$ & $2 \mathrm{~h}$ & $6 \mathrm{~h}$ \\
\hline $\mathrm{Ce}$ & 5.4 & 6.0 & 19 \\
\hline Cs & 0.2 & $<0.1$ & $<0.1$ \\
\hline $\mathrm{Sr}$ & 0.4 & 0.4 & 0.4 \\
\hline $\mathrm{Tc}$ & 189 & 392 & 527 \\
\hline Y & 2.8 & 3.4 & 4.3 \\
\hline $\mathrm{Cr}$ & $<0.1$ & $<0.1$ & 0.1 \\
\hline Co & 0.3 & 0.4 & 0.7 \\
\hline $\mathrm{Fe}$ & 0.2 & 1.0 & 1.4 \\
\hline Mn & 0.5 & 1.0 & 1.5 \\
\hline $\mathrm{Ni}$ & 0.6 & 0.9 & 1.5 \\
\hline V & $<0.1$ & $<0.1$ & $<0.1$ \\
\hline $\mathrm{Zn}$ & $<0.1$ & 0.2 & 0.6 \\
\hline $\mathrm{Zr}$ & 0.6 & 1.4 & 1.5 \\
\hline $\mathrm{U}$ & $<0.1$ & 0.4 & 0.7 \\
\hline Am & 4.9 & 5.4 & 8.8 \\
\hline
\end{tabular}

t. Reillex ${ }^{\mathrm{TM}} H P Q$ Anion Exchange Resin. Reillex ${ }^{\mathrm{TM}}$ $\mathrm{HPQ}$, a strong-base polyvinylpyridine anion exchange resin, was obtained from Reilly Industries, Inc., Indianapolis, Indiana. This resin was converted from the as-received chloride form to the nitrate form and air-dried before use.

Reillex ${ }^{\mathrm{TM}} \mathrm{HPQ}$ sorbs technetium strongly and quite selectively from DSSF simulant.

Table 39. Reillex ${ }^{\mathrm{TM}}$ HPQ Anion Exchange

Resin: Distribution of 15 Elements from

Simulated Hanford DSSF Solution

\begin{tabular}{lccr}
\hline & \multicolumn{3}{c}{ Kd Value for Specified Time } \\
\cline { 2 - 4 } Element & 30 $\mathbf{~ m i n}$ & $\mathbf{2 ~ h}$ & $\mathbf{6 ~ h}$ \\
\hline $\mathrm{Ce}$ & $<0.1$ & 1.2 & 7.4 \\
$\mathrm{Cs}$ & 2.4 & 0.5 & 0.5 \\
$\mathrm{Sr}$ & 2.8 & 0.7 & 0.8 \\
$\mathrm{Tc}$ & 254 & 293 & 332 \\
$\mathrm{Y}$ & 5.3 & 11 & 25 \\
$\mathrm{Cr}$ & 2.5 & 0.7 & 0.8 \\
$\mathrm{Co}$ & 1.9 & 1.1 & 1.6 \\
$\mathrm{Fe}$ & 2.5 & 1.8 & 2.3 \\
$\mathrm{Mn}$ & 4.1 & 8.5 & 12 \\
$\mathrm{Ni}$ & $<0.1$ & 2.5 & 10 \\
$\mathrm{~V}$ & 1.4 & 0.3 & 0.3 \\
$\mathrm{Zn}$ & 1.6 & 0.6 & 0.9 \\
$\mathrm{Zr}$ & 1.7 & 1.4 & 2.3 \\
$\mathrm{U}$ & 1.5 & 0.4 & 0.9 \\
$\mathrm{Am}$ & 3.9 & 5.7 & 10 \\
\hline \hline
\end{tabular}


u. Resin Tech ${ }^{\mathrm{TM}} 3972$ Resin. Resin Tech ${ }^{\mathrm{TM}}$ 3972, a styrene/divinylbenzene copolymer with phosphorous acid functionality, is manufactured by Resin Tech, Inc., Cherry Hill, New Jersey. This resin was air-dried before use.

Resin Tech ${ }^{\mathrm{TM}} 3972$ offers useful Kd values for sorbing strontium, manganese, yttrium, and iron from DSSF simulant.

Table 40. Resin Tech ${ }^{\mathrm{TM}} 3972$ Resin:

Distribution of 15 Elements from Simulated Hanford DSSF Solution

\begin{tabular}{lrrr}
\hline & \multicolumn{3}{c}{ Kd Value for Specified Time } \\
\cline { 2 - 4 } Element & $\mathbf{3 0} \mathbf{~ m i n}$ & $\mathbf{2 ~ h}$ & $\mathbf{6 ~ h}$ \\
\hline $\mathrm{Ce}$ & $<0.1$ & $<0.1$ & $<0.1$ \\
$\mathrm{Cs}$ & 5.8 & 6.7 & 6.6 \\
$\mathrm{Sr}$ & 17 & 51 & 93 \\
$\mathrm{Tc}$ & 5.7 & 6.6 & 6.6 \\
$\mathrm{Y}$ & 4.1 & 12 & 25 \\
$\mathrm{Cr}$ & 5.3 & 6.5 & 6.4 \\
$\mathrm{Co}$ & 0.3 & 0.9 & 1.7 \\
$\mathrm{Fe}$ & 2.3 & 8.7 & 20 \\
$\mathrm{Mn}$ & 3.6 & 14 & 32 \\
$\mathrm{Ni}$ & 0.7 & 3.8 & 6.6 \\
$\mathrm{~V}$ & $<0.1$ & $<0.1$ & $<0.1$ \\
$\mathrm{Zn}$ & $<0.1$ & 0.4 & 0.6 \\
$\mathrm{Zr}$ & 0.3 & 1.1 & 2.1 \\
$\mathrm{U}$ & $<0.1$ & 0.2 & 0.4 \\
$\mathrm{Am}$ & 1.2 & 1.6 & 2.3 \\
\hline \hline
\end{tabular}

v. SRS Resorcinol/Formaldehyde (BSC-187) Resin. Jane Bibler of Westinghouse Savannah River Company provided this sample of batch BSC-187 resin and recommended that we convert it from the as-received potassium form to a sodium form. We did this by passing ten volumes of $10 \% \mathrm{NaOH}$ solution through a column of potassium-form resin, rinsed the column with 15 column volumes of water. The resin was air-dried before use.

SRS resorcinol/formaldehyde resin sorbs chromium, technetium, iron, cesium, strontium, and manganese with triple-digit Kd values. Five other elements are sorbed with double-digit $\mathrm{Kd}$ values.

\begin{tabular}{lcrr}
\hline \hline \multicolumn{3}{l}{$\begin{array}{l}\text { Table 41. SRS Resorcinol/Formaldehyde } \\
\text { (BSC-187) Resin: Distribution of } 15 \text { Elements }\end{array}$} \\
from Simulated Hanford DSSF Solution \\
\hline \multicolumn{4}{c}{ Kd Value for Specified Time } \\
\cline { 2 - 4 } Element & $\mathbf{3 0}$ min & $\mathbf{2 ~ h}$ & $\mathbf{6 h}$ \\
\hline $\mathrm{Ce}$ & 0.3 & $<0.1$ & 0.8 \\
$\mathrm{Cs}$ & 46 & 140 & 236 \\
$\mathrm{Sr}$ & 42 & 88 & 124 \\
$\mathrm{Tc}$ & 3.3 & 39 & 374 \\
$\mathrm{Y}$ & 14 & 34 & 54 \\
$\mathrm{Cr}$ & 2.9 & 43 & 413 \\
$\mathrm{Co}$ & 5.9 & 19 & 41 \\
$\mathrm{Fe}$ & 72 & 209 & 330 \\
$\mathrm{Mn}$ & 20 & 56 & 111 \\
$\mathrm{Ni}$ & 6.8 & 21 & 50 \\
$\mathrm{~V}$ & $<0.1$ & $<0.1$ & $<0.1$ \\
$\mathrm{Zn}$ & 0.6 & 1.4 & 1.6 \\
$\mathrm{Zr}$ & 13 & 37 & 68 \\
$\mathrm{U}$ & 3.8 & 11 & 23 \\
$\mathrm{Am}$ & 0.8 & 2.6 & 5.1 \\
\hline \hline
\end{tabular}


w. Tannin Absorber. Tannin absorber was obtained from Mitsubishi Nuclear Fuels Corporation, Japan. We airdried this absorber before testing for reasons detailed in Section II.C.

Tannin sorbs iron, chromium, strontium, manganese, and zirconium with at least triple-digit $\mathrm{Kd}$ values. All 15 elements except vanadium are sorbed with at least a double-digit $\mathrm{Kd}$ value.

\begin{tabular}{lrrr}
\hline \multicolumn{4}{l}{ Table 42. Tannin Absorber: Distribution of $\mathbf{1 5}$} \\
Elements from Simulated Hanford DSSF \\
Solution \\
\hline \multicolumn{4}{l}{ Kd Value for Specified Time } \\
\cline { 2 - 4 } Element & $\mathbf{3 0 ~ m i n}$ & $\mathbf{2} \mathbf{h}$ & $\mathbf{6 ~ h}$ \\
\hline $\mathrm{Ce}$ & $<0.1$ & 8.5 & 48 \\
$\mathrm{Cs}$ & 12 & 12 & 12 \\
$\mathrm{Sr}$ & 203 & 476 & 761 \\
$\mathrm{Tc}$ & 4.5 & 14 & 85 \\
$\mathrm{Y}$ & 15 & 25 & 40 \\
$\mathrm{Cr}$ & 6.7 & 59 & 2213 \\
$\mathrm{Co}$ & 13 & 29 & 49 \\
$\mathrm{Fe}$ & 452 & 721 & $>1600$ \\
$\mathrm{Mn}$ & 123 & 217 & 362 \\
$\mathrm{Ni}$ & 6.6 & 12 & 10 \\
$\mathrm{~V}$ & $<0.1$ & $<0.1$ & $<0.1$ \\
$\mathrm{Zn}$ & 8.5 & 13 & 16 \\
$\mathrm{Zr}$ & 87 & 168 & 260 \\
$\mathrm{U}$ & 20 & 37 & 57 \\
$\mathrm{Am}$ & 1.9 & 7.2 & 15 \\
\hline \hline
\end{tabular}

2. Experimental Inorganic Materials. Six experimental inorganic materials were included in our study. Five are pillared layered materials and one is a layered hydrotalcite material.

Pillared layered materials are obtained by modifying selected inorganic layered compounds. The modification technique first involves intercalating polar molecules, such as amines, to spread apart the layers before pillaring. Pillaring then replaces the alkylammonium ions that are initially between the layers with large metal oxy-hydroxide cations. Subsequent calcination drives off water and releases protons to create metal oxide pillars, which creates an expanded structure with large channels and cavities of fixed size and a reservoir of exchangeable protons.

a. $K W-3-21 x . \mathrm{KW}-3-21 \mathrm{x}$ consists of $\mathrm{HSb}\left(\mathrm{PO}_{4}\right)_{2}$ pillared with chromium oxide. The $\mathrm{d}$-spacing of this material is $27.8 \AA$. This pillared layered material, prepared by Karen L. Wade of LANL, was used as received.

KW-3-21x provides high and selective sorption of strontium at the shortest contact time of $30 \mathrm{~min}$; however, the decreasing $\mathrm{Kd}$ values for longer contact times may indicate instability of this material in alkaline solution.

\section{Table 43. KW-3-21x: Distribution of 15 Elements from Simulated Hanford DSSF Solution}

\begin{tabular}{lccr}
\hline & \multicolumn{3}{c}{ Kd Value for Specified Time } \\
\cline { 2 - 4 } Element & $\mathbf{3 0}$ min & $\mathbf{2} \mathbf{~ h}$ & $\mathbf{6 ~ h}$ \\
\hline $\mathrm{Ce}$ & 0.6 & 4.3 & $\mathbf{5 . 4}$ \\
$\mathrm{Cs}$ & $<0.1$ & 0.2 & $<0.1$ \\
$\mathrm{Sr}$ & 624 & 169 & 80 \\
$\mathrm{Tc}$ & 3.2 & 4.2 & 5.0 \\
$\mathrm{Y}$ & 5.8 & 2.8 & 1.9 \\
$\mathrm{Cr}$ & 1.0 & 1.8 & 1.9 \\
$\mathrm{Co}$ & $<0.1$ & 0.3 & 0.6 \\
$\mathrm{Fe}$ & 12 & 27 & 21 \\
$\mathrm{Mn}$ & 15 & 44 & 40 \\
$\mathrm{Ni}$ & 1.0 & 1.4 & 1.8 \\
$\mathrm{~V}$ & $<0.1$ & $<0.1$ & $<0.1$ \\
$\mathrm{Zn}$ & 5.2 & 18 & 23 \\
$\mathrm{Zr}$ & 4.3 & 12 & 12 \\
$\mathrm{U}$ & 1.4 & 4.8 & 17 \\
$\mathrm{Am}$ & 2.4 & 3.8 & 3.9 \\
\hline
\end{tabular}


b. $K W-3-58 x$. KW-3-58x consists of $\mathrm{HSb}\left(\mathrm{PO}_{4}\right)_{2}$ pillared with chromium oxide. The $d$-spacing of this material is $15.0 \AA$. This pillared layered material, prepared by Karen $L$. Wade of LANL, was used as received.

$\mathrm{KW}-3-58 \mathrm{x}$, similar to $\mathrm{KW}-3-21 \mathrm{x}$, provides high and selective sorption of strontium at the shortest contact time of $30 \mathrm{~min}$, with decreasing $\mathrm{Kd}$ values for longer contact times. This material is less selective than KW-3$21 \mathrm{x}$, and the $\mathrm{Kd}$ values for iron and zinc also decrease as the contact time increases.

Table 44. KW-3-58x: Distribution of 15 Elements from Simulated Hanford DSSF Solution

\begin{tabular}{lrrr}
\hline & \multicolumn{3}{c}{ Kd Value for Specified Time } \\
\cline { 2 - 4 } Element & $\mathbf{3 0 ~} \mathbf{~ m i n}$ & $\mathbf{2} \mathbf{h}$ & $\mathbf{6 ~ h}$ \\
\hline $\mathrm{Ce}$ & 3.1 & 3.6 & 25 \\
$\mathrm{Cs}$ & $<0.1$ & $<0.1$ & 0.1 \\
$\mathrm{Sr}$ & 840 & 215 & 97 \\
$\mathrm{Tc}$ & 2.3 & 2.7 & 3.8 \\
$\mathrm{Y}$ & 5.2 & 3.4 & 2.8 \\
$\mathrm{Cr}$ & 3.1 & 3.6 & 3.9 \\
$\mathrm{Co}$ & 0.3 & 0.4 & 0.7 \\
$\mathrm{Fe}$ & 64 & 49 & 32 \\
$\mathrm{Mn}$ & 118 & 131 & 109 \\
$\mathrm{Ni}$ & 2.1 & 2.7 & 3.7 \\
$\mathrm{~V}$ & $<0.1$ & $<0.1$ & $<0.1$ \\
$\mathrm{Zn}$ & 40 & 35 & 22 \\
$\mathrm{Zr}$ & 17 & 22 & 16 \\
$\mathrm{U}$ & 3.8 & 6.0 & 16 \\
$\mathrm{Am}$ & 2.5 & 2.3 & 8.7 \\
\hline \hline
\end{tabular}

c. $K W-4-40 x$. KW-4-40x consists of $\mathrm{HTaWO}_{6}$ pillared with chromium oxide. The d-spacing of this material is $19.6 \AA$. This pillared layered material, prepared by Karen $L$. Wade of LANL, was used as received.

The Kd values for strontium sorption offered by $\mathrm{KW}-4-40 \mathrm{x}$ were too high to measure accurately and did not decrease with increased contact time. However, many other elements also are sorbed with at least tripledigit $\mathrm{Kd}$ values from the DSSF simulant.

Table 45. KW-4-40x: Distribution of 15 Elements from Simulated Hanford DSSF Solution

\begin{tabular}{lrrr}
\hline & \multicolumn{3}{c}{ Kd Value for Specified Time } \\
\cline { 2 - 4 } Element & $\mathbf{3 0 ~} \mathbf{~ m i n}$ & $\mathbf{2} \mathbf{~ h}$ & $\mathbf{6 ~ h}$ \\
\hline $\mathrm{Ce}$ & 186 & 339 & 299 \\
$\mathrm{Cs}$ & 0.3 & $<0.1$ & $<0.1$ \\
$\mathrm{Sr}$ & $>26 \mathrm{~K}$ & $>25 \mathrm{~K}$ & $>26 \mathrm{~K}$ \\
$\mathrm{Tc}$ & 0.1 & 0.3 & 0.3 \\
$\mathrm{Y}$ & 77 & 154 & 283 \\
$\mathrm{Cr}$ & $<0.1$ & $<0.1$ & 0.1 \\
$\mathrm{Co}$ & 0.4 & 0.8 & 1.1 \\
$\mathrm{Fe}$ & 939 & $>2800$ & $>2900$ \\
$\mathrm{Mn}$ & 384 & 1189 & 2373 \\
$\mathrm{Ni}$ & 2.7 & 5.6 & 9.9 \\
$\mathrm{~V}$ & $<0.1$ & $<0.1$ & $<0.1$ \\
$\mathrm{Zn}$ & 126 & 386 & 752 \\
$\mathrm{Zr}$ & 18 & 54 & 115 \\
$\mathrm{U}$ & 1.4 & 3.1 & 4.5 \\
$\mathrm{Am}$ & 60 & 70 & $\mathbf{7 5}$ \\
\hline \hline
\end{tabular}


d. $K W-4-41 x$. KW-4-41x consists of $\mathrm{HTaWO}_{6}$ pillared with chromium oxide. The d-spacing of this material is $19.3 \AA$. This pillared layered material, prepared by Karen $L$. Wade of LANL, was used as received.

The Kd values for strontium sorption offered by $\mathrm{KW}-4-41 \mathrm{x}$ were too high to measure accurately and did not decrease with increased contact time. However, many other elements also are sorbed with at least tripledigit Kd values from the DSSF simulant.

Table 46. KW-4-41x: Distribution of 15 Elements from Simulated Hanford DSSF Solution

\begin{tabular}{lcrr}
\hline & \multicolumn{3}{c}{ Kd Value for Specified Time } \\
\cline { 2 - 4 } Element & $\mathbf{3 0} \mathbf{~} \mathbf{m i n}$ & $\mathbf{2 ~ h}$ & $\mathbf{6 ~ h}$ \\
\hline $\mathrm{Ce}$ & 121 & 214 & 233 \\
$\mathrm{Cs}$ & 0.1 & $<0.1$ & $<0.1$ \\
$\mathrm{Sr}$ & $11 \mathrm{~K}$ & $>26 \mathrm{~K}$ & $>25 \mathrm{~K}$ \\
$\mathrm{Tc}$ & 0.5 & 0.2 & 0.4 \\
$\mathrm{Y}$ & 77 & 164 & 260 \\
$\mathrm{Cr}$ & $<0.1$ & $<0.1$ & 0.2 \\
$\mathrm{Co}$ & 0.6 & 0.9 & 1.0 \\
$\mathrm{Fe}$ & 752 & $>2800$ & $>2800$ \\
$\mathrm{Mn}$ & 364 & 983 & 2444 \\
$\mathrm{Ni}$ & 2.6 & 4.4 & 8.7 \\
$\mathrm{~V}$ & $<0.1$ & $<0.1$ & $<0.1$ \\
$\mathrm{Zn}$ & 121 & 361 & 755 \\
$\mathrm{Zr}$ & 18 & 51 & 102 \\
$\mathrm{U}$ & 2.2 & 3.7 & 7.2 \\
$\mathrm{Am}$ & 46 & 59 & 60 \\
\hline \hline
\end{tabular}

e. $K W-4-42 x$. KW-4-42x consists of $\mathrm{H}_{3} \mathrm{Sb}_{3} \mathrm{O}_{6}\left(\mathrm{PO}_{4}\right)_{2}$ pillared with chromium oxide. Thed-spacing of this material is $20.1 \AA$. This pillared layered material, prepared by Karen L. Wade of LANL, was used as received.

$\mathrm{KW}-4-42 \mathrm{x}$ provides high sorption of strontium at the shortest measured contact time of $30 \mathrm{~min}$; however, the decreasing $\mathrm{Kd}$ values for longer contact times may indicate instability of this material in alkaline solution. The selectivity for strontium decreases at the longer contact times.

Table 47. KW-4-42x: Distribution of 15 Elements from Simulated Hanford DSSF Solution

\begin{tabular}{lrrr}
\hline & \multicolumn{3}{c}{ Kd Value for Specified Time } \\
\cline { 2 - 4 } Element & $\mathbf{3 0}$ $\mathbf{~ i n}$ & $\mathbf{2} \mathbf{~ h}$ & $\mathbf{6 ~ h}$ \\
\hline $\mathrm{Ce}$ & 8.0 & 13 & 23 \\
$\mathrm{Cs}$ & 2.0 & 1.9 & 1.9 \\
$\mathrm{Sr}$ & 3109 & 1023 & 297 \\
$\mathrm{Tc}$ & 11 & 10 & 10 \\
$\mathrm{Y}$ & 21 & 13 & 10 \\
$\mathrm{Cr}$ & 5.9 & 8.6 & 9.7 \\
$\mathrm{Co}$ & 0.5 & 0.8 & 1.0 \\
$\mathrm{Fe}$ & 192 & 429 & 334 \\
$\mathrm{Mn}$ & 129 & 328 & 542 \\
$\mathrm{Ni}$ & 1.3 & 2.8 & 4.5 \\
$\mathrm{~V}$ & $<0.1$ & $<0.1$ & $<0.1$ \\
$\mathrm{Zn}$ & 37 & 102 & 130 \\
$\mathrm{Zr}$ & 14 & 48 & 81 \\
$\mathrm{U}$ & 2.7 & 6.3 & 12 \\
$\mathrm{Am}$ & 6.5 & 6.3 & 9.7 \\
\hline \hline
\end{tabular}


f. MgAlHT. MgAlHT, a hydrotalcite, is an inorganic layered double-hydroxide compound, that could have an affinity for multivalent anions from high $\mathrm{pH}$ solution. This material, provided by Jim Amonette of PNL, was hydrated overnight with $0.1 \mathrm{M} \mathrm{NaCl}$ solution (per Amonette's instructions) before use.

MgAlHT sorbs strontium, cerium, yttrium, and americium from DSSF simulant with triple-digit Kd values.

\begin{tabular}{|c|c|c|c|}
\hline \multicolumn{4}{|c|}{$\begin{array}{l}\text { Table 48. MgAlHT: Distribution of } 15 \\
\text { Elements from Simulated Hanford DSSF } \\
\text { Solution }\end{array}$} \\
\hline \multirow[b]{2}{*}{ Element } & \multicolumn{3}{|c|}{ Kd Value for Specified Time } \\
\hline & $30 \mathrm{~min}$ & $2 \mathrm{~h}$ & $6 h$ \\
\hline $\mathrm{Ce}$ & 378 & 664 & 673 \\
\hline Cs & 0.5 & 0.5 & 0.4 \\
\hline $\mathrm{Sr}$ & 301 & 513 & 710 \\
\hline $\mathrm{Tc}$ & 1.0 & 1.0 & 0.8 \\
\hline $\mathrm{Y}$ & 121 & 258 & 332 \\
\hline $\mathrm{Cr}$ & 1.8 & 1.9 & 2.2 \\
\hline Co & 0.4 & 0.6 & 0.4 \\
\hline $\mathrm{Fe}$ & 61 & 77 & 96 \\
\hline $\mathrm{Mn}$ & 20 & 40 & 90 \\
\hline $\mathrm{Ni}$ & 2.6 & 4.9 & 8.2 \\
\hline V & 0.8 & 0.6 & 0.5 \\
\hline $\mathrm{Zn}$ & 13 & 19 & 27 \\
\hline $\mathrm{Zr}$ & 8.0 & 11 & 15 \\
\hline $\bar{U}$ & 1.2 & 1.1 & 1.4 \\
\hline Am & 76 & 163 & 215 \\
\hline
\end{tabular}

3. Experimental Resins. Four experimental resins were included in our study. Two of these were prepared at New Mexico State University and two were prepared by Sybron Chemicals, Inc.

a. NK $120 \mathrm{~B}$ Resin. NK 120B, a derivative of polyvinylbenzylamine with two hydroxamic acid groups attached to the nitrogen, was prepared by Professor Amudhu Gopalan of the Department of Chemistry and Biochemistry, New Mexico State University. This resin was air-dried before use.

NK 120B sorbs iron, strontium, manganese, and zirconium from DSSF simulant with triple-digit $\mathrm{Kd}$ values.

Table 49. NK 120B Resin: Distribution of 15 Elements from Simulated Hanford DSSF Solution

\begin{tabular}{lcrr}
\hline & \multicolumn{3}{c}{ Kd Value for Specified Time } \\
\cline { 2 - 4 } Element & $\mathbf{3 0 ~} \mathbf{~ m i n}$ & $\mathbf{2} \mathbf{~ h}$ & $\mathbf{6 ~ h}$ \\
\hline $\mathrm{Ce}$ & $<0.1$ & 3.9 & 1.7 \\
$\mathrm{Cs}$ & 0.8 & 0.3 & 0.2 \\
$\mathrm{Sr}$ & 211 & 251 & 273 \\
$\mathrm{Tc}$ & 3.0 & 3.0 & 2.4 \\
$\mathrm{Y}$ & 16 & 23 & 30 \\
$\mathrm{Cr}$ & 1.0 & 0.5 & 0.3 \\
$\mathrm{Co}$ & 0.4 & 1.5 & 2.9 \\
$\mathrm{Fe}$ & 616 & 591 & 511 \\
$\mathrm{Mn}$ & 148 & 218 & 251 \\
$\mathrm{Ni}$ & 38 & 55 & 73 \\
$\mathrm{~V}$ & $<0.1$ & $<0.1$ & $<0.1$ \\
$\mathrm{Zn}$ & 0.5 & 0.9 & 1.1 \\
$\mathrm{Zr}$ & 199 & 169 & 176 \\
$\mathrm{U}$ & 4.0 & 4.9 & 3.8 \\
$\mathrm{Am}$ & 6.0 & 7.3 & 9.8 \\
\hline \hline
\end{tabular}


b. NK 194Resin. NK 194, a derivative of polyallylamine containing two amidoxime groups attached to the amine nitrogen, was prepared by Professor Amudhu Gopalan of the Department of Chemistry and Biochemistry, New Mexico State University. This resin was air-dried before use.

NK 194 sorbs six elements at moderate Kd values from DSSF simulant.

Table 50. NK 194 Resin: Distribution of 15 Elements from Simulated Hanford DSSF

\section{Solution}

\begin{tabular}{lrrr}
\hline & \multicolumn{3}{c}{ Kd Value for Specified Time } \\
\cline { 2 - 4 } Element & $\mathbf{3 0} \mathbf{~ m i n}$ & $\mathbf{2 ~ h}$ & $\mathbf{6} \mathbf{h}$ \\
\hline $\mathrm{Ce}$ & $<0.1$ & $<0.1$ & 0.7 \\
$\mathrm{Cs}$ & 6.3 & 5.1 & 3.4 \\
$\mathrm{Sr}$ & 15 & 13 & 10 \\
$\mathrm{Tc}$ & 13 & 9.6 & 7.5 \\
$\mathrm{Y}$ & 24 & 31 & 27 \\
$\mathrm{Cr}$ & 6.9 & 6.1 & 4.2 \\
$\mathrm{Co}$ & 0.5 & 1.9 & 3.7 \\
$\mathrm{Fe}$ & 11 & 19 & 39 \\
$\mathrm{Mn}$ & 21 & 31 & 35 \\
$\mathrm{Ni}$ & 21 & 20 & 20 \\
$\mathrm{~V}$ & $<0.1$ & 1.2 & 3.6 \\
$\mathrm{Zn}$ & 4.6 & 3.8 & 3.8 \\
$\mathrm{Zr}$ & 32 & 45 & 47 \\
$\mathrm{U}$ & 0.4 & $<0.1$ & $<0.1$ \\
$\mathrm{Am}$ & 3.6 & 6.3 & 9.0 \\
\hline \hline
\end{tabular}

c. Sybron (Et) ${ }_{3} N$ Anion Exchange Resin. This experimental, macroporous strong-base anion exchange resin with triethyl amine as the functional group was obtained from Sybron Chemicals, Inc., Birmingham, New Jersey. A previous study ${ }^{9}$ reported that this resin offers a significant increase over (Me) ${ }_{3} \mathrm{~N}$ resin for sorbing $\mathrm{Pu}(\mathrm{IV})$ from dilute nitric acid. This resin was air-dried before use.

The behavior of this experimental resin in DSSF simulant is fairly similar to that of Purolite ${ }^{\mathrm{TM}}$ A-520-E resin (its commercial equivalent).

\begin{tabular}{|c|c|c|c|}
\hline \multirow{2}{*}{ Element } & \multicolumn{3}{|c|}{ Kd Value for Specified Time } \\
\hline & $30 \mathrm{~min}$ & 2 h & $6 \mathrm{~h}$ \\
\hline $\mathrm{Ce}$ & $<0.1$ & $<0.1$ & $<0.1$ \\
\hline Cs & 4.1 & 5.0 & 2.2 \\
\hline $\mathrm{Sr}$ & 11 & 12 & 8.0 \\
\hline $\mathrm{Tc}$ & 167 & 401 & 471 \\
\hline $\mathrm{Y}$ & 3.0 & 6.0 & 10 \\
\hline $\mathrm{Cr}$ & 4.2 & 5.2 & 2.4 \\
\hline Co & 0.4 & 0.6 & 0.7 \\
\hline $\mathrm{Fe}$ & 1.1 & 2.6 & 3.2 \\
\hline Mn & 1.7 & 2.6 & 3.1 \\
\hline $\mathrm{Ni}$ & 1.0 & 2.1 & 2.9 \\
\hline V & $<0.1$ & $<0.1$ & $<0.1$ \\
\hline $\mathrm{Zn}$ & $<0.1$ & 0.5 & 0.5 \\
\hline $\mathrm{Zr}$ & 0.2 & 0.6 & 0.8 \\
\hline $\mathrm{U}$ & 0.1 & 0.3 & 0.5 \\
\hline Am & 5.5 & 6.0 & 6.3 \\
\hline
\end{tabular}


d. Sybron $(\mathrm{Pr})_{3} \mathrm{~N}$ Anion Exchange Resin. This experimental, macroporous strong-base anion exchange resin with tripropyl amine as the functional group was obtained from Sybron Chemicals, Inc., Birmingham, New Jersey. This resin was air-dried before use.

This resin sorbs technetium well with high selectivity, similar to most other anion exchange resins.

Table 52. Sybron (Pr) ${ }_{3} \mathrm{~N}$ Anion Exchange Resin: Distribution of 15 Elements from Simulated Hanford DSSF Solution

\begin{tabular}{lrrr}
\hline & \multicolumn{3}{c}{ Kd Value for Specified Time } \\
\cline { 2 - 4 } Element & $\mathbf{3 0 ~} \mathbf{~ m i n}$ & $\mathbf{2 ~ h}$ & $\mathbf{6 ~ h}$ \\
\hline $\mathrm{Ce}$ & $<0.1$ & $<0.1$ & $<0.1$ \\
$\mathrm{Cs}$ & 4.3 & 5.9 & 4.1 \\
$\mathrm{Sr}$ & 4.9 & 6.7 & 5.0 \\
$\mathrm{Tc}$ & 96 & 257 & 390 \\
$\mathrm{Y}$ & 0.8 & 1.9 & 3.0 \\
$\mathrm{Cr}$ & 4.2 & 5.9 & 4.2 \\
$\mathrm{Co}$ & 0.2 & 0.7 & 0.8 \\
$\mathrm{Fe}$ & 0.8 & 1.0 & 1.7 \\
$\mathrm{Ni}$ & $<0.1$ & 0.8 & 1.2 \\
$\mathrm{~V}$ & $<0.1$ & $<0.1$ & $<0.1$ \\
$\mathrm{Mn}$ & 0.7 & 1.1 & 1.5 \\
$\mathrm{Zn}$ & 0.2 & 0.6 & 0.7 \\
$\mathrm{Zr}$ & 0.2 & 0.5 & 0.8 \\
$\mathrm{U}$ & $<0.1$ & 0.3 & 0.6 \\
$\mathrm{Am}$ & 4.0 & 5.6 & 5.2 \\
\hline \hline
\end{tabular}

4. Polyacrylonitrile (PAN) Composite Absorbers. Although inorganic ion exchangers are known to offer high selectivity, high capacity, and rapid kinetics, their granular and mechanical properties often make them unsuitable for column applications. One way to circumvent these limitations is to incorporate the inorganic exchange materials in beads of a suitable porous polymer. ${ }^{10}$

The 16 composite absorbers prepared by Dr. Ferdinand Sebesta of the Czech Technical University in Prague consist of various inorganic exchange materials dispersed in modified-binding-polymer beads of PAN. ${ }^{11}$

Although Dr. Sebesta asked that these PAN composites be kept wet because their performance would be seriously degraded if they were dried, we chose to air-dry them to put them on an equivalent basis with the other absorbers. We therefore note that the excellent performance obtained with many PAN composites might be even better had we followed Dr. Sebesta's instructions. In particular, the frequently observed slow sorption kinetics might be faster.

a. AMP-PAN Ammonium Molybdophosphate Composite. The ammonium molybdophosphate content of the dry composite was $81 \%$. We air-dried this composite before testing for reasons detailed in Section II.C.

The AMP-PAN composite sorbs strontium and yttrium moderately from DSSF simulant.

Table 53. AMP-PAN Composite: Distribution of 15 Elements from Simulated Hanford DSSF

Solution

\begin{tabular}{lccc}
\hline & \multicolumn{3}{c}{ Kd Value for Specified Time } \\
\cline { 2 - 4 } Element & 30 $\mathbf{~ m i n}$ & $\mathbf{2 ~ h}$ & $\mathbf{6 ~ h}$ \\
\hline $\mathrm{Ce}$ & $<0.1$ & 3.7 & 7.0 \\
$\mathrm{Cs}$ & 0.4 & 0.4 & 0.4 \\
$\mathrm{Sr}$ & 18 & 26 & 33 \\
$\mathrm{Tc}$ & 1.7 & 1.8 & 2.2 \\
$\mathrm{Y}$ & 7.2 & 17 & 32 \\
$\mathrm{Cr}$ & 0.2 & 0.3 & 0.4 \\
$\mathrm{Co}$ & 0.5 & 0.4 & 0.7 \\
$\mathrm{Fe}$ & 2.4 & 2.8 & 4.5 \\
$\mathrm{Mn}$ & 2.0 & 3.4 & 7.0 \\
$\mathrm{Ni}$ & 0.8 & 1.3 & 4.5 \\
$\mathrm{~V}$ & 0.3 & $<0.1$ & $<0.1$ \\
$\mathrm{Zn}$ & 0.6 & 0.6 & 0.9 \\
$\mathrm{Zr}$ & 1.9 & 2.7 & 3.7 \\
$\mathrm{U}$ & 0.6 & 0.4 & 1.1 \\
$\mathrm{Am}$ & 2.9 & 8.6 & 11 \\
\hline \hline
\end{tabular}




\section{b. Ba(Ca)SO $-P A N$ Barium/Calcium Sulfate} Composite. The barium/calcium sulfate content of the dry $\mathrm{Ba}(\mathrm{Ca}) \mathrm{SO}_{4}$-PAN composite was $85 \%$. We air-dried this composite before testing for reasons detailed in Section II.C.

The $\mathrm{Ba}(\mathrm{Ca}) \mathrm{SO}_{4}-\mathrm{PAN}$ composite sorbs yttrium well and several other elements moderately from DSSF simulant. The observed slow kinetics for sorbing yttrium may be a consequence of air-drying this composite.

Table 54. $\mathrm{Ba}(\mathrm{Ca}) \mathrm{SO}_{4}$-PAN Composite: Distribution of 15 Elements from Simulated Hanford DSSF Solution

\begin{tabular}{lrrr}
\hline & \multicolumn{3}{c}{ Kd Value for Specified Time } \\
\cline { 2 - 4 } Element & 30 $\mathbf{~ m i n}$ & $\mathbf{2} \mathbf{~ h}$ & $\mathbf{6 ~ h}$ \\
\hline $\mathrm{Ce}$ & $<0.1$ & $<0.1$ & 2.3 \\
$\mathrm{Cs}$ & 1.1 & 0.4 & 0.3 \\
$\mathrm{Sr}$ & 17 & 22 & 25 \\
$\mathrm{Tc}$ & 1.6 & 1.0 & 1.1 \\
$\mathrm{Y}$ & 28 & 74 & 197 \\
$\mathrm{Cr}$ & 7.7 & 11 & 14 \\
$\mathrm{Co}$ & $<0.1$ & $<0.1$ & 0.1 \\
$\mathrm{Fe}$ & 2.5 & 3.0 & 3.9 \\
$\mathrm{Mn}$ & 2.6 & 3.5 & 5.6 \\
$\mathrm{Ni}$ & $<0.1$ & 0.6 & 2.7 \\
$\mathrm{~V}$ & 0.3 & $<0.1$ & $<0.1$ \\
$\mathrm{Zn}$ & 0.3 & 0.3 & 0.3 \\
$\mathrm{Zr}$ & 5.7 & 9.1 & 13 \\
$\mathrm{U}$ & 0.6 & 1.0 & 2.8 \\
$\mathrm{Am}$ & 7.3 & 10 & 15 \\
\hline \hline
\end{tabular}

c. CSbA-PAN Crystalline Polyantimonic Acid Composite. The polyantimonic acid content of the dry composite was $86 \%$. We air-dried this composite before testing for reasons detailed in Section II.C.

The CSbA-PAN composite offers very high sorption and selectivity for strontium from DSSF simulant.

Table 55. CSbA-PAN Composite: Distribution of 15 Elements from Simulated Hanford DSSF Solution

\begin{tabular}{lrrr}
\hline & \multicolumn{3}{c}{ Kd Value for Specified Time } \\
\cline { 2 - 4 } Element & $\mathbf{3 0 ~} \mathbf{~ m i n}$ & $\mathbf{2} \mathbf{~ h}$ & $\mathbf{6 ~ h}$ \\
\hline $\mathrm{Ce}$ & 1.7 & 4.1 & 6.1 \\
$\mathrm{Cs}$ & $<0.1$ & $<0.1$ & $<0.1$ \\
$\mathrm{Sr}$ & $5 \mathrm{~K}$ & $18 \mathrm{~K}$ & $19 \mathrm{~K}$ \\
$\mathrm{Tc}$ & 1.3 & 1.6 & 1.8 \\
$\mathrm{Y}$ & 14 & 25 & 43 \\
$\mathrm{Cr}$ & 0.1 & 0.3 & 0.3 \\
$\mathrm{Co}$ & $<0.1$ & 0.3 & 0.6 \\
$\mathrm{Fe}$ & 6.3 & 9.5 & 14 \\
$\mathrm{Mn}$ & 2.7 & 5.3 & 9.6 \\
$\mathrm{Ni}$ & 0.6 & 2.9 & 13 \\
$\mathrm{~V}$ & $<0.1$ & $<0.1$ & $<0.1$ \\
$\mathrm{Zn}$ & 0.3 & 0.5 & 0.8 \\
$\mathrm{Zr}$ & 6.1 & 10 & 13 \\
$\mathrm{U}$ & 5.7 & 11 & 17 \\
$\mathrm{Am}$ & 5.6 & 9.2 & 10 \\
\hline \hline
\end{tabular}


d. M315-PAN Synthetic Mordenite Composite. The synthetic mordenite content of the dry M315-PAN composite was $93 \%$. We air-dried this composite before testing for reasons detailed in Section II.C.

The M315-PAN composite offers low to moderate sorption of several elements from DSSF simulant.

Table 56. M315-PAN Composite: Distribution of 15 Elements from Simulated Hanford DSSF Solution

\begin{tabular}{lrrr}
\hline & \multicolumn{3}{c}{ Kd Value for Specified Time } \\
\cline { 2 - 4 } Element & $\mathbf{3 0} \mathbf{~ m i n}$ & $\mathbf{2 ~ h}$ & $\mathbf{6 ~ h}$ \\
\hline $\mathrm{Ce}$ & $<0.1$ & $<0.1$ & - \\
$\mathrm{Cs}$ & 29 & 30 & 29 \\
$\mathrm{Sr}$ & 5.7 & 8.7 & 15 \\
$\mathrm{Tc}$ & 1.0 & 0.6 & 0.7 \\
$\mathrm{Y}$ & 12 & 23 & 33 \\
$\mathrm{Cr}$ & 0.5 & 0.2 & 0.1 \\
$\mathrm{Co}$ & 0.3 & 0.5 & 0.6 \\
$\mathrm{Fe}$ & 0.9 & 1.3 & 1.6 \\
$\mathrm{Mn}$ & 0.6 & 1.4 & 1.7 \\
$\mathrm{Ni}$ & 0.7 & 1.3 & 4.4 \\
$\mathrm{~V}$ & $<0.1$ & $<0.1$ & $<0.1$ \\
$\mathrm{Zn}$ & 0.4 & 0.7 & 0.8 \\
$\mathrm{Zr}$ & 1.7 & 2.1 & 2.3 \\
$\mathrm{U}$ & $<0.1$ & 0.4 & 0.3 \\
$\mathrm{Am}$ & 3.8 & 6.1 & 13 \\
\hline \hline
\end{tabular}

e. MgO-PAN Magnesium Oxide Composite. The magnesium oxide content of the dry MgO-PAN composite was $80 \%$. We air-dried this composite before testing for reasons detailed in Section II.C.

The MgO-PAN composite sorbs strontium, zinc, iron, and yttrium from DSSF simulant with at least tripledigit $\mathrm{Kd}$ values.

Table 57. MgO-PAN Composite: Distribution of 15 Elements from Simulated Hanford DSSF Solution

\begin{tabular}{lrrr}
\hline & \multicolumn{3}{c}{ Kd Value for Specified Time } \\
\cline { 2 - 4 } Element & $\mathbf{3 0 ~} \mathbf{~ m i n}$ & $\mathbf{2} \mathbf{~ h}$ & $\mathbf{6 ~ h}$ \\
\hline $\mathrm{Ce}$ & $<0.1$ & $<0.1$ & - \\
$\mathrm{Cs}$ & 2.2 & 1.1 & 0.7 \\
$\mathrm{Sr}$ & 751 & 1214 & 1690 \\
$\mathrm{Tc}$ & 3.8 & 2.6 & 2.4 \\
$\mathrm{Y}$ & 83 & 164 & 394 \\
$\mathrm{Cr}$ & 2.0 & 0.9 & 0.6 \\
$\mathrm{Co}$ & 0.4 & 0.6 & 0.9 \\
$\mathrm{Fe}$ & 174 & 304 & 403 \\
$\mathrm{Mn}$ & 41 & 57 & 70 \\
$\mathrm{Ni}$ & 2.3 & 9.2 & 34 \\
$\mathrm{~V}$ & $<0.1$ & $<0.1$ & $<0.1$ \\
$\mathrm{Zn}$ & 251 & 429 & 502 \\
$\mathrm{Zr}$ & 15 & 25 & 41 \\
$\mathrm{U}$ & 0.6 & 2.0 & 4.2 \\
$\mathrm{Am}$ & 11 & 13 & 38 \\
\hline \hline
\end{tabular}


f. MnO-PAN Manganese Dioxide Composite. The manganese dioxide content of the dry $\mathrm{MnO}-\mathrm{PAN}$ composite was $85 \%$. We air-dried this composite before testing for reasons detailed in Section II.C.

The MnO-PAN composite sorbs strontium, manganese, and iron with four-digit $\mathrm{Kd}$ values and yttrium, americium, zinc, cerium, and zirconium with triple-digit $\mathrm{Kd}$ values.

Table 58. MnO-PAN Composite: Distribution of 15 Elements from Simulated Hanford DSSF Solution

\begin{tabular}{lrrr}
\hline & \multicolumn{3}{c}{ Kd Value for Specified Time } \\
\cline { 2 - 4 } Element & $\mathbf{3 0} \mathbf{~ m i n}$ & $\mathbf{2} \mathbf{h}$ & $\mathbf{6 ~ h}$ \\
\hline $\mathrm{Ce}$ & 4.1 & 26 & 193 \\
$\mathrm{Cs}$ & 0.3 & $<0.1$ & $<0.1$ \\
$\mathrm{Sr}$ & $8 \mathrm{~K}$ & $>27 \mathrm{~K}$ & $>27 \mathrm{~K}$ \\
$\mathrm{Tc}$ & 1.3 & 0.9 & 1.0 \\
$\mathrm{Y}$ & 60 & 336 & 665 \\
$\mathrm{Cr}$ & $<0.1$ & $<0.1$ & $<0.1$ \\
$\mathrm{Co}$ & 0.5 & 1.8 & 3.8 \\
$\mathrm{Fe}$ & $>1300$ & $>1400$ & $>1400$ \\
$\mathrm{Mn}$ & 483 & $>4200$ & $>4600$ \\
$\mathrm{Ni}$ & 2.2 & 4.4 & 5.3 \\
$\mathrm{~V}$ & $<0.1$ & $<0.1$ & $<0.1$ \\
$\mathrm{Zn}$ & 68 & 132 & 241 \\
$\mathrm{Zr}$ & 59 & 112 & 171 \\
$\mathrm{U}$ & 2.6 & 4.0 & 4.8 \\
$\mathrm{Am}$ & 22 & 83 & 473 \\
\hline \hline
\end{tabular}

g. NaTiO-PAN Sodium Titanate Composite. The sodium titanate content of the dry NaTiO-PAN composite was $92 \%$. We air-dried this composite before testing for reasons detailed in Section II.C.

The NaTiO-PAN composite sorbs strontium, iron, zirconium, manganese, and yttrium well from DSSF simulant. Uranium, zinc, and americium sorb at moderate levels.

\begin{tabular}{|c|c|c|c|}
\hline $\begin{array}{l}\text { Table } 59 \\
\text { of } 15 \text { Ele } \\
\text { Solution }\end{array}$ & $\begin{array}{l}\text { PAN Con } \\
\text { m Simul }\end{array}$ & $\begin{array}{l}\text { ite: D } \\
\text { Hanf }\end{array}$ & $\begin{array}{l}\text { ution } \\
\text { DSSF }\end{array}$ \\
\hline & Kd Valu & r Spec & Time \\
\hline Element & $30 \mathrm{~min}$ & $2 \mathrm{~h}$ & $6 \mathrm{~h}$ \\
\hline$\overline{\mathrm{Ce}}$ & $<0.1$ & $<0.1$ & - \\
\hline $\mathrm{Cs}$ & 2.3 & 1.6 & 1.0 \\
\hline $\mathrm{Sr}$ & 2415 & $9 \mathrm{~K}$ & $25 \mathrm{~K}$ \\
\hline $\mathrm{Tc}$ & 2.1 & 1.7 & 1.3 \\
\hline $\mathrm{Y}$ & 52 & 135 & 389 \\
\hline $\mathrm{Cr}$ & 1.6 & 1.1 & 0.6 \\
\hline $\mathrm{Co}$ & 0.3 & 0.4 & 0.6 \\
\hline $\mathrm{Fe}$ & 120 & 602 & 1373 \\
\hline Mn & 58 & 218 & 622 \\
\hline $\mathrm{Ni}$ & 0.6 & 1.4 & 5.7 \\
\hline V & $<0.1$ & $<0.1$ & $<0.1$ \\
\hline $\mathrm{Zn}$ & 5.5 & 11 & 23 \\
\hline $\mathrm{Zr}$ & 68 & 460 & 981 \\
\hline $\mathrm{U}$ & 12 & 32 & 69 \\
\hline Am & 5.9 & 7.9 & 19 \\
\hline
\end{tabular}


h. NiFC-PAN Nickel Hexacyanoferrate Composite. The nickel hexacyanoferrate content of the dry NiFC-PAN composite was $85 \%$. We air-dried this composite before testing for reasons detailed in Section II.C.

The NiFC-PAN composite sorbs strontium, iron, nickel, and zinc with four-digit Kd values. Yttrium, manganese, cobalt, and americium also sorb well.

Table 60. NiFC-PAN Composite: Distribution of 15 Elements from Simulated Hanford DSSF Solution

\begin{tabular}{lrrr}
\hline & \multicolumn{3}{c}{ Kd Value for Specified Time } \\
\cline { 2 - 4 } Element & $\mathbf{3 0}$ $\mathbf{m i n}$ & $\mathbf{2} \mathbf{~ h}$ & $\mathbf{6 ~ h}$ \\
\hline $\mathrm{Ce}$ & 7.6 & 9.3 & 19 \\
$\mathrm{Cs}$ & 16 & 2.6 & 2.4 \\
$\mathrm{Sr}$ & 1750 & $5 \mathrm{~K}$ & $12 \mathrm{~K}$ \\
$\mathrm{Tc}$ & 0.1 & 0.2 & 2.6 \\
$\mathrm{Y}$ & 174 & 379 & 940 \\
$\mathrm{Cr}$ & 1.1 & 1.1 & 3.9 \\
$\mathrm{Co}$ & 29 & 65 & 89 \\
$\mathrm{Fe}$ & 586 & 2621 & $>4400$ \\
$\mathrm{Mn}$ & 58 & 235 & 232 \\
$\mathrm{Ni}$ & 357 & 1290 & $>1800$ \\
$\mathrm{~V}$ & 1.8 & 1.6 & 1.3 \\
$\mathrm{Zn}$ & 309 & 819 & 1116 \\
$\mathrm{Zr}$ & 10 & 11 & 13 \\
$\mathrm{U}$ & 0.9 & 1.1 & 1.0 \\
$\mathrm{Am}$ & 53 & 93 & 170 \\
\hline \hline
\end{tabular}

i. NM-PAN Nickel Hexacyanoferrate/Manganese Dioxide Composite. The nickel hexacyanoferrate content and the manganese dioxide content of the dry composite were each $42.8 \%$. We air-dried this composite before testing for reasons detailed in Section II.C.

The NM-PAN composite sorbs seven elements with at least triple-digit $\mathrm{Kd}$ values. Strontium sorbs especially well.

Table 61. NM-PAN Composite: Distribution of 15 Elements from Simulated Hanford DSSF

Solution

\begin{tabular}{lcrr}
\hline & \multicolumn{3}{c}{ Kd Value for Specified Time } \\
\cline { 2 - 4 } Element & $\mathbf{3 0} \mathbf{~ m i n}$ & $\mathbf{2 ~ h}$ & $\mathbf{6 ~ h}$ \\
\hline $\mathrm{Ce}$ & 8.5 & 18 & 29 \\
$\mathrm{Cs}$ & 8.7 & 1.6 & 1.6 \\
$\mathrm{Sr}$ & $5 \mathrm{~K}$ & $27 \mathrm{~K}$ & $>28 \mathrm{~K}$ \\
$\mathrm{Tc}$ & 1.2 & 2.1 & 2.8 \\
$\mathrm{Y}$ & 128 & 316 & 635 \\
$\mathrm{Cr}$ & 1.0 & 2.1 & 2.6 \\
$\mathrm{Co}$ & 20 & 39 & 45 \\
$\mathrm{Fe}$ & 524 & 1353 & 1592 \\
$\mathrm{Mn}$ & 46 & 296 & 1364 \\
$\mathrm{Ni}$ & 150 & 612 & 660 \\
$\mathrm{~V}$ & 0.9 & 0.5 & 0.3 \\
$\mathrm{Zn}$ & 163 & 364 & 483 \\
$\mathrm{Zr}$ & 10 & 14 & 19 \\
$\mathrm{U}$ & 1.0 & 1.2 & 1.2 \\
$\mathrm{Am}$ & 38 & 83 & 132 \\
\hline \hline
\end{tabular}


j. SnSbA-PAN Stannic Antimonate Composite. The stannic antimonate content of the dry composite was $86 \%$. We air-dried this composite before testing for reasons detailed in Section II.C.

The SnSbA-PAN composite sorbs strontium strongly, whereas the Kd values for other sorbed elements are at least 100 -fold lower.

\begin{tabular}{|c|c|c|c|}
\hline $\begin{array}{l}\text { Table } 62 \\
\text { of } 15 \mathrm{El} \\
\text { Solution }\end{array}$ & $\begin{array}{l}\text { PAN Cor } \\
\text { m Simu }\end{array}$ & $\begin{array}{l}\text { ite: D } \\
\text { Hanf }\end{array}$ & $\begin{array}{l}\text { Dution } \\
\text { DSSF }\end{array}$ \\
\hline & Kd Valt & r Spec & Time \\
\hline Element & $30 \mathrm{~min}$ & $2 \mathrm{~h}$ & $6 \mathrm{~h}$ \\
\hline $\mathrm{Ce}$ & 1.3 & 2.4 & 1.4 \\
\hline Cs & $<0.1$ & $<0.1$ & $<0.1$ \\
\hline $\mathrm{Sr}$ & 1105 & 4911 & $9 \mathrm{~K}$ \\
\hline Tc & 0.7 & 1.1 & 1.2 \\
\hline Y & 9.6 & 23 & 57 \\
\hline $\mathrm{Cr}$ & 0.2 & 0.4 & 0.5 \\
\hline Co & $<0.1$ & 0.4 & 0.6 \\
\hline $\mathrm{Fe}$ & 24 & 45 & 71 \\
\hline $\mathrm{Mn}$ & 9.5 & 16 & 29 \\
\hline $\mathrm{Ni}$ & 2.3 & 5.6 & 18 \\
\hline V & $<0.1$ & $<0.1$ & $<0.1$ \\
\hline $\mathrm{Zn}$ & 4.7 & 8.5 & 16 \\
\hline $\mathrm{Zr}$ & 8.4 & 14 & 17 \\
\hline U & 1.4 & 1.6 & 2.1 \\
\hline Am & 5.5 & 8.8 & 8.5 \\
\hline
\end{tabular}

k. TiO-PANTitanium Dioxide Composite. The titanium dioxide content of the dry TiO-PAN composite was $85 \%$. We air-dried this composite before testing for reasons detailed in Section II.C.

The TiO-PAN composite sorbs five elements with at least four-digit Kd values. Strontium sorbs especially well.

Table 63. TiO-PAN Composite: Distribution of 15 Elements from Simulated Hanford DSSF Solution

\begin{tabular}{|c|c|c|c|}
\hline \multirow[b]{2}{*}{ Element } & \multicolumn{3}{|c|}{ Kd Value for Specified Time } \\
\hline & $30 \mathrm{~min}$ & $2 \mathrm{~h}$ & $6 \mathrm{~h}$ \\
\hline $\mathrm{Ce}$ & 0.6 & 34 & $>100$ \\
\hline Cs & $<0.1$ & $<0.1$ & $<0.1$ \\
\hline $\mathrm{Sr}$ & $6 \mathrm{~K}$ & $24 \mathrm{~K}$ & $>29 \mathrm{~K}$ \\
\hline $\mathrm{Tc}$ & 0.4 & 0.7 & 0.9 \\
\hline Y & 108 & 429 & 622 \\
\hline $\mathrm{Cr}$ & 0.3 & 0.5 & 0.6 \\
\hline Co & 0.1 & 0.3 & 0.9 \\
\hline $\mathrm{Fe}$ & 1174 & $>4900$ & $>5 \mathrm{~K}$ \\
\hline $\mathrm{Mn}$ & 318 & 658 & 1483 \\
\hline $\mathrm{Ni}$ & 3.7 & 4.3 & 11 \\
\hline V & $<0.1$ & $<0.1$ & $<0.1$ \\
\hline $\mathrm{Zn}$ & 217 & 317 & 365 \\
\hline $\mathrm{Zr}$ & 2242 & 4780 & 4841 \\
\hline U & 574 & 1707 & 2671 \\
\hline Am & 17 & 135 & 647 \\
\hline
\end{tabular}


l. TiP-PAN Titanium Phosphate Composite. The titanium phosphate content of the dry composite was $92 \%$. We air-dried this composite before testing for reasons detailed in Section II.C.

The TiP-PAN composite sorbs strontium with at least a four-digit $\mathrm{Kd}$ value and sorbs five other elements with triple-digit $\mathrm{Kd}$ values.

Table 64. TiP-PAN Composite: Distribution of 15 Elements from Simulated Hanford DSSF

Solution

\begin{tabular}{lrrr}
\hline & \multicolumn{3}{c}{ Kd Value for Specified Time } \\
\cline { 2 - 4 } Element & $\mathbf{3 0} \mathbf{~} \mathbf{n i n}$ & $\mathbf{2} \mathbf{~ h}$ & $\mathbf{6 ~ h}$ \\
\hline $\mathrm{Ce}$ & 10 & 34 & 65 \\
$\mathrm{Cs}$ & $<0.1$ & $<0.1$ & $<0.1$ \\
$\mathrm{Sr}$ & 2708 & $6 \mathrm{~K}$ & $9 \mathrm{~K}$ \\
$\mathrm{Tc}$ & 0.6 & 0.6 & 0.7 \\
$\mathrm{Y}$ & 19 & 37 & 66 \\
$\mathrm{Cr}$ & 0.3 & 0.4 & 0.5 \\
$\mathrm{Co}$ & 0.5 & 0.8 & 0.6 \\
$\mathrm{Fe}$ & 70 & 99 & 131 \\
$\mathrm{Mn}$ & 67 & 129 & 217 \\
$\mathrm{Ni}$ & 1.1 & 2.4 & 4.0 \\
$\mathrm{~V}$ & 0.2 & $<0.1$ & - \\
$\mathrm{Zn}$ & 72 & 228 & 334 \\
$\mathrm{Zr}$ & 108 & 260 & 461 \\
$\mathrm{U}$ & 101 & 369 & 872 \\
$\mathrm{Am}$ & 10 & 19 & 31 \\
\hline \hline
\end{tabular}

m. TiSbA-PAN Titanium Antimonate Composite. The titanium antimonate content of the dry composite was $86 \%$. We air-dried this composite before testing for reasons detailed in Section II.C.

The TiSbA-PAN composite sorbs strontium with a four-digit Kd value and sorbs five other elements with triple-digit $\mathrm{Kd}$ values.

Table 65. TiSbA-PAN Composite: Distribution of 15 Elements from Simulated Hanford DSSF Solution

\begin{tabular}{lcrr}
\hline & \multicolumn{3}{c}{ Kd Value for Specified Time } \\
\cline { 2 - 4 } Element & $\mathbf{3 0 ~} \mathbf{~ m i n}$ & $\mathbf{2} \mathbf{~ h}$ & $\mathbf{6 ~ h}$ \\
\hline $\mathrm{Ce}$ & 65 & 212 & 376 \\
$\mathrm{Cs}$ & $<0.1$ & 0.1 & $<0.1$ \\
$\mathrm{Sr}$ & 935 & 1671 & 3644 \\
$\mathrm{Tc}$ & 0.6 & 0.7 & 0.9 \\
$\mathrm{Y}$ & 51 & 167 & 413 \\
$\mathrm{Cr}$ & $<0.1$ & 0.2 & 0.3 \\
$\mathrm{Co}$ & $<0.1$ & 0.3 & 0.7 \\
$\mathrm{Fe}$ & 97 & 308 & 519 \\
$\mathrm{Mn}$ & 52 & 160 & 372 \\
$\mathrm{Ni}$ & 1.4 & 2.7 & 8.9 \\
$\mathrm{~V}$ & $<0.1$ & $<0.1$ & $<0.1$ \\
$\mathrm{Zn}$ & 4.0 & 8.2 & 20 \\
$\mathrm{Zr}$ & 79 & 453 & 892 \\
$\mathrm{U}$ & 5.2 & 15 & 69 \\
$\mathrm{Am}$ & 28 & 52 & 95 \\
\hline \hline
\end{tabular}


n. ZrO-PAN Zirconium Oxide Composite. The zirconium oxide content of the dry composite was $75 \%$. We air-dried this composite before testing for reasons detailed in Section II.C.

The ZrO-PAN composite sorbs strontium with a four-digit $\mathrm{Kd}$ value, whereas three other elements sorb with triple-digit Kd values.

\begin{tabular}{|c|c|c|c|}
\hline \multirow[b]{2}{*}{ Element } & \multicolumn{3}{|c|}{ Kd Value for Specified Time } \\
\hline & $30 \mathrm{~min}$ & $2 \mathrm{~h}$ & $6 \mathrm{~h}$ \\
\hline $\mathrm{Ce}$ & $<0.1$ & $<0.1$ & $<0.1$ \\
\hline Cs & 5.5 & 3.3 & 2.0 \\
\hline $\mathrm{Sr}$ & 43 & 398 & 2077 \\
\hline $\mathrm{Tc}$ & 6.9 & 5.3 & 4.0 \\
\hline Y & 3.1 & 7.8 & 13 \\
\hline $\mathrm{Cr}$ & 5.8 & 3.9 & 2.5 \\
\hline Co & 0.5 & 1.0 & 2.0 \\
\hline $\mathrm{Fe}$ & 13 & 63 & 291 \\
\hline Mn & 12 & 46 & 143 \\
\hline $\mathrm{Ni}$ & 1.9 & 3.9 & 12 \\
\hline V & 1.4 & 2.2 & 5.0 \\
\hline $\mathrm{Zn}$ & 5.5 & 15 & 30 \\
\hline $\mathrm{Zr}$ & 10 & 44 & 170 \\
\hline $\mathbf{U}$ & 6.3 & 23 & 89 \\
\hline Am & 1.3 & 2.9 & 3.8 \\
\hline
\end{tabular}

o. ZrOP-PANZirconium Oxide/Zirconium Phosphate Composite. The zirconium oxide content and the zirconium phosphate content of the dry composite were $60 \%$ and $15 \%$, respectively. We air-dried this composite before testing for reasons detailed in Section II.C.

The ZrOP-PAN composite sorbs strontium, iron, zirconium, and manganese quite well at the longer contact times. The noticeably slow kinetics may be a consequence of air-drying this composite.

Table 67. ZrOP-PAN Composite: Distribution of 15 Elements from Simulated Hanford DSSF Solution

\begin{tabular}{lrrr}
\hline & \multicolumn{3}{c}{ Kd Value for Specified Time } \\
\cline { 2 - 4 } Element & $\mathbf{3 0} \mathbf{~} \mathbf{m i n}$ & $\mathbf{2} \mathbf{~ h}$ & $\mathbf{6 ~ h}$ \\
\hline $\mathrm{Ce}$ & 0.6 & 2.4 & 1.6 \\
$\mathrm{Cs}$ & $<0.1$ & $<0.1$ & $<0.1$ \\
$\mathrm{Sr}$ & 15 & 113 & 1031 \\
$\mathrm{Tc}$ & 1.1 & 1.7 & 2.3 \\
$\mathrm{Y}$ & 3.0 & 13 & 55 \\
$\mathrm{Cr}$ & 0.4 & 0.4 & 0.6 \\
$\mathrm{Co}$ & $<0.1$ & 0.9 & 1.7 \\
$\mathrm{Fe}$ & 4.2 & 21 & 134 \\
$\mathrm{Mn}$ & 4.8 & 24 & 131 \\
$\mathrm{Ni}$ & 0.9 & 2.5 & 8.6 \\
$\mathrm{~V}$ & 0.8 & 2.3 & 3.4 \\
$\mathrm{Zn}$ & 2.0 & 8.8 & 22 \\
$\mathrm{Zr}$ & 3.5 & 17 & 102 \\
$\mathrm{U}$ & 1.3 & 10 & 40 \\
$\mathrm{Am}$ & 0.3 & 3.8 & 6.4 \\
\hline \hline
\end{tabular}


p. ZrP-PAN Zirconium Phosphate Composite. The zirconium phosphate content of the dry composite was $92 \%$. We air-dried this composite before testing for reasons detailed in Section II.C.

The ZrP-PAN composite sorbs six elements with at least four-digit $\mathrm{Kd}$ values from DSSF simulant.

Table 68. ZrP.PAN Composite: Distribution of 15 Elements from Simulated Hanford DSSF Solution

\begin{tabular}{lrrr}
\hline & \multicolumn{3}{c}{ Kd Value for Specified Time } \\
\cline { 2 - 4 } Element & $\mathbf{3 0 ~ \mathbf { ~ m i n }}$ & $\mathbf{2} \mathbf{~ h}$ & \multicolumn{1}{c}{$\mathbf{~ h}$} \\
\hline $\mathrm{Ce}$ & $>1500$ & $>1500$ & $>1500$ \\
$\mathrm{Cs}$ & $<0.1$ & $<0.1$ & 0.1 \\
$\mathrm{Sr}$ & $6 \mathrm{~K}$ & $>26 \mathrm{~K}$ & $>27 \mathrm{~K}$ \\
$\mathrm{Tc}$ & 0.8 & 0.9 & 1.1 \\
$\mathrm{Y}$ & 456 & 644 & 1340 \\
$\mathrm{Cr}$ & 0.4 & 0.6 & 0.7 \\
$\mathrm{Co}$ & 1.3 & 0.7 & 0.8 \\
$\mathrm{Fe}$ & $>1400$ & $>1800$ & $>1900$ \\
$\mathrm{Mn}$ & 1072 & $>5 \mathrm{~K}$ & $>5 \mathrm{~K}$ \\
$\mathrm{Ni}$ & 6.5 & 9.5 & 12 \\
$\mathrm{~V}$ & 2.3 & 39 & 44 \\
$\mathrm{Zn}$ & 18 & 64 & 92 \\
$\mathrm{Zr}$ & 2032 & $>3400$ & $>3600$ \\
$\mathrm{U}$ & 51 & 296 & 340 \\
$\mathrm{Am}$ & $>580$ & $>590$ & $>590$ \\
\hline \hline
\end{tabular}

5. Phenolsulfonic-Formaldehyde (PSF) Composite Absorbers. These two composites were prepared and provided to us by Dr. Jerzy Narbutt, Head of the Department of Radiochemistry, Institute of Nuclear Chemistry and Technology, Warsaw, Poland. In these two composite resins, the inorganic exchange material is dispersed in a phenolsulfonic-formaldehyde matrix. ${ }^{12}$ These dry composites were used as received.

a. CoFC-PSF Cobalt Hexacyanoferrate Composite. The cobalt hexacyanoferrate content of the CoFC-PSF composite was approximately $20 \%$.

Of the four elements sorbed by this composite from DSSF simulant with at least triple-digit $\mathrm{Kd}$ values, strontium sorbs most strongly.

\begin{tabular}{lcrr}
\hline Table 69. CoFC-PSF Composite: Distribution \\
of 15 Elements from Simulated Hanford DSSF \\
Solution \\
\hline \multicolumn{4}{c}{ Kd Value for Specified Time } \\
\cline { 2 - 4 } Element & $\mathbf{3 0}$ min & $\mathbf{2 ~ h}$ & $\mathbf{6 ~ h}$ \\
\hline $\mathrm{Ce}$ & $<0.1$ & 7.0 & 46 \\
$\mathrm{Cs}$ & 55 & 213 & 354 \\
$\mathrm{Sr}$ & 34 & 140 & 1222 \\
$\mathrm{Tc}$ & 5.9 & 1.2 & 1.3 \\
$\mathrm{Y}$ & 1.8 & 4.4 & 20 \\
$\mathrm{Cr}$ & 5.8 & 1.3 & 1.5 \\
$\mathrm{Co}$ & 1.3 & 4.6 & 9.7 \\
$\mathrm{Fe}$ & 5.2 & 31 & 145 \\
$\mathrm{Mn}$ & 7.8 & 39 & 217 \\
$\mathrm{Ni}$ & 1.7 & 5.2 & 9.3 \\
$\mathrm{~V}$ & $<0.1$ & $<0.1$ & $<0.1$ \\
$\mathrm{Zn}$ & 1.0 & 5.2 & 14 \\
$\mathrm{Zr}$ & 0.9 & 4.5 & 11 \\
$\mathrm{U}$ & 0.6 & 3.2 & 6.1 \\
$\mathrm{Am}$ & 3.5 & 6.2 & 28 \\
\hline \hline
\end{tabular}


b. TiFC-PSF Titanium Hexacyanoferrate Composite. The titanium hexacyanoferrate content of the TiFC-PSF composite was approximately $17 \%$.

Of the four elements sorbed by this composite from DSSF simulant with at least triple-digit Kd values, strontium sorbs most strongly.

\begin{tabular}{|c|c|c|c|}
\hline \multicolumn{4}{|c|}{$\begin{array}{l}\text { Table 70. TiFC-PSF Composite: Distribution of } \\
15 \text { Elements from Simulated Hanford DSSF } \\
\text { Solution }\end{array}$} \\
\hline \multirow[b]{2}{*}{ Element } & \multicolumn{3}{|c|}{ Kd Value for Specified Time } \\
\hline & $30 \mathrm{~min}$ & $2 \mathrm{~h}$ & $6 \mathrm{~h}$ \\
\hline $\mathrm{Ce}$ & $<0.1$ & $<0.1$ & 7.7 \\
\hline Cs & 14 & 20 & 23 \\
\hline $\mathrm{Sr}$ & 147 & 1076 & 1716 \\
\hline $\mathrm{Tc}$ & 6.1 & 1.6 & 1.4 \\
\hline $\mathrm{Y}$ & 8.7 & 31 & 68 \\
\hline $\mathrm{Cr}$ & 5.3 & 1.2 & 1.6 \\
\hline Co & 0.8 & 5.5 & 14 \\
\hline $\mathrm{Fe}$ & 13 & 115 & 230 \\
\hline $\mathrm{Mn}$ & 12 & 108 & 283 \\
\hline $\mathrm{Ni}$ & 3.0 & 18 & 33 \\
\hline V & $<0.1$ & $<0.1$ & $<0.1$ \\
\hline $\mathrm{Zn}$ & 1.5 & 9.8 & 19 \\
\hline $\mathrm{Zr}$ & 9.1 & 74 & 195 \\
\hline U & 2.7 & 19 & 40 \\
\hline $\mathrm{Am}$ & 6.5 & 4.1 & 9.1 \\
\hline
\end{tabular}

6. Liquid Extractants. We prepared and evaluated porous beads impregnated with three different liquid extractants.

a. Aliquat ${ }^{\mathrm{TM}}$ 336. We diluted $5 \mathrm{~g}$ of Aliquat ${ }^{\mathrm{TM}} 336$ (methyltricaprylammonium chloride), obtained from Aldrich Chemical Co., Milwaukee, Wisconsin, with $10 \mathrm{~mL}$ of hexane and added $17.32 \mathrm{~g}$ of Ambersorb ${ }^{\mathrm{TM}} 563$ porous carbon beads, obtained from Rohm \& Haas, Philadelphia, Pennsylvania, to absorb the liquid. The cyclohexane evaporated to yield $26.2 \mathrm{~g}$ of the loaded Ambersorb ${ }^{\mathrm{TM}}$ beads.

This extractant sorbs technetium strongly and selectively from DSSF simulant. Its very low sorption of technetium from acidic solution, determined in a previous study, ${ }^{1}$ indicates that technetium could be stripped by nitric acid.

Table 71. Aliquat ${ }^{\mathrm{TM}}$ 336: Distribution of 15 Elements from Simulated Hanford DSSF Solution

\begin{tabular}{lrrr}
\hline & \multicolumn{3}{c}{ Kd Value for Specified Time } \\
\cline { 2 - 4 } Element & 30 $\mathbf{~ m i n}$ & $\mathbf{2 ~ h}$ & $\mathbf{6 ~ h}$ \\
\hline $\mathrm{Ce}$ & 3.1 & 4.8 & 6.6 \\
$\mathrm{Cs}$ & $<0.1$ & $<0.1$ & $<0.1$ \\
$\mathrm{Sr}$ & 0.4 & $\mathbf{0 . 7}$ & 0.9 \\
$\mathrm{Tc}$ & 177 & 464 & 524 \\
$\mathrm{Y}$ & 2.7 & 3.9 & 4.2 \\
$\mathrm{Cr}$ & 0.1 & 0.3 & 0.1 \\
$\mathrm{Co}$ & 0.5 & 0.9 & 1.0 \\
$\mathrm{Fe}$ & 1.1 & 1.6 & 2.0 \\
$\mathrm{Mn}$ & 0.7 & 1.3 & 1.5 \\
$\mathrm{Ni}$ & 0.1 & 1.0 & 1.1 \\
$\mathrm{~V}$ & $<0.1$ & $<0.1$ & $<0.1$ \\
$\mathrm{Zn}$ & 0.4 & 0.6 & 0.8 \\
$\mathrm{Zr}$ & 0.9 & 1.1 & 1.4 \\
$\mathrm{U}$ & 0.5 & 0.9 & 1.1 \\
$\mathrm{Am}$ & 2.2 & 4.2 & 5.4 \\
\hline \hline
\end{tabular}


b. Cyanex ${ }^{\mathrm{TM}}$ 923. We diluted $10 \mathrm{~mL}$ of Cyanex ${ }^{\mathrm{TM}} 923$ (trialkylphosphine oxide), obtained from the American Cyanamid Company, Wayne, New Jersey, with $20 \mathrm{~mL}$ of cyclohexane and added $26.83 \mathrm{~g}$ of Ambersorb ${ }^{\mathrm{TM}} 563$ porous carbon beads, obtained from Rohm \& Haas, Philadelphia, Pennsylvania, to absorb the liquid. The cyclohexane evaporated to yield $36.8 \mathrm{~g}$ of the loaded Ambersorb ${ }^{\mathrm{TM}}$ beads.

This extractant strongly and selectively sorbs technetium from DSSF simulant.

Table 72. Cyanex TM 923: Distribution of 15 Elements from Simulated Hanford DSSF Solution

\begin{tabular}{lrrr}
\hline & \multicolumn{3}{c}{ Kd Value for Specified Time } \\
\cline { 2 - 4 } Element & $\mathbf{3 0 ~} \mathbf{~ m i n}$ & $\mathbf{2} \mathbf{~ h}$ & $\mathbf{6 ~ h}$ \\
\hline $\mathrm{Ce}$ & $<0.1$ & $<0.1$ & $<0.1$ \\
$\mathrm{Cs}$ & 1.4 & 4.6 & 3.8 \\
$\mathrm{Sr}$ & 1.9 & 5.5 & 5.6 \\
$\mathrm{Tc}$ & 121 & 244 & 230 \\
$\mathrm{Y}$ & 2.1 & 1.4 & 1.8 \\
$\mathrm{Cr}$ & 1.2 & 4.4 & 3.8 \\
$\mathrm{Co}$ & 1.3 & 0.7 & 1.0 \\
$\mathrm{Fe}$ & 1.7 & 1.3 & 1.4 \\
$\mathrm{Mn}$ & 1.6 & 0.9 & 1.5 \\
$\mathrm{Ni}$ & $<0.1$ & 0.6 & 0.7 \\
$\mathrm{~V}$ & 1.0 & 0.2 & 0.2 \\
$\mathrm{Zn}$ & 1.2 & 0.5 & 0.9 \\
$\mathrm{Zr}$ & 1.3 & 0.7 & 1.1 \\
$\mathrm{U}$ & 1.4 & 0.7 & 1.2 \\
$\mathrm{Am}$ & $<0.1$ & 1.3 & 2.1 \\
\hline \hline
\end{tabular}

c. $L I X^{\mathrm{TM}}-54$. We diluted $10 \mathrm{~mL}$ of $\mathrm{LIX}^{\mathrm{TM}}-54$ (a beta diketone), obtained from the Henkel Corporation, Tucson, Arizona, with $20 \mathrm{~mL}$ of cyclohexane and added $26.80 \mathrm{~g}$ of Ambersorb ${ }^{\mathrm{TM}} 563$ porous carbon beads, obtained from Rohm \& Haas, Philadelphia, Pennsylvania, to absorb the liquid. The cyclohexane evaporated to yield $34.6 \mathrm{~g}$ of the loaded Ambersorb $^{\mathrm{TM}}$ beads.

This extractant sorbs strontium, nickel, and yttrium at useful levels from DSSF simulant.

Table 73. LIX ${ }^{\mathrm{TM}_{-} 54 \text { : Distribution of } 15}$ Elements from Simulated Hanford DSSF Solution

\begin{tabular}{lrrr}
\hline & \multicolumn{3}{c}{ Kd Value for Specified Time } \\
\cline { 2 - 4 } Element & $\mathbf{3 0} \mathbf{~} \mathbf{m i n}$ & $\mathbf{2 ~ h}$ & $\mathbf{6 ~ h}$ \\
\hline $\mathrm{Ce}$ & $<0.1$ & $<0.1$ & 1.8 \\
$\mathrm{Cs}$ & 3.5 & 2.3 & 1.2 \\
$\mathrm{Sr}$ & 32 & 108 & 185 \\
$\mathrm{Tc}$ & 3.2 & 2.6 & 1.6 \\
$\mathrm{Y}$ & 13 & 25 & 59 \\
$\mathrm{Cr}$ & 3.4 & 2.3 & 1.2 \\
$\mathrm{Co}$ & 1.0 & 1.4 & 2.1 \\
$\mathrm{Fe}$ & 1.7 & 2.5 & 4.2 \\
$\mathrm{Mn}$ & 1.3 & 2.2 & 3.4 \\
$\mathrm{Ni}$ & 12 & 27 & 64 \\
$\mathrm{~V}$ & 0.1 & $<0.1$ & $<0.1$ \\
$\mathrm{Zn}$ & $<0.1$ & 0.3 & 0.6 \\
$\mathrm{Zr}$ & 0.8 & 1.5 & 2.4 \\
$\mathrm{U}$ & 0.2 & 0.6 & 0.6 \\
$\mathrm{Am}$ & 3.3 & 4.1 & 9.5 \\
\hline \hline
\end{tabular}


7. Sandia/NM Absorbers. Materials designated as SNL/CST are a new class of inorganic ion exchangers called crystalline silico-titanates (CSTs). These materials, jointly invented by Sandia National Laboratories/New Mexico (SNL) and Texas A\&M University (a patent application has been filed), show a significant potential for removing cesium from defense wastes that contain more than $5 \mathrm{M} \mathrm{Na}^{+}$and more than $1 \mathrm{M} \mathrm{OH}^{-}$. CST materials are very fine powders composed of cuboidal crystals with particle sizes of several hundred angstroms. Different numerical values in the absorber designations represent different synthesis procedures.

Because the composition of the various CST materials we evaluated is proprietary, we can provide only general information. As the development effort progressed, however, a baseline composition was selected for larger-scale synthesis, characterization, and evaluation of properties. SNL/CST 141 and 149 are baseline materials that are being developed for the removal of cesium and other radionuclides from a wide range of waste solutions.

SNL/CST 141 powder has already been prepared in commercial quantities by the UOP Corporation, Des Plaines, Illinois, Sandia/NM's partner in a cooperative research and development agreement (CRADA). An engineered form of CST suitable for use in ion exchange columns is scheduled to be commercially available in 1995. a. SNL/CST 120 Crystalline Silico-Titanate. SNL/CST 120 strongly and selectively sorbs strontium from DSSF simulant. The Kd value for manganese, the next most strongly extracted element, is more than 100 -fold lower.

Table 74. SNL/CST 120: Distribution of 15 Elements from Simulated Hanford DSSF Solution

\begin{tabular}{|c|c|c|c|}
\hline \multirow[b]{2}{*}{ Element } & \multicolumn{3}{|c|}{ Kd Value for Specified Time } \\
\hline & $30 \mathrm{~min}$ & $2 \mathrm{~h}$ & $6 h$ \\
\hline $\mathrm{Ce}$ & 1.1 & 0.3 & 0.3 \\
\hline Cs & 20 & 26 & 27 \\
\hline $\mathrm{Sr}$ & $13 \mathrm{~K}$ & $>32 \mathrm{~K}$ & $>32 \mathrm{~K}$ \\
\hline $\mathrm{Tc}$ & $<0.1$ & 0.4 & 0.1 \\
\hline Y & 32 & 67 & 93 \\
\hline $\mathrm{Cr}$ & 0.4 & 0.9 & 0.7 \\
\hline Co & 0.2 & 0.3 & 0.5 \\
\hline $\mathrm{Fe}$ & 8.4 & 12 & 19 \\
\hline $\mathrm{Mn}$ & 7.2 & 36 & 240 \\
\hline $\mathrm{Ni}$ & 1.2 & 1.8 & 2.6 \\
\hline V & $<0.1$ & $<0.1$ & $<0.1$ \\
\hline $\mathrm{Zn}$ & 1.1 & 1.0 & 1.1 \\
\hline $\mathrm{Zr}$ & 36 & 31 & 57 \\
\hline$\vec{U}$ & 26 & 25 & 28 \\
\hline Am & 6.6 & 6.1 & 10 \\
\hline
\end{tabular}


b. SNL/CST 141 Crystalline Silico-Titanate.

SNL/CST 141 strongly sorbs both strontium and cesium from DSSF simulant. None of the other 13 elements sorb with $\mathrm{Kd}$ values higher than 20 .

Table 75. SNL/CST 141: Distribution of 15 Elements from Simulated Hanford DSSF Solution

\begin{tabular}{lcrr}
\hline & \multicolumn{3}{c}{ Kd Value for Specified Time } \\
\cline { 2 - 4 } Element & $\mathbf{3 0 ~} \mathbf{~ m i n}$ & $\mathbf{2 ~ h}$ & $\mathbf{6 h}$ \\
\hline $\mathrm{Ce}$ & 6.5 & 9.6 & 17 \\
$\mathrm{Cs}$ & 530 & 649 & 736 \\
$\mathrm{Sr}$ & 1319 & 1839 & 2343 \\
$\mathrm{Tc}$ & $<0.1$ & $<0.1$ & $<0.1$ \\
$\mathrm{Y}$ & 17 & 16 & 17 \\
$\mathrm{Cr}$ & $<0.1$ & 0.2 & 0.3 \\
$\mathrm{Co}$ & 0.4 & 0.5 & 0.7 \\
$\mathrm{Fe}$ & 4.5 & 6.7 & 9.7 \\
$\mathrm{Mn}$ & 2.5 & 4.0 & 6.4 \\
$\mathrm{Ni}$ & 1.4 & 1.8 & 1.9 \\
$\mathrm{~V}$ & $<0.1$ & $<0.1$ & $<0.1$ \\
$\mathrm{Zn}$ & 0.6 & 0.6 & 0.9 \\
$\mathrm{Zr}$ & 13 & 20 & 17 \\
$\mathrm{U}$ & 5.2 & 8.0 & 11 \\
$\mathrm{Am}$ & 6.0 & 8.3 & 12 \\
\hline \hline
\end{tabular}

c. SNL/CST 149 Crystalline Silico-Titanate. SNL/CST 149 strongly sorbs both strontium and cesium from DSSF simulant. None of the other 13 elements sorb with $\mathrm{Kd}$ values higher than 28 .

Table 76. SNL/CST 149: Distribution of 15 Elements from Simulated Hanford DSSF Solution

\begin{tabular}{lrrr} 
& \multicolumn{3}{c}{ Kd Value for Specified Time } \\
\cline { 2 - 4 } Element & $\mathbf{3 0} \mathbf{~} \mathbf{m i n}$ & $\mathbf{2 ~ h}$ & $\mathbf{6 ~ h}$ \\
\hline $\mathrm{Ce}$ & $<0.1$ & 3.3 & 9.9 \\
$\mathrm{Cs}$ & 436 & 570 & 612 \\
$\mathrm{Sr}$ & 2047 & 3808 & 4692 \\
$\mathrm{Tc}$ & 0.4 & 0.1 & 0.1 \\
$\mathrm{Y}$ & 19 & 23 & 27 \\
$\mathrm{Cr}$ & 0.5 & 0.5 & 0.5 \\
$\mathrm{Co}$ & 0.3 & 0.5 & 0.7 \\
$\mathrm{Fe}$ & 4.2 & 6.2 & 8.2 \\
$\mathrm{Mn}$ & 2.2 & 3.5 & 5.8 \\
$\mathrm{Ni}$ & 0.9 & 1.6 & 1.7 \\
$\mathrm{~V}$ & $<0.1$ & $<0.1$ & $<0.1$ \\
$\mathrm{Zn}$ & 0.6 & 0.8 & 1.0 \\
$\mathrm{Zr}$ & 16 & 25 & 28 \\
$\mathrm{U}$ & 5.4 & 8.7 & 12 \\
$\mathrm{Am}$ & 2.2 & 5.6 & $\mathbf{8 . 7}$ \\
\hline \hline
\end{tabular}


d. SNL/HTO Amorphous Hydrous Titanium Dioxide. As expected, the behavior of hydrous titanium dioxide is very different from that of the crystalline silico-titanates. Many elements sorb strongly from DSSF simulant.

\begin{tabular}{|c|c|c|c|}
\hline \multicolumn{4}{|c|}{$\begin{array}{l}\text { Table 77. SNL/HTO: Distribution of } 15 \\
\text { Elements from Simulated Hanford DSSF } \\
\text { Solution }\end{array}$} \\
\hline \multirow[b]{2}{*}{ Element } & \multicolumn{3}{|c|}{ Kd Value for Specified Time } \\
\hline & $30 \mathrm{~min}$ & $2 \mathrm{~h}$ & $6 \mathrm{~h}$ \\
\hline$\overline{\mathrm{Ce}}$ & 282 & 416 & 542 \\
\hline $\mathrm{Cs}$ & 0.5 & 0.3 & 0.3 \\
\hline $\mathrm{Sr}$ & $23 \mathrm{~K}$ & $10 \mathrm{~K}$ & $>24 \mathrm{~K}$ \\
\hline $\mathrm{Tc}$ & $<0.1$ & $<0.1$ & $<0.1$ \\
\hline $\mathrm{Y}$ & 245 & 288 & 465 \\
\hline $\mathrm{Cr}$ & 0.6 & 0.7 & 0.7 \\
\hline $\mathrm{Co}$ & 0.6 & 1.5 & 2.7 \\
\hline $\mathrm{Fe}$ & 526 & 267 & 253 \\
\hline $\mathrm{Mn}$ & 313 & 353 & 501 \\
\hline $\mathrm{Ni}$ & 2.1 & 4.6 & 10 \\
\hline V & $<0.1$ & $<0.1$ & $<0.1$ \\
\hline $\mathrm{Zn}$ & 107 & 170 & 207 \\
\hline $\mathrm{Zr}$ & 1444 & 1625 & 2735 \\
\hline $\mathrm{U}$ & 622 & 1419 & $>2300$ \\
\hline Am & 66 & 104 & 172 \\
\hline
\end{tabular}

\section{FUTURE STUDIES}

This screening study met its objective of identifying specific absorbers that seem capable of partitioning targeted elements from Hanford DSSF solution. The best absorbers and promising new materials identified in our screening studies will be evaluated with realistic simulant compositions that represent other Hanford tanks, especially those scheduled to be processed first. We will continue to use radiotracers, which provide a rapid, reliable, and inexpensive way to obtain large quantities of distribution data.

Because even the best simulant solutions cannot accurately represent the contents of any HLW storage tank, we are anxious to obtain and test actual samples from the Hanford waste tanks. Only by testing genuine waste solutions can we obtain sorption data that are sufficiently reliable to permit the design of full-scale partitioning processes to begin. We recognize that even tests with actual wastes will not be conclusive because the compositions of the Hanford tanks vary greatly and that individual tanks exhibit large heterogeneities in their horizontal and vertical compositions. However, as we obtain sorption data for the most promising absorbers with samples from various HLW tanks, we hope to identify absorbers that sorb the target elements well from a wide variety of waste compositions.

Finally, chemical and radiation stabilities are important factors to consider when selecting materials for processing radioactive waste solutions. The long-term chemical stability and the effect of radiation on the most promising absorbers from our screening studies should be determined (if such information is not already available) before absorbers are selected for use in large-scale recovery processes.

\section{v. CONCLUSIONS}

Our screening study of many absorbers from a realistic simulant for Hanford DSSF has met the initial objective of identifying many promising absorbers. Moreover; because we measured the sorption of so many different elements, our study provides important selectivity information about which unwanted elements are most likely to compete for absorber sites. Based on our experimental data, it appears that many of the separations required for processing HLW from Hanford DSSF solution, and perhaps from other underground storage tanks as well, can be achieved using available absorbers and existing, proven technology.

\section{A. Experimental Procedure}

Radiotracers, as used in our study, provide a fast, reliable, and cost-effective way to obtain large quantities of distribution data. Follow-on studies should measure the distribution of key elements from other Hanford waste tank compositions onto the most promising absorbers identified by completed screening studies.

\section{B. Individual Elements}

All elements studied except vanadium sorb from DSSF simulant with good to excellent Kd values on at least one of the absorbers tested. 


\section{Individual Absorbers}

- The performance of the 58 absorbers tested with this PNL-prepared DSSF simulant solution is often much different from the performance reported for similar absorbers tested in solutions of more simple chemical composition.

- Low-cost partitioning agents such as Aliquat ${ }^{\mathrm{TM}} 336$, Cyanex ${ }^{\mathrm{TM}}$ 923, and Reillex ${ }^{\mathrm{TM}} \mathrm{HPQ}$ often outperform other materials whose cost is many times higher.

- The silico-titanate absorbers from Sandia show high sorption of cesium and strontium from simulated Hanford DSSF solution. Because the sorption of cesium on silico-titanates appears to be irreversible, this material should be considered for use in the interim storage of radioactive waste, for incorporation into HLW glass, or for use as a final waste form.

\section{ACKNOWLEDGMENTS}

This study was supported by the Tank Waste Remediation System (TWRS) of DOE/Richland Operations Office; the TWRS Technology Development Program Office (TDPO) of Westinghouse Hanford Company; and the Hanford Program Office, EM-36, of the Office of Environmental Restoration and Waste Management, U.S. Department of Energy.

Clifford Mills of the Nuclear Materials Process Technology Group at Los Alamos designed the tip-filter system that allowed disposable hypodermic syringes to be successfully used as container-dispensers during our many hundreds of dynamic contact experiments.

Frank McGarvey of Sybron Chemicals, Inc., provided samples of macroporous anion exchange resins with trimethyl, triethyl, tripropyl, and tributyl amine functional groups.

Jane Bibler of Westinghouse Savannah River Company provided the sample of SRS resorcinol/formaldehyde resin (batch BSC-187).

Dennis Fennelly of UOP Molecular Sieves Division provided samples of Ionsiv'TM TIE-96 for evaluation.

Elmer Klavetter and Norman Brown of Sandia National Laboratories/New Mexico provided samples of crystalline silico-titanate (SNL/CST) absorbers and hydrous titanium oxide (SNL/HTO) absorber.

Ferdinand Sebesta, Department of Nuclear Chemistry, Czech Technical University, Prague, Czech Republic, prepared and provided samples of 16 PAN-matrix composite absorbers for our evaluation.

Jerzy Narbutt, Department of Radiochemistry, Institute of Nuclear Chemistry and Technology, Warsaw, Poland, prepared and provided samples of two PSFmatrix composite absorbers for our evaluation.
Leonard Mausner and Katherine Kolsky of the Medical Isotopes Program, Brookhaven National Laboratory, provided the ${ }^{56} \mathrm{Ni}$ and ${ }^{48} \mathrm{~V}$ radiotracers.

The simulated DSSF solution was prepared and provided by Garrett Brown of Battelle Pacific Northwest Laboratory.

Stephen Yarbro and Gordon Jarvinen of the Nuclear Materials Process Technology Group at Los Alamos provided valuable advice and suggestions during numerous technical discussions.

Norman Brown of Sandia/NM provided valuable advice and suggestions during numerous technical discussions and also peer-reviewed this manuscript.

We especially appreciate the assistance and cooperation of many members of the Separations and Radiochemistry Group, the Nuclear Chemistry and Analysis Group, and the Medical Radioisotopes and Reactor Applications Group at Los Alamos.

\section{REFERENCES}

1. S. F. Marsh, Z. V. Svitra, and S. M. Bowen, "Distributions of 14 Elements on 63 Absorbers from Three Simulant Solutions (Acid-Dissolved Sludge, Acidified Supernate, and Alkaline Supernate) for Hanford HLW Tank 102-SY," Los Alamos National Laboratory report LA-12654, Rev. (August 1994).

2. J. L. Ryan and E. J Wheelwright, "Recovery and Purification of Plutonium by Anion Exchange," Ind. Eng. Chem. 51(1), 60-65 (1959).

3. W. L. Poe, A. W. Joyce, and R. I. Martens, "Np-237 and Pu-238 Separation at the Savannah River Plant," I\&EC Proc. Design Devel. 3(4), 314-322 (1964).

4. J. A. Kelly, "Ion Exchange Process for Separating Americium and Curium from Irradiated Plutonium," Savannah River Laboratory report DP-1308 (1972).

5. J. Korkisch, Handbook of Ion Exchange Resins; Their Application to Inorganic Analytical Chemistry, Vol. I (CRC Press, Boca Raton, Florida, 1989), p. 33.

6. R. Gunnink and J. B. Niday, "Computerized Quantitative Analysis by Gamma-Ray Spectrometry. Vol. 1. Description of the Gamanal Program," Lawrence Livermore Laboratory report UCRL51061, Vol. 1 (March 1972). 
7. T. M. Benjamin, Nuclear Chemistry and Analysis Group, Los Alamos National Laboratory, personal communication, April 1994.

8. F. X. McGarvey and R. Gonzales, "Ion Exchange Studies on Strongly Basic Anion Exchange Resins Prepared with Tertiary Amines of Varying Molecular Weight," in Ion Exchange Advances, Proceedings of IEX '92, M. J. Slater, Ed. (Elsevier Science Publishing Ltd., Essex, England, 1992), pp. 97-103.

9. S. F. Marsh, "The Effect of Triethyl, Trimethyl, Tripropyl, and Tributyl Amine Functional Groups in Strong-Base Anion Exchange Resin on the Sorption of Pu(IV) from Nitric Acid," in Ion Exchange Processes: Advances and Applications, A. Dyer, M. J. Hudson, and P. A. Williams, Eds. (Royal Society of Chemistry, Cambridge, England, 1993), pp. 81-89.
10. F. Sebesta, A. Motl, J. John, M. Prazsky, and J. Binka, "Composite Ion-Exchangers and Their Possible Use in Treatment of Low/Intermediate Level Liquid Radioactive Wastes," in Proc. 1993 International Conference on Nuclear Waste Management and Environmental Remediation, R. Baschwitz, R. Kohout, J. Marek, P. I. Richter, and S. C. Slate, Eds. (American Society of Mechanical Engineers, New York, 1993), Vol. 3, pp. 871-878.

11. F. Sebesta and J. John, "An Overview of the Development, Testing, and Application of Composite Absorbers," Los Alamos National Laboratory report LA-12875-MS (in press).

12. J. Narbutt, A. Bilewicz, and B. Bartos, "Composite Ion Exchangers for Radiocaesium Removal from Nuclear Reactor Wastes," in Proc. Management of Low and Intermediate Level Radioactive Wastes (International Atomic Energy Agency, Vienna, Austria, 1989), IAEA-SM-303/152P, Vol. 2, pp. 266-268. 